\title{
ATP-sensitive potassium channels and their physiological and pathophysiological roles
}

\author{
Andrew Tinker, Qadeer Aziz, Yiwen Li and Mark Specterman \\ William Harvey Heart Centre, \\ Barts \& The London School of Medicine \& Dentistry, \\ Queen Mary, University of London \\ Charterhouse Square, \\ London EC1M 6BQ.
}

Tel: 0207882 5783, E-mail: a.tinker@qmul.ac.uk

Running Head: ATP-sensitive potassium channels 


\begin{abstract}
ATP sensitive potassium channels $\left(\mathrm{K}_{\mathrm{ATP}}\right)$ are so named because they open as cellular ATP levels fall. This leads to membrane hyperpolarisation and thus links cellular metabolism to membrane excitability. They also respond to MgADP and are regulated by a number of cell signalling pathways. They have a rich and diverse pharmacology with a number of agents acting as specific inhibitors and activators. $\mathrm{K}_{\mathrm{ATP}}$ channels are formed of pore-forming subunits, Kir6.1 and Kir6.2, and a large auxiliary subunit, the sulphonylurea receptor (SUR1, SUR2A and SUR2B). The Kir6.0 subunits are a member of the inwardly rectifying family of potassium channels and the sulphonylurea receptor is part of the ATP binding cassette family of proteins. Four SURs and four Kir6.x form an octameric channel complex and the association of a particular SUR with a specific Kir6.x subunit constitutes the $\mathrm{K}_{\text {ATP }}$ current in a particular tissue. A combination of mutagenesis work combined with structural studies has identified how these channels work as molecular machines. They have a variety of physiological roles including controlling the release of insulin from pancreatic $\beta$ cells and regulating blood vessel tone and blood pressure. Furthermore, mutations in the genes underlie human diseases such as congenital diabetes and hyperinsulinism. Additionally, opening of these channels is protective in a number of pathological conditions such as myocardial ischaemia and stroke.
\end{abstract}




\section{Didactic Synopsis}

Major teaching points

- $\quad$ ATP-sensitive potassium channels $\left(\mathrm{K}_{\mathrm{ATP}}\right)$ are widely distributed and characteristically are activated by falling cellular ATP levels.

- $\mathrm{K}_{\text {ATP }}$ channels link membrane excitability to cellular metabolism.

- $\mathrm{K}_{\mathrm{ATP}}$ channels have a rich and diverse pharmacology with specific inhibitors such as glibenclamide and openers such as diazoxide.

- The channel is an octamer formed of four inwardly rectifying potassium channels of the Kir6.0 family and four sulphonylurea receptor subunits, a member of the ATP binding cassette family of proteins.

- Extensive mutagenesis experiments and recent structural studies have defined many aspects of how the channel works as a molecular machine.

- $\mathrm{K}_{\mathrm{ATP}}$ channels are key to the release of insulin from pancreatic $\beta$ cells.

- $\mathrm{K}_{\mathrm{ATP}}$ channels in the heart are involved in adaptation to exercise and cellular protection and in vascular smooth muscle controlling vascular tone and blood pressure.

- $\mathrm{K}_{\mathrm{ATP}}$ channels are present in the brain and may be involved in neuroprotection and nutrient sensing.

- Mutations in $\mathrm{K}_{\text {ATP }}$ channel subunits can result in human disease and includes disorders of insulin handling, cardiac arrhythmia, cardiomyopathy and neurological abnormalities. 


\section{Introduction}

Potassium conductances in cell membranes play an important role are important in determining membrane potential and in excitable cells in shaping repetitive firing and action potential characteristics. Opening potassium channels hyperpolarises the membrane potential towards the potassium equilibrium potential and can lead to repolarisation of an action potential. A number of families of potassium channel are distinguished by their electrophysiological properties with even greater molecular diversity underpinning these functional attributes $(182 ; 251 ; 455)$.

One such family of potassium channel are the ATP-sensitive potassium $\left(\mathrm{K}_{\mathrm{ATP}}\right)$ channels. The fundamental property of $\mathrm{K}_{\mathrm{ATP}}$ channels is that they open in response to metabolic challenge, specifically a fall in ATP andlor a rise in ADP. They are widely found in a number of tissues. They have been described in cardiac myocytes $(391 ; 544)$, pancreatic $\beta$ cells $(9 ; 88 ; 446)$, skeletal muscle $(498)$, neurones $(18 ; 154)$, smooth muscle $(38 ; 500)$, the kidney (234) and epithelial cells $(296 ; 297)$. They thus link cellular metabolism to membrane excitability. In one of the early reviews before the molecular identity of the channels was determined a number of different families were distinguished based on ATP sensitivity (15). In this review we consider only those channels constituted of Kir6.0 subunits with the exception of the mitochondrial $\mathrm{K}_{\mathrm{ATP}}$ channel. For example, it is now known that in kidney tubules, where the channels are sensitive to ATP inhibition, albeit to mM ATP concentrations, the pore-forming subunits are likely constituted of Kir1.0 subunits (223).

\section{Biophysical and physiological properties}

The $\mathrm{K}_{\mathrm{ATP}}$ channel is considered to be a member of the inwardly rectifying family of potassium channels. Inward rectification refers to the fact that this class of channel passes more inward current at potentials negative to the potassium equilibrium potential whilst less 
current is passed at membrane potentials positive to that. Thus the driving force for the current is determined by the difference between the membrane potential and the potassium equilibrium potential and not simply the membrane potential as with voltage-gated potassium channels (192). However, the degree of rectification can vary substantially and is relatively weak for $\mathrm{K}_{\mathrm{ATP}}$ channels compared to other members of the inward rectifier family such as those responsible for the cardiac current, $\mathrm{I}_{\mathrm{K} 1}$. Thus, in single channel studies from inside-out patches in $\sim 140 \mathrm{mM}$ symmetrical potassium concentration the single-channel conductance is ohmic with a conductance of $50-80 \mathrm{pS}(88 ; 391 ; 446)$. In contrast, in cell-attached patches there is significant inward rectification largely accounted for by voltage-dependent block by magnesium ions $(142 ; 143)$. Figure 1 shows some typical single-channel recordings of $\mathrm{K}_{\mathrm{ATP}}$ channels. Lower values reported in some papers have asymmetric potassium concentrations often with one or both concentrations significantly lower than the above. The channel is highly selective for potassium over sodium ions with a permeability ratio of $\mathrm{P}_{\mathrm{Na}} / \mathrm{P}_{\mathrm{K}} \sim 0.01$ (499). Like all potassium channels, ion conduction is likely best modelled using multi-ion conduction models which entail multiple potassium ions binding within the pore and ion-toion repulsion ensuring high transport rates and selective binding $(222 ; 421 ; 499)$. Indeed, we now have crystal structures of a number of potassium channels which identify multiple potassium ion binding sites and reveal how selectivity over the smaller sodium ion is achieved (see below). Models of ion conduction now use molecular dynamics simulations with these actual structures.

Opening of an inward rectifier potassium channel is largely thought to influence the resting membrane potential buffering it close to the potassium equilibrium potential. However in cells with a high intrinsic potassium permeability the major effects may be on repolarisation. In addition, $\mathrm{K}_{\mathrm{ATP}}$ channels are weak inward rectifiers and Kir6.1 containing channel complexes may actually have a degree of outward rectification even in whole cell 
recording with relatively physiological solutions $(20 ; 22)$.

The direct response of the channel to adenine nucleotides can be assessed best in inside-out patches and subsequent measurement of the change in open probability with bath perfusion, equivalent to the cytosol, of different nucleotide containing solutions. Channel activity is inhibited by ATP with a $\mathrm{K}_{\mathrm{i}}$ in the range of 10-500 $\mu \mathrm{M}$ with a Hill coefficient between 1 and $2(11 ; 88 ; 256 ; 446 ; 499)$. There are variations according to the tissue and exact recording conditions with pancreatic channels being more sensitive than cardiac ones $(11 ; 256)$. The inhibitory effect is not reliant on magnesium ions and ATP can be substituted with non-hydrolysable derivatives $(10 ; 547)$. Furthermore adenine dinucleotides can inhibit channel activity in magnesium free solutions (144). In early single-channel formulations of gating kinetics at least a single open and two closed states were necessary to describe the open and closed time distributions. The channel conforms to "bursting" behaviour with bursts of opening separated by long closed intervals $(446 ; 499)$. ATP promotes channel inhibition by decreasing the number of opening per burst, shortening the length of the burst, increasing the length of closed times and decreasing the open time (499). The main feature affecting open probability is the increase in long closed times. ADP is able to relieve the inhibition of $\mathrm{K}_{\text {ATP }}$ channels by ATP. The action is distinct from that of ATP inhibition as it requires MgADP $(144 ; 303)$. More recent gating models have attempted to integrate key features revealed from cloning and functional work into more structurally realistic schemes. For example, an allosteric model has been proposed based on the tetrameric pore structure with four ATP binding sites $(129 ; 130)$.

These properties apply to most of the well-studied and known $\mathrm{K}_{\text {ATP }}$ channel populations. However, smooth muscle $\mathrm{K}_{\mathrm{ATP}}$ channels have unique properties. Specifically, the single-channel conductance is lower at $\sim 35 \mathrm{pS}$ and there is an absolute dependence for activity on cytosolic nucleotide diphosphates being present in the solution and this has led to 


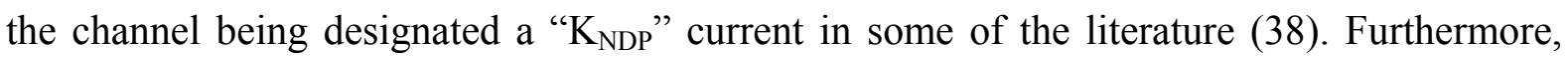
these channels are generally less sensitive to ATP inhibition $(38 ; 101)$.

Rundown of $\mathrm{K}_{\mathrm{ATP}}$ channels was noted even in the earliest publications. This refers to a steady decrease in channel activity in excised patches or whole-cell recordings. The channel activity can be refreshed to some extent by exposure to low $\mu \mathrm{M}$ concentrations of MgATP $(145 ; 394)$. In early studies this was attributed to direct protein kinase regulation of the channel. However it is now known that channel activity is absolutely dependent on the provision of the anionic phospholipid phosphatidylinositol $(4,5)$ bisphosphate $\left(\mathrm{PIP}_{2}\right)$ for activity $(37 ; 132 ; 220 ; 484)$.

\section{The pharmacology of $\mathbf{K}_{\mathrm{ATP}}$ channels}

$\mathrm{K}_{\mathrm{ATP}}$ channels have a diverse pharmacology with both inhibitors and activators of the channel described. In addition, therapeutic agents often developed with another target or use in mind can have off-target effects on $\mathrm{K}_{\text {АTP }}$ channels. Figure 2 summarises the structures of some select drugs that modulate $\mathrm{K}_{\mathrm{ATP}}$ channels. Table 1 summarises the properties of key potassium channel openers and inhibitors.

\section{Sulphonylureas and related agents}

The hypoglycaemic effects of sulphonylureas were discovered by chance when investigating their potential antibacterial action against typhoid fever. Since then a number of derivatives have been synthesised (Figure 2 and Table 1). They act by inhibiting $\mathrm{K}_{\text {ATP }}$ channels present in the pancreatic $\beta$ cell leading to the depolarization of pancreatic $\beta$ cells and increase in intracellular calcium levels resulting in the release of insulin (185).

A number of developments were made in generating sulphonylureas or sulphonylurearelated agents. In the first generation they have relatively low affinity and include drugs such 
as tolbutamide and chlorpropamide. The second group have a higher affinity and include agents such as glibenclamide, glipizide and gliclazide. Finally, a new generation of agent have emerged, the "glinides" including meglitinide and repaglinide and these resemble the non-sulphonyurea component of glibenclamide. The affinity of the pancreatic $\mathrm{K}_{\mathrm{ATP}}$ channel for glibenclamide is high enough se that equilibrium radioligand-binding studies can be performed (389).

Although the main target of these drugs is the pancreatic $\mathrm{K}_{\mathrm{ATP}}$ channel, earlier sulphonylureas also interact with cardiac channels and may lead to undesired cardiovascular side effects such as increased cardiovascular mortality in patients with type II diabetes (170). Recent developments in sulphonylurea chemistry have led to the synthesis of new derivatives that show tissue-specific selectivity. For example, the sulphonylurea HMR-1098 shows 400800 fold selectivity for the cardiac $K_{\text {ATP }}$ over the pancreatic $K_{\text {ATP }}$ channel (338). In comparison, the benzoic acid derivative insulin secretagogue mitiglinide has a 1000 fold greater affinity for the pancreatic over the cardiac and smooth muscle $\mathrm{K}_{\mathrm{ATP}}$ channels (430).

Two novel but selective non-sulphonylurea $\mathrm{K}_{\mathrm{ATP}}$ channel inhibitors are the compounds PNU99963 and PNU37883A. They were initially developed as potentially selective agents for the vascular channel. PNU99963 is a cyanoguanidine similar to pinacidil whilst the PNU37883A is a morpholinoguanidine $(233 ; 278 ; 350)$. In the initial characterisation of these agents it was shown that PNU99963 and PNU37886A inhibited dilation of blood vessels induced by various potassium channel openers $(233 ; 278 ; 350)$. Electrophysiological studies showed PNU37883A at low micromolar concentrations inhibited $\mathrm{K}_{\text {ATP }}$ currents in single vascular smooth muscle cells but not currents in cardiac and skeletal myocytes (568). Subsequent molecular studies revealed that PNU99963 interacted with high nanomolar affinity with the sulphonylurea receptor whilst PNU37883A was a direct poreblocker and showed some selectivity to Kir6.1-containing channel complexes $(100 ; 289)$. 


\section{Potassium Channel Openers}

Pharmacophores of widely different structures are able to activate $\mathrm{K}_{\text {ATP }}$ channels and lead to hyperpolarization and reduced electrical activity. These include; diazoxide (benzothiadiazines), minoxidil (pyrimidine sulfate), nicorandil (pyridyl nitrates), cromakalim (benzopyrans), aprikalim (carbothiamides) and pinacidil (cyanoguanidines) (Figure 2) (337). Initially these drugs were developed on the basis of their ability to relax smooth muscle in low (up to $20 \mathrm{mM}$ ) but not high $(>50 \mathrm{mM})$ potassium containing external media and the ability to stimulate potassium flux $(89 ; 419)$. A comprehensive study was performed to compare their capacity to dilate smooth muscle in various tissue types. The conclusions were that diazoxide has lower dilator potency in comparison to rilmakalim in aorta, coronary artery and trachea, and nicorandil shows higher tissue selectivity to aorta than trachea (337).

Differences in the pharmacological properties of the $\mathrm{K}_{\text {ATP }}$ openers were also observed in clinical settings and in in-vivo studies using animal models. Diazoxide was found to be a hypotensive agent, to promote hyperglycaemia $(450 ; 576)$ and have a cardioprotective effect through its anti-ischaemic properties $(169 ; 564)$. Nicorandil, used to treat patients with angina, has a dual pharmacological effect acting both as a cardiac $\mathrm{K}_{\mathrm{ATP}}$ channel opener and at the same time being a nicotinamide nitrate derivative as a NO donor $(226 ; 295 ; 514)$. In contrast, pinacidil fails to reverse glibenclamide-induced hypoglycaemia in rats (78) but shows a potent hypotensive effect in man $(53 ; 63 ; 369 ; 565)$.

Radioligand-binding has allowed the study of the molecular interaction of potassium channel openers with the $\mathrm{K}_{\mathrm{ATP}}$ channel providing further information on the differences in their binding sites and tissue-specific selectivity. Examples include an analogue of pinacidil ([3H] P 1075), which can be radiolabelled (52). [3H] P 1075 binds with high affinity to cardiac $\mathrm{K}_{\mathrm{ATP}}$ but not to pancreatic $\mathrm{K}_{\mathrm{ATP}}$ and its binding is inhibited by glibenclamide (137; 
551). These observations were consistent with normoglycaemia on the administration of pinacidil in the intact animal. The detailed pharmacology of potassium channel openers acting on the $\mathrm{K}_{\mathrm{ATP}}$ channel are summarised in Table 1.

\section{Miscellaneous agents}

$\mathrm{K}_{\text {ATP }}$ channels like many other potassium channels are blocked by the generic agents barium, tetraethylammonium and 4-amino-pyridine $(15 ; 516)$. They most likely act by directly occluding the pore. A number of clinically used drugs may actually exert some of their therapeutic effects through $\mathrm{K}_{\mathrm{ATP}}$ channel modulation. For example baclofen is a muscle relaxant primarily used to treat spasticity in multiple sclerosis and stroke. It also has an antidepressant effect. In mice, co-administration of low doses of glibenclamide with baclofen showed a synergistic antidepressant-like effect in the forced swimming test and a low dose of cromakalim inhibited these effects suggesting that baclofen has an antidepressant action through its inhibition on $\mathrm{K}_{\mathrm{ATP}}$ channels (376). The anticonvulsant drug carbamazepine used for treating epilepsy can inhibit $\mathrm{K}_{\mathrm{ATP}}$ channel activity by disrupting the response to MgADP (613). Moreover, a number of drugs that display anticonvulsant properties in animal models may exert their effects through $\mathrm{K}_{\mathrm{ATP}}$ channels. Examples include the inotropic calcium

sensitizers levosimendan (183), glycolytic inhibitor 2-deoxy-D-glucose (594), $\mathrm{K}^{+}$-sparing diuretic riamterene (594), hypnotic agent zolpidem (469) and fatty acid caprylic acid (472) though the mechanisms are complex and mostly seem to be indirect in nature. Another interesting example is the anticonvulsant and analgesic gabapentin which decreases $[3 \mathrm{H}]$ noradrenaline release from rat hippocampal and human neocortical slices. This effect can be mimicked by pinacidil, and antagonized by glibenclamide and suggests an involvement of $\mathrm{K}_{\text {ATP }}$ channels. As a drug to treat nerve pain, using an inflammatory pain model in diabetic rat, glibenclamide blocked the gabapentin-induced antinociception (492). Other classes of 
drug may also be able to inhibit $\mathrm{K}_{\mathrm{ATP}}$ channels such as phenformin but not metformin (21). Rosiglitazone may also have an off target inhibitory effect which shows selectivity for the vascular channel and acts through the pore-forming subunit $(601 ; 602)$.

\section{Cloning and isoform distribution}

The inwardly-rectifying family of potassium channels were cloned using expression cloning techniques $(223 ; 293)$ and this then led to additional homology based approaches and the description of a substantial gene family and multiple members in various subfamilies (386). The Kir subunits have two transmembrane domains with an intracellular N and Cterminus and assemble as a tetramer. An H5 segment intercalates into the membrane and contains a consensus motif (GYG or GFG) responsible for potassium selectivity (535). However when expressed alone none of the isolated cDNAs robustly recapitulated the properties of $\mathrm{K}_{\mathrm{ATP}}$ channels. Using classic protein purification based on sulphonylurea binding activity, a second and distinct class of protein was isolated namely the sulphonylurea receptor (SUR) (1). The breakthrough then came when SUR1 was coexpressed with Kir6.2 and this led to currents that recapitulated many of the properties of the native pancreatic $\beta$ cell $\mathrm{K}_{\mathrm{ATP}}$ channel $(241 ; 454)$. Further cloning efforts revealed two isoforms of Kir6.0 (Kir6.1 and Kir6.2) and two SURs (SUR1 and SUR2 with two splice variants SUR2A and SUR2B) (240; 247; 587) (Inagaki et al., 1996; Isomoto et al., 1996; Yamada et al., 1997). SUR is a member of the superfamily of ATP binding cassette (ABC) proteins and is related to the subfamily which includes multidrug resistant-related proteins $(219 ; 539)$. They are classified into the $\mathrm{ABCC}$ family and have seventeen transmembrane segments grouped into three domains comprised of five (TMD0), six (TMD1) and six (TMD2) membrane spanning helices respectively. The N-terminus is extracellular, each of these domains are connected by cytosolic linkers and then an intracellular C-terminus (87). Another distinctive feature is the 
presence of nucleotide binding domains (NBD) with Walker A and Walker B motifs in the TMD1-TMD2 linker and C-terminus. These domains generally bind and hydrolyse adenine nucleotides and in multidrug resistant-related proteins enable the active transport of drugs and other molecules out of the cell (318). The genes encoding SUR1 and Kir6.2, and SUR2 and Kir6.1 are adjacent to one another on $11 \mathrm{p} 15.1$ and $12 \mathrm{p} 12.1$, respectively in the human genome (76; 242). Kir6.1 (KCNJ8, gene ID: 3764) has five exons, Kir6.2 (KCNJ11, gene ID: 3767) has three exons, SUR1 (ABCC8, gene ID: 6833) has 39 exons and SUR2 (ABCC9, gene ID: 10060) has 42 exons. Alternative splicing is best established for SUR2 which generates two variants SUR2A and SUR2B differing in the sequence of the terminal Cterminus (240). Other splice variants in SUR1 and SUR2 have been proposed but their importance isn’t clearly established $(131 ; 196 ; 417)$. Four Kir6.0 subunits and four SUR subunits come together in a hetero-octamer to form the basic channel complex $(83 ; 487)$. Figure 3 shows a cartoon and schematic of $\mathrm{K}_{\mathrm{ATP}}$ channel assembly.

The properties of the current are determined by the assembly of a particular SUR with a Kir6.0 subunit. So for example, the channel present in pancreatic $\beta$ cells is almost certainly constituted of SUR1 \Kir6.2. This generates a channel with a single-channel conductance of $70 \mathrm{pS}$, a $\mathrm{K}_{\mathrm{i}}$ for ATP inhibition in the $10-30 \mu \mathrm{M}$ range and inhibition by tolbutamide $(1 ; 12$; 377 ; 454). In contrast, Kir6.1 \SUR2B may underlie the $\mathrm{K}_{\text {ATP }}$ current in many smooth muscles and this leads to a single channel conductance of $35 \mathrm{pS}$, an absolute requirement for adenine nucleotides for activation and activation by levcromakalim $(101 ; 587)$.

The octameric structure means that heteromultimeric populations might occur, combining different Kir subunits and different SUR subunits. In heterologous expression systems the co-assembly of Kir6.1 and Kir6.2 can be readily demonstrated (99). Furthermore, it might also occur in native tissues such as endothelial cells, some smooth muscles and the cardiac conduction system $(31 ; 525 ; 600)$. In contrast we and others have been unable to 
conclusively demonstrate heteromultimeric populations of SUR subunits $(172 ; 542)$ whilst other laboratories have data demonstrating this might be a possibility (70). In practice this is likely to be less of an issue as the expression of SURs is more tissue-specific and coexpression of different subunits in the same cell is more limited. Secondly, the composition of the channels may show subtle but important anatomic variations. Indeed, single neurons within a defined brain region may have specific expression of different SUR subunits which leads to differences in metabolic sensitivity (319).

\section{$\mathrm{K}_{\mathrm{ATP}}$ channel trafficking, assembly and association with auxiliary proteins}

The discovery that co-expression of two subunits was necessary to fully reconstitute the channel and that expression of the Kir6.0 alone did not lead to substantive currents led to the question of why this occurred. The two possibilities are that the subunits are present at the plasma membrane but functionally inactive or alternatively the assembly of SUR with the Kir6.0 subunit is necessary for the channel complex to traffic through the secretory pathway. The first clue to the answer to this question came with studies showing that truncation of the C-terminus of Kir6.2 by 36 amino acids led to the expression of an ATP-sensitive potassium selective current with the characteristic single channel conductance of $\sim 70 \mathrm{pS}$ (548). Coexpression of SUR was necessary to endow the channel with sulphonylurea and diazoxide sensitivity and activation by MgADP (548). Other investigators then identified an RKR motif in both Kir6.0 subunits and SUR subunits that behaved as an endoplasmic retention\retrieval signal (605). The mutual masking of these signals between each Kir6.0 and SUR subunit is thought to allow only mature octameric channels to progress through the secretory pathway and enter the plasma membrane. The arginine based retention $\backslash$ retrieval motif recognises coat protein I complexes and this vesicle population is involved in retrograde transport from the golgi to the endoplasmic reticulum (604). Furthermore, this interaction is antagonised by 
interaction with $14-3-3$ proteins and also by phosphorylation by protein kinase A $(7 ; 218)$.

A second and related question raised by the cloning work was which domains were responsible for the assembly of the $\mathrm{K}_{\mathrm{ATP}}$ channel complex? In the inward rectifier family it seems the M2 transmembrane domain and proximal C-terminus are important with contributions from the N-terminus $(535 ; 546 ; 579)$. Furthermore, essentially all regions in inward rectifiers have been implicated in the interaction with SUR (173; 465). Finally it appears the TMD0 region is important for the assembly of SUR with the Kir6.0 subunits (66). Many of these studies were subsequently supported by the solution of the recent crystal structures as discussed below.

In addition to the obligatory co-assembly of SUR and Kir6.0 subunits, it is also apparent that $\mathrm{K}_{\mathrm{ATP}}$ channels may assemble with other auxiliary proteins. In the first studies investigators focused on specific proteins and were able to show interaction of $\mathrm{K}_{\mathrm{ATP}}$ channels with adenylate cyclase (64), creatinine kinase (95), lactate dehydrogenase (94), various glycolytic enzymes $(115 ; 225)$, syntaxin-1A (409), exchange proteins directly activated by cAMP (402) and Ankyrin (282). In more recent work using modern proteomic techniques and co-purification strategies a number of proteins were isolated from cell lines of heart tissue, endothelial cells, pancreatic $\beta$ cells and the brain (277). A bioinformatics analysis revealed enrichment of proteins involved in metabolic processes, in particular glycolysis, but also fatty acid metabolism particularly in the heart and in proteins involved in endocytic and membrane trafficking (277). Specifically for the proteins involved in trafficking association was shown with cytoskeletal proteins (non-muscle myosins, F-actin capping proteins, dynein etc) and endosomal trafficking checkpoints (various ras related proteins and ADP ribosylation factors etc) (277). It is interesting that these interactions may explain some functional observations. For example, it is known that $\mathrm{K}_{\mathrm{ATP}}$ channels in ventricular myocytes are preferentially modulated by ATP derived from glycolysis (566). Furthermore, the pancreatic $\beta$ cell $\mathrm{K}_{\text {ATP }}$ 
channel is subject to endocytosis and this leads to changes in the membrane current-density (336). Finally, drugs that disrupt the cytoskeleton can change the functional behaviour of $\mathrm{K}_{\text {ATP }}$ channels (164).

\section{$\mathrm{K}_{\mathrm{ATP}}$ channels as molecular machines}

This topic can be viewed at a number of different levels of sophistication. Initially the questions of conduction, gating and drug binding were approached using biophysical models. However after the cloning of potassium channel genes, numerous studies were undertaken in which single amino acids were mutated or domains were swapped between different channels using standard molecular techniques. The mutated andlor chimaeric channels and subunits were then expressed in heterologous expression systems such as xenopus laevis occytes or mammalian cell lines and studied using two-electrode voltage-clamp and patch-clamp. The functional consequences could then be interpreted in an attempt to define binding sites. Ultimately these experiments would be optimally complemented by high resolution structural information. Recently, this aspiration has culminated in three land mark publications (305; $310 ; 342$ ) and these have superseded lower resolution structures (353). Figure 4 and 5 show structures obtained in these studies. Most work has focussed on pancreatic (SUR1) and cardiac (SUR2A) channels with Kir6.2 constituting the pore-forming subunit.

\section{Ion conduction}

Kir6.1 and Kir6.2 contain a GFG motif in the H5 domain which is a recognised variant of the classic $\mathrm{K}^{+}$channel selectivity sequence GYG (212). Whilst there have been only a few direct studies of ion permeation in $\mathrm{K}_{\mathrm{ATP}}$ channels it seems likely it will follow the general principles developed from the study of other potassium channels using mutagenesis and structural studies. In particular the latter has been revolutionary in developing our 
understanding $(118 ; 298)$. The technical breakthrough, allowing the production of large quantities of protein in bacteria suitable for protein purification and crystallisation, came from the use of prokaryotic ion channels. In the crystal structures of KcsA and KirBac1.1 the channel contains a number of binding sites for potassium. The ion is complexed by the backbone carbonyl groups of the amino acids of the potassium channel signature sequence (VGYG) acting to replace the water molecules that the potassium ion would normally complex with if it were in solution. The structure is rigid and will not accommodate the smaller sodium ion in an energetically favourable position $(118 ; 298)$ and this steric factor accounts for the exquisite potassium selectivity. Furthermore in the KcsA structure four helix dipoles further stabilise potassium ions in the central channel cavity. The KcsA channel likely represents an open conformation whilst the KirBac1.1 structure is closed. In the latter the pore is closed shut on the cytosolic side by hydrophobic residues (phenylalanine 146 in KirBac1.1) at the end of the second transmembrane segment also labelled as the inner helix in the crystal structures. The crystal structure of the pancreatic $K_{\text {ATP }}$ (Kir6.2\SUR1) channel has been solved to 5 to 6 angstrom resolution $(305 ; 310 ; 342)$. The structure of Kir6.2 closely resembles that of KcsA and the structure of the eukaryotic Kir3.2 (570). The pore is closed at the cytoplasmic face by the inner helices and outer helices forming a critical constriction $(305 ; 310 ; 342 ; 570)$. Thus the mechanism of potassium selectivity and pore gating are likely to be broadly similar to that in other potassium channels.

Although $\mathrm{K}_{\text {ATP }}$ channels do not show pronounced inward rectification, it is instructive to look at the molecular basis for why this is the case. Inward rectification arises from voltage-dependent block by cytosolic magnesium and cellular polyamines i.e. as the membrane voltage becomes more depolarised these species are increasingly driven into the pore but are unable to permeate and this leads to occlusion of ion flow $(329 ; 330 ; 385)$. The block by polyamines is extremely high affinity and practically it is very difficult to "wash 
off" these molecules even when recording in inside-out patches. This accounts for what was previously ascribed to be an "intrinsic" gate. Site-directed mutagenesis revealed that acidic amino acids such as aspartate and glutamate in the second transmembrane segment and the proximal C-terminus act as two potential key binding sites $(140 ; 329 ; 332 ; 501 ; 596)$. In the crystal structure these acidic amino acids form two rings of negative charge, one within the membrane and the other in a C-terminal cytosolic extension of the transmembrane domains (298). $\mathrm{K}_{\text {ATP }}$ channels show little sensitivity to polyamines (588) and this is likely accounted for by not having acidic residues in homologous positions to those in the strong inward rectifiers. For example, in Kir6.2 the M2 transmembrane residue is a neutrally charged asparagine and not a negatively charged aspartic acid.

\section{Inhibition by ATP}

The central defining property of $\mathrm{K}_{\mathrm{ATP}}$ channels is the inhibition of channel gating by cytosolic ATP. This property is determined by residues in the pore-forming Kir6.0 subunit and was revealed using a C-terminal deletion mutant of Kir6.2 that was able to express at the plasma membrane of the cell in the absence of the sulphonylurea receptor (see above) (548). In inside-out patches the mutant had an $\mathrm{IC}_{50}$ (the concentration at which activity is inhibited by $50 \%$ ) for inhibition by ATP of $\sim 100 \mu \mathrm{M}$. However the sulphonylurea receptor is not without some role as expression with SUR1 decreases the $\mathrm{IC}_{50}$ to $\sim 10 \mu \mathrm{M}$ indicative of an allosteric effect (548). Co-expression of Kir6.2 with SUR2 does not result in this change in IC $_{50}$. Generally Kir6.1 is not thought to be as ATP-sensitive though it can be shown under specific experimental conditions $(24 ; 101)$. Furthermore, both Kir6.1 and Kir6.2 containing channels are activated by metabolic challenge (134). Site-directed mutagenesis in the Cterminal deleted Kir6.2 was then used to define key residues influencing $\mathrm{K}_{\text {ATP }}$ channel inhibition by ATP and thus delineating a potential binding site. A series of such studies 
implicated R50, C166, I167, T171, I182, K185, R201 and G334 amongst others $(5 ; 254 ; 431$; 540). A key feature is that these mutations do not significantly perturb the gating model (86; 541). For example, it is possible that mutations could modify gating without affecting ATP binding but in functional assays the ability of ATP to inhibit the channel could still be impaired (86; 541). In the crystal structure the residues R38, R50 and K185 form a cluster of positively charged amino acids unique to the Kir6.0 family and in a pocket that could accommodate the adenosine ring of ATP (310). However in this crystal structure the Kir6.2 \SUR1 octamer was crystallised in the absence of ATP. In contrast, in the other crystallographic studies ATP was included in the solution. In this case ATP is adjacent to $\mathrm{K} 185$ and a pocket is defined by the interface of adjacent $\mathrm{N}$ and $\mathrm{C}$ domains in Kir6.2 which includes I182, L205, Y330, F333, and G334 from the same subunit, and R50 from the other subunit (342). In the second structure (305), this is resolved even more clearly. ATP lies in a horseshoe shape in a pocket defined by 182-185 (IFSK) and 332-335 (KFGN) in one subunit whilst residues N48 and R50 from the neighbouring subunit making two hydrogen bonds with the adenine base of ATP (Figure 5). The channel complex was seen to bind four molecules of ATP and this is compatible with Hill coefficients of more than one when describing the dose-response curve for channel inhibition by ATP $(5 ; 130)$. Binding of a single ATP to one subunit is sufficient to close the channel (554).

\section{Activation by MgADP}

In contrast to ATP inhibition, activation by ADP is dependent on the provision of magnesium. In its absence ADP leads to inhibition probably acting via the ATP inhibitory site on Kir6.2. In contrast in the presence of a SUR the channel complex becomes sensitive to activation by MgADP and specifically is determined by residues in the nucleotide binding domains (NBD) $(187 ; 483)$. NBDs in other ABC transporters adopt a two lobed structure with 
the larger one containing the Walker A and Walker B motifs followed by aspartate ("D") and histidine ("H") loop residues. The smaller lobe is an $\alpha$-helical domain and comprises the $\mathrm{ABC}$ transporter signature sequence (usually LSGGQ) and a "Q-loop". Characteristically the larger lobe of NBD1 interacts with the smaller lobe of NBD2 to form a functional unit capable of hydrolysing adenine nucleotides. A second functional unit is formed by the large lobe of NBD2 and small lobe of NBD1. The Walker A motif contains a lysine that is critical for beta and gamma phosphate binding of ATP. The Walker B motif has a conserved aspartate amino acid that complexes magnesium ions and is central to nucleotide hydrolysis. The $\mathrm{ABC}$ signature sequence is part of a helix-dipole important for positioning ATP in the catalytic site (521; 555). There are functional and now structural data that the NBDs in SURs are asymmetric in the closed conformation.

The first critical evidence for the involvement of NBDs in activation of the channel complex by MgADP was that mutagenesis of key residues such as lysines and others in the Walker A, linker and Walker B motifs abolished or altered stimulation by $\operatorname{MgADP}(187 ; 483)$. However the NBDs are asymmetrical in functional behaviour and seem to differ in whether they bind and \or hydrolyse MgATP. Biochemical studies support the proposition that NBD1 binds ATP without $\mathrm{Mg}^{2+}$ with slow hydrolysis whilst NBD2 binds and hydrolyses MgATP rapidly $(42 ; 112 ; 550)$. The post and pre-hydrolytic states in the NBDs can be mimicked by using vanadate and beryllium in electrophysiological experiments and support the notion that MgATP hydrolysis at NBD2 is needed for increases in channel activity in Kir6.2 $\mathrm{SUUR} 2 \mathrm{~A}$ complexes (615). However in excised patch-clamp recordings, MgADP clearly stimulates the channel and this implies that nucleotide hydrolysis is not a prerequisite for channel modulation. In addition, there are only a few reports of direct hydrolysis by SUR NBDs and if it were necessary for channel gating this would violate microscopic reversibility $(42 ; 344)$. Furthermore, non-hydrolysable ATP derivatives may lead to conformational changes in the 
NBDs (400). It is also a general feature of ABC transporters that dimerization of the NBDs in the fashion detailed above is necessary for ATP hydrolysis to occur (318). The NBDs in SUR however are asymmetric in terms of their primary sequence with a degenerate Walker B motif in NBD1 and a degenerate ABC signature sequence in NBD2 (555). In the crystal structures the NBDs are clearly separate and asymmetric in relative position $(310 ; 342)$. However this is a closed channel configuration co-crystallised in the presence of glibenclamide and it is possible that the NBDs might align and dimerise in an open configuration. Thus it is possible that whilst SURs may retain the ability to hydrolyse nucleotides it is not central to activation. However the adoption of the post-hydrolytic and MgADP bound state in NBD2 in a dimeric NBD structure is crucial for activation. It is however possible that the hydrolytic properties of the SUR subunit might be crucial for other functions though, for example, no clear transport ligand has been identified.

New light has been shed on these issues with the very recent publication of a high resolution structure of the pancreatic $\mathrm{K}_{\mathrm{ATP}}$ channel co-crystallised with magnesium nucleotides and $\mathrm{PIP}_{2}(305)$. They distinguished two forms: a propeller like overall structure similar to those studied previously and a new quatrefoil shape. Crucially in the latter structure nucleotides were bound to SUR1 and reveal a canonical ABC transporter like structure with transmembrane segments 9 and 10 from NBD1 and transmembrane segments 15 and 16 from NBD2 reaching across to interact with the other half NBD. The NBDs form head to tail dimers with the signature 'LSGGQ' motif in NBD1 disengaged from the bound MgADP leading to an open consensus ATPase site whilst the signature sequence in NBD2 is mutated to 'FSQGQ' directly contacting ATP and leads to a closed and degenerate ATPase site. The presence of ADP in one NBD site and ATP in another is a unique feature for an ABC transporter. The authors suggest that the ADP binding consensus site is an ADP sensor without a hydrolysis cycle during gating. In another structural feature, the lasso motif in 
SUR1 is disengaged from the ATP binding site and C-terminal domain on Kir6.2 in the quatrefoil but not in the propeller structure. The significance of this for gating however is not clear.

\section{Pharmacological Inhibitors}

Once the $\mathrm{K}_{\mathrm{ATP}}$ channels were cloned a priority for mutagenesis work was to determine the likely binding sites for sulphonylureas. Given that SUR1 was initially cloned by the use of high affinity binding and protein purification, it was clear that this subunit was the major binding site (1). However, in studies with tolbutamide in Xenopus laevis oocyte membrane patches expressing Kir6.2 \SUR1, the dose-response curve for inhibition was best described by two independent binding sites. The curve was biphasic with a high affinity and low affinity site respectively (188). This is a feature of other sulphonylureas and related compounds $(184 ; 185 ; 203)$. The high affinity component corresponds to the binding site on SUR and the low affinity site to one on the pore forming Kir6.2 subunit $(16 ; 188)$. Furthermore, there are differential effects of these agents between SUR1 and SUR2 containing channels. Thus glibenclamide, glimepiride, repaglinide and meglitinide show high affinity block in both SUR1 and SUR2 containing channels whilst tolbutamide, gliclazide, chlorpropamide and nateglinide do not exhibit high affinity block with SUR2 (185). This observation drove an approach in which chimaeras were constructed between SUR1 and SUR2 and high affinity tolbutamide inhibition was assayed (16). The results indicated that the last group of transmembrane domains was important specifically the cytoplasmic loop between helices 15 and 16 in SUR1 (16). Subsequent studies isolated S1237 as being the key amino acid residue (203) and introduction of serine at an equivalent residue in SUR2B led to an increase in the affinity of glibenclamide binding (195). The cryo-EM structures are not clear as regards glibenclamide binding and will need higher resolution structures to 
unambiguously identify it. In the structure where glibenclamide is present, it might lie close to the S1237 residue but also that it might interact with the linker between TMD0 and TMD1 (“L0”) specifically residue Y230 (342). There is some support from biochemical work for such a model $(354 ; 574)$. For example deletion of TMD0 and L0 but not TMD0 led to an abolition of glibenclamide binding. The L0 domain interdigitates with Kir6.2 and thus would be optimally placed to regulate Kir6.2 gating. Finally, the structural studies suggest that glibenclamide might distort the relationship between the NBDs preventing alignment, dimerisation and consequent channel activation $(310 ; 342)$.

At the physiological level there are also interactions between MgADP and sulphonylurea block. In inside-out patches tolbutamide acting at the high affinity site only leads to partial but not complete channel block in SUR1 containing channels. However in intact whole cells or in the presence of MgADP the action of tolbutamide is much more complete (188). This is a general feature of sulphonylureas and related compounds (185). This interaction with MgADP is not a feature of SUR2 containing channels and in fact they are less effective when MgADP concentrations are high (427).

\section{Pharmacological Openers}

As discussed above there are a wide variety of pharmacophores that can activate $\mathrm{K}_{\text {ATP }}$ channels. Nicorandil, pinacidil and cromakalim are selective for SUR2 containing channels whilst diazoxide is probably more specific for SUR1 containing subunits though it does activate SUR2B (172; 337). Diazoxide can activate SUR2A and cardiac channels under specific circumstances with high cellular MgADP (104). Studies using chimaeric approaches and binding studies have identified regions within TMD2 in particular the cytoplasmic linker between TM13 and TM14 and the last TM helices, TM16 and TM17, as responsible for the activation by pinacidil and cromakalim $(25 ; 367 ; 551)$. The binding site for diazoxide is less 
well mapped though it is known that binding is nucleotide-dependent and occurs between TM6 to TM11 and NBD1 (25). The presence of more than one binding site on SUR for potassium channel openers may help rationalise the observed structural diversity of potassium channel openers. The binding sites are separate between that of the sulphonylureas and the potassium channel openers though there is some interaction which is likely to be allosteric in nature $(195 ; 327)$. The pharmacological topology of drug-SUR interaction is summarised in Figure 6. It is worth noting that this has largely been determined from sitedirected mutagenesis and chimaeric studies and the contribution of structural studies using cryo electron microscopy is currently modest.

\section{Principles of assembly determined from structural studies}

The cryo-EM structures have unambiguously delineated the key regions for the assembly and interaction of SUR1 with Kir6.2 in the closed channel configuration $(310 ; 342)$ (and see Figure 4). Four SUR1 subunits are arranged peripherally to the pore-forming tetramer of Kir6.2. The complex is 125 angstroms in height, 200 angstroms wide and shaped like a propeller blade (Figure 4). The TMD0 and linker L0 contact the N-terminus of Kir6.2 and also the proximal C-terminus close to the putative PIP $_{2}$ and ATP binding site (see below). This is the primary point of contact and essentially TMD0-L0 is sandwiched between Kir6.2 and TMD1 and TMD2 of SUR1. At the other interface between TMD0-L0 and TMD1-TMD2 of SUR1 there is a so called "lasso" motif bound onto transmembrane segments M7, M15 and M16. Both of the cryo-EM structures are in a closed conformation however it is possible to speculate about sequences of events that might occur to gate the pore into an open state. MgADP binding for example could dimerise the NBDs and in other ABC transporters this results in motions of M6 and M7 in TMD1 and M15 and M16 in NBD2 relative to one another. This in turn is transmitted to the lasso and L0 linker which results in clockwise 
rotation of the proximal C-terminal domain of Kir6.2 opening the pore $(310 ; 342)$.

\section{The regulation of $K_{\mathrm{ATP}}$ channels}

\section{Metabolism and pH}

The direct regulation of $\mathrm{K}_{\mathrm{ATP}}$ channels by intracellular nucleotides has already been discussed. It is worth noting that in cardiac cells it seems that $\mathrm{K}_{\mathrm{ATP}}$ channels preferentially sense ATP derived from glycolysis (567). This is supported by more recent observations of direct association of glycolytic enzymes with the $\mathrm{K}_{\mathrm{ATP}}$ channel complex as discussed above (225). However cardiac cells also possess well developed phosphotransfer networks, using adenylate kinase and creatinine kinase, allowing mitochondrial energy homeostasis to be sensed and relayed to channels in the sarcolemma $(64 ; 124)$. In contrast, in pancreatic beta cells mitochondrial oxidative metabolism is essential for $\mathrm{K}_{\text {ATP }}$ channel regulation by ATP $(120 ; 214)$.

Intracellular acidification is an activator of $\mathrm{K}_{\text {ATP }}$ channels such as may occur with cellular anaerobic metabolism $(111 ; 563 ; 583)$. The exact molecular basis for this effect is not clear though it involves an antagonism of ATP inhibition (581) and residues T71 and His-175 in the Kir6.2 subunit $(98 ; 584)$. The latter residue is a good candidate for a direct $\mathrm{pH}$ sensor as it could readily be titratable by protons. In studies examining natively expressed $\mathrm{K}_{\mathrm{ATP}}$ channels, the cardiac channel seems less sensitive to changes in intracellular $\mathrm{pH}$ than the skeletal muscle channel $(111 ; 290 ; 303)$.

\section{Regulation by phosphatidylinositol $(4,5)$ bisphosphate $\left(\mathrm{PIP}_{2}\right)$}

An emerging theme in ion channel research has been the dependency of channel activity on the presence of $\mathrm{PIP}_{2}$ and perhaps other anionic phospholipids in the plasma 
membrane $(220 ; 221) . \mathrm{PIP}_{2}$ is a relatively minor lipid component of the plasma membrane making up less than $0.5 \%$ of total lipid composition $(102 ; 560)$. Run-down could often be ameliorated by the provision of ATP or ATP-generating systems. The key observation was that this rundown in inside-out patches was reversed by the addition of $\mathrm{PIP}_{2}$ (either in lipid vesicles or as a water soluble derivative). This was also the case with the application of other anionic phospholipids but this was more variable and dependent on the specific channel being studied. This fundamental lipid dependency was observed for a number of channels and transporters and specifically with Kir6.2 containing $\mathrm{K}_{\text {ATP }}$ channels $(132 ; 220 ; 484)$. Furthermore, with $\mathrm{K}_{\text {ATP }}$ channels the addition of increasing concentrations of $\mathrm{PIP}_{2}$ profoundly antagonised ATP inhibition $(37 ; 484)$. This suggests that ATP inhibition and metabolic regulation might be subject to dynamic regulation within the cell. The Kir6.0 subunit determines the PIP $_{2}$ sensitivity and there have been mutagenesis studies that have identified key positively charged residues in the slide helix. In particular basic residues in the Cterminus (regions 176-222 and 301-314) have been identified as being important (485). The binding site for $\mathrm{PIP}_{2}$ in the cryo-EM structures was not particularly well resolved. However a binding pocket was better determined in other inward rectifier potassium channels $(204 ; 570)$. It consisted of an interface between the transmembrane domain which confers non-specific lipid binding through hydrophobic acyl chains in $\mathrm{PIP}_{2}$ and the cytoplasmic domain which generates a specific phosphatidylinositol-binding region. The latter site is also contributed to by amino acid residues from the N-terminus. The effects of $\mathrm{PIP}_{2}$ are through direct binding. For example, it is possible to bind the C-terminus of Kir6.0 channels to phospholipid arrays and the ion channel activity of other inward rectifiers such as Kir2.0 channels can be reconstituted into $\mathrm{PIP}_{2}$ containing lipid vesicles $(103 ; 422)$. Interestingly, in the binding assays the Kir6.0 channel domain is able to bind a wider array of phosphatidylinositol species and there are some indications that this might have functional significance in terms of 
regulation of $\mathrm{K}_{\text {АTP }}$ channel activity for phosphatidylinositol (4) phosphate (437).

$\mathrm{PIP}_{2}$ is an important substrate for a number of signalling enzymes including phospholipase $\mathrm{C}$ and phosphatidylinositol (3) phosphate kinase. One key question is whether $\mathrm{PIP}_{2}$ can act as a signalling molecule in its own right or whether cellular $\mathrm{PIP}_{2}$ depletion is ever sufficient to inhibit channels. Such regulatory phenomena can be demonstrated after heterologous expression of various components in cell lines and Xenopus laevis oocytes however these approaches lead to high and often non-physiological levels of expression. The critical point is what happens in native cells. There are studies examining phospholipase $\mathrm{C}$ activation via muscarinic receptors in neurones and these have revealed that $\mathrm{PIP}_{2}$ levels can fall by up to $60-70 \%(96 ; 572)$. However the remaining fraction is protected from depletion and once the agonist is removed the levels of $\mathrm{PIP}_{2}$ recover rapidly (generally within a minute). Ion channels regulated by $\mathrm{PIP}_{2}$ show a wide range of apparent affinities (441). Indeed in the Kir6.0 family, Kir6.1 has a higher affinity than Kir6.2 and this may account for why these channel complexes are less sensitive to ATP (422). The best evidence for $\mathrm{PIP}_{2}$ acting as a true second messenger in signalling is the muscarinic receptor-mediated inhibition of the M-current (Kv7.0 channels) $(56 ; 608)$. It is notable that these channels have low affinity $\mathrm{PIP}_{2}$ binding and the channel activity is exquisitely sensitive to changes in cellular $\mathrm{PIP}_{2}(291 ; 438)$. In many other channels including $\mathrm{K}_{\mathrm{ATP}}$ channels such strong evidence is not evident and the jury is out on the potential signalling significance of the lipid regulation. In intracellular vesicles and organelles there are much lower amounts of $\mathrm{PIP}_{2}$. Thus one idea is that the $\mathrm{PIP}_{2}$ sensitivity of the majority of ion channels leads to them being closed in intracellular compartments. This would minimise ionic fluxes and water movement across these membranes (221).

\section{Regulation by other lipids}


Other lipid species in particular fatty acids and metabolites are able to modulate $\mathrm{K}_{\mathrm{ATP}}$ channel function. Fatty acids can also be metabolised by oxidation to acetyl CoA derivatives and independent of entering the citric acid cycle can modulate $\mathrm{K}_{\text {ATP }}$ channel function (321). These can directly activate $\mathrm{K}_{\text {ATP }}$ channels and seem to do so using the same binding site and mechanisms as $\operatorname{PIP}_{2}(339 ; 464)$. The effects are more pronounced on cardiac than pancreatic channels though both are regulated to some degree $(51 ; 159)$. Furthermore oleate is able to activate $\mathrm{K}_{\mathrm{ATP}}$ channels in hypothalamic neurones: an effect that is independent of metabolism $(105)$.

\section{Regulation by protein kinases}

\section{Vascular smooth muscle cells}

It is clear that in vascular smooth muscle phosphorylation of $\mathrm{K}_{\mathrm{ATP}}$ channels is important in physiological function. It has been known for many years that vasodilators can activate $\mathrm{K}_{\mathrm{ATP}}$ channels with subsequent membrane hyperpolarisation, decreased calcium entry and relaxation of vascular smooth muscle (420). This occurs through the classic signalling pathway where binding of an agonist to a G-protein coupled receptor activates the stimulatory G-protein $(46 ; 174)$. This then leads to production of cAMP by adenylate cyclase and the activation of protein kinase A. Adenosine released from metabolically challenged tissue can bind to the adenosine receptor G-protein coupled receptors A2A and perhaps A2B $(107 ; 109 ; 281)$. Calcitonin gene-related peptide is present in sensory nerve endings and leads to vasodilatation when it binds to the calcitonin receptor-like receptor which complexes with a receptor activity-modifying protein to form the mature receptor in vascular smooth muscle $(34 ; 378 ; 569)$. Vasoactive intestinal polypeptide is another example of a vasodilator that is released from peripheral nerves and binds to its cognate receptor probably VIPR2 (597). 
Vascular smooth muscle cells contain $\alpha 1$ and $\beta 2$ receptors and thus norepinephrine released from nerve endings will cause vasoconstriction whilst increases in circulating epinephrine will activate $\beta 2$ receptors and cause relaxation $(61 ; 227 ; 518)$. The response to exercise in an individual tissue is viewed as an interaction between a local signal, indicating metabolic demand, that can override the nervous signal mediated by sympathetic innervation. Finally endothelial mediators such as prostacyclin can activate their relevant GPCR in smooth muscle and this is particularly important in the pulmonary circulation $(250 ; 463)$. It is worth emphasising that the activation of $\mathrm{K}_{\mathrm{ATP}}$ channels is not the sole mechanism by which these vasodilators act and for example in some vascular beds the effects are only partially inhibited by sulphonylureas (280).

Protein kinase A acts by directly phosphorylating the channel complex. On the SUR2B complex T633, S1387 and S1465 are important whilst on Kir6.1 S385 is involved (423; 477). The phosphorylation sites on SUR2B are in and around the NBDs and it is plausible they promote MgADP binding and channel activation. It is also conceivable that the sequential phosphorylation of increasing numbers of these residues allows a graded increase in open probability and response with increasing strength of upstream signal (423).

In contrast vasoconstrictors can inhibit the $\mathrm{K}_{\mathrm{ATP}}$ channel and this leads to membrane depolarisation, increased calcium entry and vasoconstriction (420). The vasoconstrictors include endothelin-I, an endothelial mediator, circulating angiotensin II, norepinephrine from sympathetic nerve endings and histamine released from mast cells $(50 ; 210 ; 292 ; 361)$. The binding of relevant agonists to their cognate G-protein coupled receptors leads to the activation of the $\mathrm{G}_{\mathrm{q} \backslash 11}$ family of $\mathrm{G}$-proteins and then activation of phospholipase $\mathrm{C}$ beta (45). This in turn leads to the production of diacylglycerol and inositol trisphosphate from $\mathrm{PIP}_{2}$. The former activates protein kinase $\mathrm{C}$ and the later mobilises $\mathrm{Ca}^{2+}$ from intracellular stores (41). It seems that protein kinase $\mathrm{C}$ is the important mediator. The vascular channel binds 
$\mathrm{PIP}_{2}$ with high affinity and it functions more like a cofactor necessary for channel activity than a signalling mediator (422). Where detailed measurements have been performed it seems likely that there is only ever modest depletion of $\mathrm{PIP}_{2}$ in native cells after receptor activation $(375 ; 572)$. Electrophysiological studies support the involvement of calcium independent isoforms of protein kinase C and specifically the epsilon isoform (210). The inhibitory effect is dependent on phosphorylation of a cluster of serine residues in the distal C-terminus of the Kir6.1 subunit (S354, S379, S385, S391 and S397) (476). The Kir6.2lSUR2B channel complex can also be regulated by $\mathrm{PKC}$ but in this case the effect is calcium dependent and a single residue S372 is key (23). Whilst it is clear that PKC can directly inhibit channel opening it also seems that it can promote channel internalisation perhaps via caveolae (23; 253). The modulation of $\mathrm{K}_{\mathrm{ATP}}$ via PKC may contribute to vasoconstrictor action but it is clear that other potassium channels can be inhibited such as voltage-gated potassium channels $(211 ; 424)$. In addition, $\mathrm{IP}_{3}$ mediated calcium release will directly promote vascular smooth muscle contraction.

There a number of ways the contractile response via $\mathrm{K}_{\mathrm{ATP}}$ channels can be amplified. Agonist bound angiotensin receptor (AT-1) activates PKC via the Gq\11 family of heterotrimeric G-proteins but in smooth muscle it also couples to inhibitory G-proteins. This has the effect of inhibiting adenylate cyclase and down regulating basal PKA activity and vasodilatation (210). Phosphatases are important in reversing the action of protein kinases. Calcineurin (also known as PP2B) is a calcium dependent phosphatase and it can inhibit $\mathrm{K}_{\text {ATP }}$ channels in vascular smooth muscle (573). It is likely it does this through reversing PKAmediated phosphorylation (398). As vasoconstrictors promote calcium mobilisation, this will reverse PKA-mediated channel phosphorylation through the activation of calcineurin. Exchange proteins activated by cAMP represent a PKA independent signalling pathway. The emergence of good pharmacological tools to separate the two systems has implicated them in 
a number of cellular signalling events (308). Activation of exchange proteins by cAMP inhibits smooth muscle $\mathrm{K}_{\mathrm{ATP}}$ channels via $\mathrm{Ca}^{2+}$ mobilisation and subsequent activation of calcineurin (418).

Caveolae are cholesterol rich vesicles and are involved in native smooth muscle in compartmentalising both PKA and PKC mediated signalling. Thus adenylate cyclase and Kir6.1 localise in caveolae as determined by sucrose gradient separation and electron microscopy (457). Cholesterol depletion, which disrupts caveolae formation, attenuates PKA mediated signalling (457). Protein kinase C epsilon translocates to caveolae on angiotensin II receptor activation (456). The PKA-mediated activation of $\mathrm{K}_{\text {ATP }}$ channels in vascular smooth muscle cells might also be enabled by A-kinase anchoring proteins (209). Use of a peptide which inhibits PKA binding to A-kinase anchoring proteins led to attenuation of $\mathrm{K}_{\mathrm{ATP}}$ channel activation in whole-cell recordings (209). The regulation of vascular smooth muscle $\mathrm{K}_{\mathrm{ATP}}$ channels by protein kinases is summarised in Figure 7.

\section{Cardiac myocytes}

Protein kinase $\mathrm{C}$ is thought to be a critical mediator in various cardioprotective phenomena. For example, ischaemic preconditioning describes the phenomena where short periods of ischaemia, prior to a more damaging insult, protects the heart and reduces infarct size (598). This can be mimicked by phorbol esters, diacylglycerol analogues and receptor activation of receptors coupled to the Gq\11 family of G-protein and the protective response is inhibited by PKC inhibitors $(323 ; 325 ; 326 ; 496)$. Ischaemic preconditioning could also be mirrored by potassium channel openers and prevented by sulphonylureas (495). Initially it was proposed that this involved the sarcolemmal $\mathrm{K}_{\mathrm{ATP}}$ channel but the focus quickly shifted to the mitochondrial channel (see below).

Thus protein kinase $\mathrm{C}$ modulation of cardiac $\mathrm{K}_{\mathrm{ATP}}$ channels was highly topical 
initially as an avenue for investigation. Indeed, as was expected, investigators were able to show activation of the cardiac channel by PKC. For example, perfusion of a catalytic subunit of PKC in inside-out patches increased open probability three-fold and this was inhibited by PKC inhibitors. The effect was rendered irreversible if phosphatase activity was blocked using okadaic acid (316). However the position is now known to be more complex. The prevailing level of ATP is thought to be important: thus the channel is activated by PKC under conditions of high ATP and inhibited in the presence of low ATP when channel activity is high $(313 ; 316)$. The level of intracellular $\mathrm{Ca}^{2+}$ is also influential and in conditions where physiological levels of $\mathrm{Ca}^{2+}$ prevail there is a biphasic effect with activation followed by a slower inhibition due to channel internalisation (229). This complex behaviour is determined by the Kir6.2 subunit and thus would be expected to be observed with channels in the heart and pancreas. This is in contrast to Kir6.1-containing complexes which seem to be universally inhibited by PKC. The specifics of regulation of cardiac and skeletal myocyte $\mathrm{K}_{\text {АTP }}$ channels through PKA has been little studied though it is plausible it is important during exercise (see below)

\section{Pancreatic cells and other tissues}

A wide range of hormones including incretins, growth factors and neurotransmitters can regulate glucose-stimulated insulin release in pancreatic $\beta$ cells. Two incretin hormones have been heavily studied, glucagon-like peptide 1 and glucose-dependent insulinotropic polypeptide, and it is known that both promote insulin release $(166 ; 347)$. Glucagon like peptide-1 and glucose-dependent insulinotropic polypeptide are agonists at G-protein coupled receptors and are coupled to the stimulatory G-protein. In addition there are GPCRs such as GPR40 that sense free fatty acids and also amplify insulin signalling (366). In contrast the free fatty acid receptors couple to the $\mathrm{G}_{\mathrm{q} \backslash 11}$ family of G-proteins and thus activate PKC and 
mobilise $\mathrm{Ca}^{2+}$ from intracellular stores. Drugs acting on these pathways are already being developed and taken into clinical trials (366).

Thus PKA-dependent modulation of the pancreatic $\mathrm{K}_{\mathrm{ATP}}$ channel and the cloned equivalent has an important and emerging physiological context. In pancreatic $\beta$ cells isolated from SUR1 knockout mice, glucagon-like peptide 1 was able to elevate cAMP but did not cause insulin release implicating $\mathrm{K}_{\mathrm{ATP}}$ channels in incretin action (481). In this physiological setting it would be expected that PKA-mediated signalling should inhibit $\mathrm{K}_{\mathrm{ATP}}$ channel currents thus promoting insulin release. However using the cloned subunits SUR1 and Kir6.2 and examining regulation in a heterologous expression system, PKA-mediated phosphorylation led to increased currents. Furthermore, important residues were identified that were homologous to those established to be important in SUR2B and Kir6.1 $(181 ; 317$; 423). Further studies revealed, rather like the actions of PKC, that the exact conditions used were important. Thus with $0.2 \mathrm{mM}$ ADP the phosphorylation mediated by the PKA catalytic subunit was inhibitory whilst with $0.5 \mathrm{mM}$ it was stimulatory (315). The S1488 residue in SUR1 was identified as being involved (315). There are also data, as for the vascular channel, implicating a non-PKA dependent pathway acting via cAMP and exchange proteins activated by cAMP $(262 ; 263)$. It is important to note that incretins affect multiple other events in $\beta$ cell signalling and the $\mathrm{K}_{\mathrm{ATP}}$ channel likely plays only a contributory role. For example, glucagonlike peptide 1 can also modulate TRPM channels (478) and PKA may modulate the insulin vesicle secretory apparatus.

Insulin exocytosis is mediated by soluble N-ethylmaleimide-sensible factor attachment protein receptors (SNAREs). In $\beta$ cells these include plasma membrane associated syntaxyn-1A and SNAP25/23, and granule membrane associated vesicle-associated membrane protein and synaptobrevin. These two sets of proteins interact and govern docking and fusion of insulin containing vesicles with the plasma membrane (272). $\mathrm{K}_{\mathrm{ATP}}$ channels 
interact with syntaxin-1A via the NBDs of SUR1 and the interaction inhibits channel opening. Syntaxin-1A also influences the trafficking of $\mathrm{K}_{\mathrm{ATP}}$ channels with a decrease in protein expression of syntaxin-1A leading to reduced surface expression of Kir6.2 \SUR1 (68; $384 ; 409)$.

Leptin is a satiety hormone secreted by adipocytes and its absence leads to obesity. Leptin can inhibit insulin secretion by increasing the surface expression and activity of pancreatic $\mathrm{K}_{\text {ATP }}$ channels (224). The activation of the AMP-activated protein kinase by leptin may be central to the regulation of trafficking $(406 ; 407)$ though there are also data showing that phosphoinositide 3 kinase may also be involved (585).

\section{Modulation by gasotransmitters}

Nitric oxide is an important endothelial mediator and diffuses into smooth muscle where it activates guanylate cyclase increasing cGMP and activating protein kinase G. There is no clear consensus on whether PKG can directly activate $\mathrm{K}_{\mathrm{ATP}}$ channels. For example, in cardiac ventricular myocytes activation of $\mathrm{K}_{\text {ATP }}$ channel currents has been seen $(198 ; 199)$. However nitric oxide may predominantly affect non-potassium channel dependent pathways and if it does activate potassium channels there is most evidence for the activation of large conductance $\mathrm{Ca}^{2+}$-activated $\mathrm{K}^{+}$channels $(458 ; 610)$. Nitric oxide can also directly nitrosylate proteins and some of its effects on potassium channels may occur because of this $(49 ; 373)$. Endothelial $\mathrm{K}_{\text {АTP }}$ channels can potentially modulate calcium entry and this would promote release of NO. Much less is known of the regulation of endothelial channels but they seem to be constituted of Kir6.1 ISUR2B and can be activated via Gs- coupled adenosine receptors (20).

It is clear there are more gaseous endothelial mediators than simply nitric oxide. The endothelium also generates carbon monoxide and $\mathrm{H}_{2} \mathrm{~S}$. Carbon monoxide activates guanylate 
cyclase in a manner analogous to nitric oxide (373) and $\mathrm{K}_{\mathrm{ATP}}$ channels do not seem to be prominently involved. $\mathrm{H}_{2} \mathrm{~S}$ is synthesised largely by cystathionine $\gamma$-lyase and the deletion of the gene encoding the enzyme results in hypertension in mice (593). In this case activation of vascular smooth muscle $\mathrm{K}_{\text {ATP }}$ channels is thought to be involved and occurs through $\mathrm{S}$ sulphydration of cysteine residues $(71 ; 372)$. In particular the SUR2B subunit appears to be the main target on residues $\mathrm{C} 24$ and $\mathrm{C} 1455$ (266). The regulation of $\mathrm{K}_{\mathrm{ATP}}$ channels may extend more widely than just the vasculature including into non-vascular smooth muscle and neurones $(67 ; 139)$.

\section{Mechanosensitivity of $\mathbf{K}_{\mathrm{ATP}}$ channels}

It has been known for some time that $\mathrm{K}_{\mathrm{ATP}}$ channels seem to be directly sensitive to mechanical stretch. This is an important idea as it could potentially couple workload and contraction with channel activation independent of changes in adenine nucleotides. In rat atrial myocytes, the application of a hypotonic solution increased $\mathrm{K}_{\mathrm{ATP}}$ channel activity in perforated patch whole-cell recordings (553). The channel seems to directly respond to membrane deformation such as would be generated by suction on the pipette in inside-out patch recordings (231). However this bilayer tension can be regulated by the actin cytoskeleton (231). This sensitivity was dependent on the SUR subunit and in particular nucleotide handling in NBD2 (135): specifically mutation of a residue (K1337) abolished the effect.

\section{Studying $K_{\mathrm{ATP}}$ channel function: an overview}

A number of different approaches have given major insight into the integrated function of $\mathrm{K}_{\mathrm{ATP}}$ channels in physiology. There is a long standing use of small molecule inhibitors and activators and in this regard $\mathrm{K}_{\text {ATP }}$ channels have a rich and well understood 
pharmacology (see above). Once the channel subunits were cloned this opened up engineering a variety of murine models of increasing sophistication including transgenic overexpression, global genetic deletion and conditional gene deletion and expression using crelloxP approaches. Finally modern genetics and genomics has implicated $\mathrm{K}_{\mathrm{ATP}}$ channels in human endocrine, cardiac and neurological disease and given important insights that complement the animal work. Table 2 summarises details of the various genetically modified mouse models that have been developed.

\section{Physiological and pathophysiological function of $K_{\mathrm{ATP}}$ channels}

\section{Species conservation}

Comparative genomics can be valuable in suggesting functional specialisation within the animal kingdom and identifying by homology domains key for core channel function. In general investigators will focus on traditional model organisms. In the invertebrate Drosophila melaganostar there are three inwardly rectifying channel subunits each with a GFG motif in the consensus sequence (117). A potential sulphonylurea like subunit also exists however the two proteins are expressed in different regions and there are no data on $\mathrm{K}_{\text {ATP }}$ like currents being present in native cells (374). Thus mature $\mathrm{K}_{\text {ATP }}$ currents may be a unique specialisation of vertebrates. In the lower vertebrate zebrafish (Danio rerio) subunits homologous to Kir6.1 and Kir6.2 are present but in addition there is another member of the family, Kir6.3, present in the genome (606). Two sulphonylurea subunits also exist and there is co-expression of these with Kir6.3 in the brain and heart (606). Expression of the zebrafish Kir6.3 with mammalian SUR1 in heterologous expression systems led to $\mathrm{K}_{\text {ATP }}$ like currents, however, currents in native cells were not examined and function was not further explored. However it is known that lizards, frogs and other fish have $\mathrm{K}_{\mathrm{ATP}}$ like currents in cardiac cells 
(403; 404). In a recent study $\mathrm{K}_{\mathrm{ATP}}$ currents have been found in zebrafish islet $\beta$ cells and modulation of channel activity leads to changes in glucose homeostasis illustrating conservation of function between lower and higher vertebrates (128).

\section{$K_{\mathrm{ATP}}$ channels in the endocrine tissues}

$\mathrm{K}_{\text {ATP }}$ channels play a key role in nutrient-sensing. The classical paradigm is in the pancreatic $\beta$ cell where they are central in glucose-stimulated insulin release. However more recently it has also become apparent that similar $\mathrm{K}_{\mathrm{ATP}}$ channels may have a physiological role in glucagon release from acells in the pancreas and are also present in various enteroendocrine cells in the gut. Furthermore, nutrient-sensing is also important for regulating feeding behaviour and $\mathrm{K}_{\mathrm{ATP}}$ channels in the central nervous system may be involved in this process. The major channel populations in endocrine tissues are summarised in Table 3.

\section{Insulin release and pancreatic $\beta$ cells}

Pancreatic $\beta$-cells in the islets of Langerhans synthesise, store, and secrete insulin so that the fasting blood glucose level is kept within a narrow range of 3.5-5.5 mM. Insulin promotes glucose uptake into skeletal muscle, the liver and adipose tissue and switches off glucose production by metabolic processes such as glycogenolysis. $\mathrm{K}_{\mathrm{ATP}}$ channels are essential in the tightly regulated process that couples the blood glucose concentration to the secretion of insulin ("stimulus-secretion coupling"). Pancreatic $\beta$ cells are excitable and respond to increases in glucose with membrane depolarisation and action potential firing (442; 443). It is essential that glucose is metabolised to pyruvate and enters into mitochondrial oxidative metabolism which leads to changes in the cellular ATP concentration (214). $\mathrm{K}_{\text {ATP }}$ channels constituted of SUR1 and Kir6.2 are the main glucose-sensitive 
conductance in the pancreatic $\beta$ cell and control electrical activity. In the absence of glucose the resting membrane potential is $\sim-70 \mathrm{mV}$. If exposed to $6 \mathrm{mM}$ glucose the cell depolarises due to a $70 \%$ reduction in the $\mathrm{K}_{\text {ATP }}$ conductance and this triggers action potential firing above a threshold of $-60 \mathrm{mV}$ (442). These effects can be mimicked by the use of drugs such as tolbutamide. The action potential is driven by a variety of calcium channels $(\mathrm{L}, \mathrm{R}$ and $\mathrm{T}$ types) and repolarisation by calcium-activated potassium channels (442). The repetitive action potential firing leads to calcium entry and oscillations resulting in insulin vesicle exocytosis. There are species differences with mouse islets needing higher glucose concentrations than human beta cells to trigger action potential firing and insulin release. This is likely underpinned by significantly lower $\mathrm{K}_{\mathrm{ATP}}$ current density in human beta cells together with differences in glucose transporter expression $(442 ; 443)$. A cartoon shown in Figure 8 illustrates the process of stimulus secretion coupling in pancreatic $\beta$ cells.

The use of genetically modified mice has generally supported the key involvement of $\beta$ cell $\mathrm{K}_{\mathrm{ATP}}$ channels in insulin secretion however there are some qualifications. In pancreatic islets that have expression of gain of function mutations in $\mathrm{K}_{\mathrm{ATP}}$ channel subunits there is impaired insulin release and resultant diabetes mellitus $(176 ; 288 ; 432 ; 433)$. However, in SUR1 and Kir6.2 global knockout mice and loss of function mutations, hyperinsulinism and hypoglycaemia are a highly variable finding $(232 ; 355 ; 467 ; 480)$. In fact the opposite is often true in that there is impaired insulin secretion and $\beta$ cell loss ultimately resulting in diabetes. In congenital hyperinsulinism in man, due to loss of function mutations in KCNJ11 and ABCC8, patients may be predisposed to developing diabetes mellitus later in life. (and see below). It seems $\mathrm{K}_{\text {ATP }}$ channels are important for $\beta$ cell survival and that the mouse is more predisposed to $\beta$ cell loss resulting from $\mathrm{K}_{\mathrm{ATP}}$ channel inactivation. A variety of hormones and neurotransmitters can modulate insulin release from pancreatic $\beta$ cells and this is discussed in the section above. 


\section{$K_{A T P}$ channels in pancreatic $\alpha$ cells}

Glucagon is released from pancreatic $\alpha$ cells and promotes the mobilisation of glucose. Glucagon release is inhibited by increase in blood glucose. Paradoxically $\mathrm{K}_{\text {ATP }}$ channels may also be involved in stimulus-secretion coupling in these cells (444). $\mathrm{K}_{\text {ATP }}$ channels are inhibited by the rise in blood glucose and this leads to membrane depolarisation. The key difference is that pancreatic alpha cells fire action potentials at normal blood glucose concentrations leading to the constitutive release of glucagon. Membrane depolarisation leads to an increase in action potential frequency but a reduction in amplitude. The latter is central and results in less calcium entry via $\mathrm{P} \backslash \mathrm{Q}$ calcium channels. Glucagon secretion is strongly dependent on calcium entry via $\mathrm{P} \backslash \mathrm{Q}$ calcium channels and thus secretion is reduced (444).

\section{Gut-derived hormone release}

Glucagon-like peptide-1 is released from the gut and acts as an incretin to increase insulin release from the pancreas (see above). It is one of a number of gut-derived hormones, which also includes glucose-dependent insulinotropic polypeptide, released from different enteroendocrine cell populations in response to a variety of dietary cues (fasting, carbohydrates, protein, fats etc) (186). Glucagon-like peptide-1 is released from L-cells and glucose-dependent insulinotropic polypeptide from K cells (186). In an interesting study, a reporter mouse was developed that enabled the isolation and study of this cell population. The release of glucagon-like peptide 1 is sensitive to glucose in the intestine and stimulus secretion coupling involves calcium entry and $\mathrm{K}_{\mathrm{ATP}}$ channels (429). However the mechanisms may not be as clear as with glucose-sensing in pancreatic $\beta$ cells and may involve a variety of specialised G-protein coupled receptors recognising the dietary components and their breakdown products (186). 


\section{$K_{\text {ATP }}$ channels in the heart}

The cardiac action potential is shaped by a large number of ionic conductances and the exact morphology varies between different chambers and within the conduction system (534). The calcium entry that occurs during the plateau of the action potential is central to calcium-induced calcium release and excitation-contraction coupling (146). Under resting conditions however $\mathrm{K}_{\mathrm{ATP}}$ channels seem to contribute little to resting membrane potential or action potential repolarisation.

The classic composition of the cardiac $\mathrm{K}_{\mathrm{ATP}}$ channel is thought to be Kir6.2\SUR2A and this is largely derived from studies in the ventricle. In fact $\mathrm{K}_{\mathrm{ATP}}$ currents are widely distributed including the atria and conduction tissues and there may be some nuances in subunit expression. In the His-Purkinje system heteromultimers of Kir6.1 and Kir6.2 exist together with SUR2A $(31 ; 600)$. Furthermore, in murine atrial cardiac myocytes there is good evidence that $\mathrm{K}_{\mathrm{ATP}}$ is formed by Kir6.2\SUR1 however in human atrial myocytes it is Kir6.2 \SUR2A $(136 ; 149)$. The major channel populations in striated muscle are summarised in Table 4.

\section{Physiological function}

Relatively large $\mathrm{K}_{\mathrm{ATP}}$ currents can be observed when cardiac myocytes are metabolically challenged but not under resting conditions (391). Action potential duration and contractile function in the Kir6.2 knockout mice are also normal in the basal resting physiological state (511). This raises the question of what is the exact physiological role of the channel. The study of murine models with global genetic deletion of Kir6.2 has pointed to some interesting possibilities. In an exercise treadmill stress test the Kir6.2 knockout mice had significantly lower tolerance to high intensity running (616). Furthermore when 
challenged with isoprenaline they showed impaired contractile function, failure of action potential shortening and the development of arrhythmia and myocardial necrosis (616). Thus, despite the caveats of using a mouse with global genetic deletion, this suggests the cardiac channel is involved in adaptation to the stresses of a sympathetic "fear and flight" response. Additionally, exercise may have more chronic effects leading to an increase in $\mathrm{K}_{\mathrm{ATP}}$ channel subunit expression (617). This would promote physiological adaptation to high intensity exercise.

\section{Hypoxia and ischaemia}

Classically the activation of cardiac $\mathrm{K}_{\mathrm{ATP}}$ channels occurs under pathological conditions associated with hypoxia and ischemia. Such stressors substantially shorten the action potential duration and can attenuate or even abolish contraction $(304 ; 557)$. Whilst it is difficult to envisage that these responses evolved to deal with pathological challenges, the opening of $\mathrm{K}_{\mathrm{ATP}}$ channels is likely to enhance myocyte survival and the field of cardioprotection is discussed further below. It is intriguing that $\mathrm{K}_{\text {ATP }}$ channels are localised at the neck of the t-tubule and activation could locally and preferentially inhibit t-tubule depolarisation impairing calcium induced calcium release and excitation-contraction coupling (285).

\section{Cardiac excitability}

The action potential and QT interval on the ECG shorten with exercise. It is generally thought that increased magnitude of the slow component of the delayed rectifier potassium current are responsible for counteracting and overriding the increase in inward voltagedependent calcium currents that will occur with increased sympathetic drive during exertion $(40 ; 459)$. This occurs through current accumulation at higher heart rates and direct protein 
kinase A phosphorylation of the channel $(343 ; 503)$. However given the known properties of cardiac $\mathrm{K}_{\mathrm{ATP}}$ channels it is plausible that these channels may also contribute to action potential shortening during exercise. Deviations of the ST segment from the isoelectric point occur during cardiac ischaemia and infarction and suggest spatial differences in repolarisation are occurring. These variations in ECG morphology occurring during cardiac ischaemia are reduced by glibenclamide and mimicked in the absence of ischaemia by potassium channel openers. This pharmacology is consistent with $\mathrm{K}_{\mathrm{ATP}}$ channel activation underlying these features (294). In support of this hypothesis, mice with global genetic deletion of Kir6.2 do not develop ST segment elevation in response to ischaemic episodes (311). However, SUR2 null mice do show ischaemia-provoked ST segment elevation so there may be additional mechanisms operative under some circumstances (74).

\section{Cell volume regulation}

The regulation of cell volume is important to the normal physiological function of the cell and if cell swelling is excessive membrane rupture and cell death will occur. It is known that $\mathrm{K}_{\text {ATP }}$ channels can be activated in atrial myocytes when the cells swell (453). In Kir6.2 knockout mice $\mathrm{K}_{\text {АTP }}$ currents were not activated by cell swelling and atrial natriuretic peptide release was significantly higher suggesting that $\mathrm{K}_{\text {ATP }}$ channel activation limited the release of the hormone. The Kir6.2 knockout mice also showed exaggerated atrial natriuretic peptide release with systemic volume loading (453). In separate studies, when myocytes are challenged with a mild hypo-osmotic shock or with a hyperkalaemic cardioplegic solution, they swell and myocardial contractility is impaired $(363 ; 415)$. The addition of diazoxide ameliorates this process as does the transgenic expression of a gain of function Kir6.1 mutant (213). Thus it would seem that activation of $\mathrm{K}_{\text {ATP }}$ channels prevents excessive cell swelling and myocardial contractile failure. However some results from Kir6.2 knockout mice and 
with $\mathrm{K}_{\mathrm{ATP}}$ channel inhibitors are contradictory and do not support this hypothesis $(362 ; 468)$. To some extent these contradictions can be resolved by proposing that activation of Kir6.1 \SUR1, but not of Kir6.2 \SUR2A, is the specific channel population modulating cell adaptation to swelling. The effects on cell swelling might also contribute to cardioprotection (474).

\section{$\mathrm{K}_{\mathrm{ATP}}$ channels in skeletal muscle}

It was originally assumed that Kir6.2 and SUR2A underlie $\mathrm{K}_{\text {ATP }}$ currents in skeletal muscle and this view was reinforced by studies on mice with global genetic deletion of the genes (75). However the picture may be more intricate than this. $\mathrm{K}_{\text {ATP }}$ current-density is higher in fast twitch skeletal muscle and this is accompanied by higher SUR1 expression than in other muscle fibre types (542). As in cardiac muscle the channel is closed and contributes little to the electrophysiological properties of skeletal muscle at rest (236). The precise physiological role of the current is not clearly defined. The properties of channels in striated muscle are summarised in Table 4.

\section{Muscle fatigue}

Characteristically there is a decline in force with repetitive and prolonged muscle use; a process known as fatigue. $\mathrm{K}_{\text {ATP }}$ channels are not involved directly in the initial decline of force with repetitive use however, after fatigue has developed, they help preserve a hyperpolarised membrane potential and prevent a rise in resting tension $(77 ; 180)$. Furthermore, in Kir6.2 knockout mice the recovery of muscle tension after excessive muscle use is impaired $(77 ; 180)$. The channel is also involved in preventing muscle damage after excessive exercise. Mice with global genetic deletion of Kir6.2 develop significant myofibre damage after swimming or treadmill exercise and the cellular mechanisms may be similar to 
those in analogous studies with cardiac muscle $(260 ; 528)$. This adaptation to strenuous exercise is one potentially good candidate for the physiological function of the channel in skeletal muscle.

\section{Glucose uptake}

Skeletal muscle $\mathrm{K}_{\text {ATP }}$ channels have been associated with regulation of glucose uptake. Sulphonylureas have been known to improve blood glucose control independent of their effects on pancreatic insulin release $(110 ; 440)$. Specifically they enhance uptake of glucose into skeletal muscle and this is supported by studies on Kir6.2 and SUR2 knockout mice $(75 ; 356 ; 545)$. Analogously increased activity of the channel during exercise might decrease glucose uptake and promote the use of alternative energetic substrates.

\section{Skeletal muscle metabolism}

$\mathrm{K}_{\mathrm{ATP}}$ channels in skeletal muscle may be involved more broadly in regulating metabolism. Even at low workloads $\mathrm{K}_{\text {ATP }}$ channel opening was observed and the absence of the channel led to increased heat production (614). Furthermore, these mice have a lean body phenotype with reduced glycogen and fat stores (2). They were also resistant to weight gain from high fat feeding but had impaired endurance due to inefficient muscle substrate metabolism. Absence of $\mathrm{K}_{\text {ATP }}$ channels also promoted the release of musclin, a peptide similar the natriuretic peptides that promotes mitochondrial biogenesis in muscle $(488 ; 506)$.

\section{$K_{\text {ATP }}$ channels in the vasculature}

As discussed above the channel present in the vascular smooth muscle has distinct properties namely a lower single channel conductance ( $\sim 30-35 \mathrm{pS}$ compared to $70-80 \mathrm{pS})$, is less prominently regulated by ATP and channel activity is absolutely dependent on the 
provision of intracellular dinucleotides (a "K $\mathrm{K}_{\mathrm{NDP}}$ " current) $(38 ; 79 ; 420)$. These properties, summarised in Table 5, correspond closely to that of the Kir6.1 $\backslash$ SUR2B combination and this is likely to generate the " $\mathrm{K}_{\mathrm{NDP}}$ " current in smooth muscle $(22 ; 101 ; 358 ; 587)$. In vascular smooth muscle cells from mice with genetic deletion of Kir6.1 and SUR2, $\mathrm{K}_{\text {ATP }}$ currents are no longer present, whereas similar smooth muscle cells from Kir6.2 knockout mice show a similar current-density of $\mathrm{K}_{\mathrm{ATP}}$ currents when compared to littermate control (511). This may not be universally the case and there are some indications for example in portal vein that Kir6.2 may be expressed together with Kir6.1 and SUR2B (85). Interestingly, endothelial cells also express an ATP-sensitive potassium current $(273 ; 274 ; 462)$ and this has been less studied. SUR2B is expressed in the endothelium and there is a study in human endothelial cells showing a heteromeric population of Kir6.1 and Kir6.2 (600).

\section{Blood pressure control}

$\mathrm{K}_{\mathrm{ATP}}$ currents are widely expressed in a number of vascular beds and throughout the vascular tree (379). This observation and the fact of clear regulation of vascular smooth muscle $\mathrm{K}_{\mathrm{ATP}}$ currents by vasodilators and vasoconstrictors (see above) support the potential role for the channel in blood pressure control. Smooth muscle cell contraction is promoted by the entry of $\mathrm{Ca}^{2+}$ through L-type calcium channels in the sarcolemma and $\mathrm{K}_{\mathrm{ATP}}$ channels by influencing membrane potential can promote vasodilatation and vasoconstriction. The exact effects observed will depend on whether there is tonic activity of the channel and this may not be the case in all vascular beds. It is known for example that the perfusion of glibenclamide into the coronary vascular bed increases coronary perfusion pressure (405; 426). Figure 7 shows the regulation of $\mathrm{K}_{\mathrm{ATP}}$ channels in vascular smooth muscle cells by cell signalling and how the channels could potentially be involved in blood pressure regulation.

The best evidence for the role of vascular $\mathrm{K}_{\mathrm{ATP}}$ channels in blood pressure control 
comes from the study of genetically modified mice. SUR2 and Kir6.1 global knockout mice have significantly elevated blood pressure $(74 ; 358)$. A mouse with conditional deletion of

Kir6.1 in vascular smooth muscle cells is also hypertensive though it is intermediate in magnitude between the global Kir6.1 knockout and littermate controls (22). Furthermore, vasodilators such as calcitonin gene-related peptide no longer hyperpolarise vascular smooth muscle cells and the application of the agonist no longer increases potassium currents in whole-cell recordings in the mice with genetic modification (22). Finally, mice with a gain of function mutation rendering Kir6.1 ATP-insensitive are hypotensive when this subunit is transgenically expressed in vascular smooth muscle (309).

\section{Vascular reactivity}

Mice with global genetic deletion of Kir6.1 and SUR2 have more complex phenotypes than simply hypertension $(74 ; 358)$. The two lines of mice are prone to dying suddenly and this has been attributed to coronary artery spasm in a syndrome equivalent to that of severe human Prinzmetal angina. It was proposed that the absence of the $\mathrm{K}_{\mathrm{ATP}}$ channel in vascular smooth muscle in the coronary arteries predisposed them to vasoconstriction. However this simple hypothesis may only be part of the explanation. On the background of the SUR2 knockout mouse, Kakkar et al transgenically overexpressed SUR2B selectively in smooth muscle (257). The $\mathrm{K}_{\mathrm{ATP}}$ current was fully reconstituted in the coronary arteries but vasospasm still occurred. Furthermore, a mouse with conditional deletion of Kir6.1 in smooth muscle in contrast did not have evidence of coronary artery spasm even after the administration of ergonovine (22). A key corollary of this study is that smooth muscle deletion of Kir6.1 does not fully recapitulate the phenotype and suggests the important influence of $\mathrm{K}_{\mathrm{ATP}}$ currents constituted of Kir6.1 in other tissues.

In hypertensive animal models there is remodelling of $\mathrm{K}_{\mathrm{ATP}}$ channels in vascular beds 
leading to functionally impaired and fewer $\mathrm{K}_{\mathrm{ATP}}$ channels $(47 ; 515)$. The membrane potential of vascular smooth muscle cells is more depolarised in hypertension. In addition, potassium channel openers have little effect on membrane potential compared to normotensive animals $(515)$.

\section{Endothelial $K_{A T P}$ channel}

Increases in potassium currents can influence endothelial function by hyperpolarising the membrane potential. In contrast to smooth muscle cells, hyperpolarisation promotes calcium entry and leads to the release of vasoactive mediators (390). Endothelial cells may also express an ATP-sensitive $\mathrm{K}^{+}$current $(273 ; 274 ; 462)$, activation of which can increase intracellular calcium $(167 ; 302 ; 562)$ and important mediators such as adenosine may modulate $\mathrm{K}_{\mathrm{ATP}}$ channels in the endothelium as a component of their physiological action (299). Calcium is central to many endothelial functions such as mediator release and angiogenesis (69). Kir6.1 is thought to make a significant contribution to the current but is perhaps not the sole subunit underlying it (600). Furthermore, the expression of a dominant negative $\mathrm{K}_{\text {ATP }}$ channel construct selectively in endothelial cells increased endothelin-1 release (335). We have recently completed a study in which we selectively deleted Kir6.1 in endothelial cells using crelloxP technology. This genetic manipulation abolishes $\mathrm{K}_{\mathrm{ATP}}$ currents in endothelial cells and pinacidil-induced calcium entry (20). These mice also showed impaired reactivity to hypoxia in the coronary circulation resulting in increased cardiac damage during ischaemia-reperfusion (20). The effects were potentially mediated by adenosine receptor activation in endothelial cells leading to the activation of $\mathrm{K}_{\mathrm{ATP}}$ channels. Iptakalim, a $\mathrm{K}_{\mathrm{ATP}}$ channel opener, has been developed as an anti-hypertensive agent (489) and has also been shown to increase NO release and NOS activity and to inhibit endothelin release in aortic endothelial cells (167). 


\section{$\mathrm{K}_{\mathrm{ATP}}$ channels in non-vascular smooth muscle}

$\mathrm{K}_{\text {ATP }}$ channels are ubiquitously expressed in non-vascular smooth muscles and these include throughout the gastrointestinal tract $(207 ; 255)$, bladder (155), uterus (328), urethra (524) and the respiratory airways (258). The currents are similar in properties to those of vascular smooth muscle and there is substantial evidence for the expression of Kir6.1 and SUR2B $(255 ; 524)$. There may be some variations in specific smooth muscles. For example, in the urethra there is evidence for expression of Kir6.2 and of heteromultimer formation (525) and both pore-forming subunits may also be expressed in the colonic smooth muscle (536).

In general less is known of the physiological role of these channels in these varied organ systems and they have been little studied in the various genetically modified mouse lines. The application of $\mathrm{K}_{\text {АTP }}$ channel openers and inhibitors often causes relaxation and contraction respectively of the smooth muscle and thus it is clear these currents are of sufficient density to have the potential to significantly modify organ function $(284 ; 371 ; 523)$. There is also the potential for drug development to treat conditions such as asthma or bladder instability.

\section{$K_{\text {ATP }}$ channels in the central and peripheral nervous system}

$\mathrm{K}_{\text {ATP }}$ channels are ubiquitously distributed in central and peripheral neurones and in glial cells (507). In glia the main current is probably made up of SUR1 and Kir6.1 $(125 ; 532)$ though there is also evidence for Kir6.2 expression in some limited glial populations (612). The current is activated by diazoxide as might be expected from the SUR1 expression. In neurones the most common molecular composition appears to be Kir6.2\SUR1 however in some brain regions and even between individual neurones different SURs can be expressed 
(194; 270; 271). In an interesting study, using single-cell expression analysis the individual genetic makeup of SUR subunits within a cell was correlated with the exact electrophysiological phenotype and this defined the metabolic sensitivity of the respective neuron (319). The major channel populations in the nervous system are summarised in Table 6.

\section{Neuronal excitability}

$\mathrm{K}_{\mathrm{ATP}}$ channels may contribute to modulating neuronal excitability even in the absence of hypoxia $(3 ; 194)$. Even moderate levels of neuronal spiking can lead to a significant metabolic challenge for the neuron and a consequent fall in cellular ATP levels. The activation of $\mathrm{K}_{\mathrm{ATP}}$ current will hyperpolarise the membrane potential and this limits action potential spiking. Single channel cell-attached recordings show an increase of $\mathrm{K}_{\text {ATP }}$ channel activity after a burst of action potentials and this is attenuated if energy consumption is reduced by inhibiting the sodium-potassium ATPase transporter (520).

\section{Pain}

$\mathrm{K}_{\text {ATP }}$ channels are present in dorsal root ganglion neurones and experimental studies support a role in suppressing hyperalgesia (618). Kir6.2, SUR1 and SUR2 are expressed in these neurones and severing of the nerve leads to hyperalgesia. This is accompanied by decreased subunit expression and reduced $\mathrm{K}_{\mathrm{ATP}}$ current levels. Interestingly $\mathrm{K}_{\mathrm{ATP}}$ channel subunits and currents are widely distributed in soma, axons and in Schwann cells $(276 ; 618)$. The loss of $\mathrm{K}_{\mathrm{ATP}}$ currents promotes hyperexcitability and facilitates neuronal firing. In injured dorsal root ganglion cells calcium signalling is impaired. In normal neurones, $\mathrm{K}_{\mathrm{ATP}}$ currents are enhanced by increases in intracellular calcium in a process that is sensitive to calciumcalmodulin dependent protein kinase inhibitor (275). In contrast in axotomised neurones 
calcium had no effect on $\mathrm{K}_{\text {ATP }}$ currents and this correlated with the degree of hyperalgesia. Thus $\mathrm{K}_{\text {ATP }}$ channels may be a drug target in the treatment of neuropathic pain.

\section{Locomotion and Behaviour}

$\mathrm{K}_{\mathrm{ATP}}$ channels may be involved in locomotion and behaviour. Using a broad battery of behavioural tests revealed that Kir6.2 knockout mice have reduced activity and impaired coordination (113). Normal mice characteristically actively explore new environments especially if this is associated with reward. Dopaminergic neurones in the midbrain are critical for integrating this behaviour and it is associated with increased burst firing in these neuronal populations. In Kir6.2 knockout mice this behaviour does not occur and neuronal firing is also reduced. Furthermore injection of an adeno-associated virus expressing a dominant-negative construct for Kir6.2 bilaterally into the relevant dopaminergic neurones led to a similar phenotype as in the global Kir6.2 knockout mouse (461). Kir6.2 knockout mice also have impairment in working memory as they age which was thought to be a direct result of the loss of currents in the hippocampus and not secondary to systemic metabolic abnormalities (73).

\section{Nutrient sensing and satiety}

It is now appreciated that the hypothalamus can influence hepatic glucose production through nervous innervation of the liver. Furthermore, the neurones in the hypothalamus can respond directly to glucose and to key hormones such as insulin and leptin (449; 493). This is a complex area and a number of details remain unclear. The two main neuronal populations mediating these effects are agouti-related peptide (AgRP)/neuropeptide Y (NPY)- and proopiomelanocortin (POMC)-expressing neurons of the mediobasal hypothalamus $(17 ; 265$; 449). $\mathrm{K}_{\mathrm{ATP}}$ channels are key in both cell types to integrating the response to glucose (449). 
Thus in POMC neurones physiological changes in blood and cerebrospinal fluid glucose can directly regulate neuronal excitability and firing pattern. Glucose causes changes in cellular ATP which is dependent on glucokinase and subsequent mitochondrial metabolism: analogous to the mechanisms of metabolite sensing present in the pancreatic $\beta$ cell (264). In addition, AMP-activated protein kinase may also act as a direct glucose sensor influencing cellular energetics and ATP levels (80). The net result is an increase in efferent signal from the hypothalamus and this leads to less glucose mobilisation from the liver. Insulin signalling in AgRP/NPY neurones seems key to the effects of insulin on hepatic glucose production (449). In addition to the well-known transcriptional effects, insulin receptor activation can also entrain effects on cellular excitability. Insulin and other important metabolic hormones such as leptin lead to activation of PI-3 kinase and the production of $\mathrm{PIP}_{3}$ and may represent a critical signalling node for $\mathrm{K}_{\mathrm{ATP}}$ channel activation in hypothalamic neurones $(206 ; 449)$. This then activates $\mathrm{K}_{\text {ATP }}$ channels by promoting cytoskeletal changes and also through direct lipid modulation of ATP sensitivity $(360 ; 441 ; 484 ; 494)$. This results in membrane hyperpolarisation and reduced neuronal output. The net effect of this is to supress hepatic gluconeogenesis via IL-6 dependent changes in gene transcription (449). Leptin is also able to modulate these neuronal populations but probably also via $\mathrm{K}_{\text {ATP }}$ channel independent mechanisms.

\section{Glial function}

Glia cells have a range of functions but one role pertinent to potassium channels is potassium siphoning. Inwardly rectifying potassium channels form the main potassium conductance of glial cells and set the resting membrane potential (60). These channels are key in allowing glia and astrocytes in particular to siphon potassium from areas of high neuronal activity and high extracellular concentration to areas of lower concentration. Kir4.1 is central 
to this but the opening of $\mathrm{K}_{\mathrm{ATP}}$ channels may form some kind of reserve under metabolically challenging conditions $(60 ; 396)$.

\section{Peripheral nerve function}

$\mathrm{K}_{\mathrm{ATP}}$ channels are also present in peripheral nerves and specifically appear to have a role in controlling autonomic function. For example, inhibition using glibenclamide led to potentiation of the heart effect of both vagal and sympathetic nerve stimulation likely through presynaptic rather than direct cardiac action $(4 ; 365)$.

\section{$K_{\mathrm{ATP}}$ channels and immune function}

Sepsis can impose a substantial load on the cardiovascular system and at its most lethal can engender shock often with a high mortality. There have been a number of contradictory studies of the role of $\mathrm{K}_{\mathrm{ATP}}$ channels in sepsis. Initially, it was proposed that excessive $\mathrm{K}_{\text {ATP }}$ channel activation occurs in septic shock leading to hypotension which could be reversed by sulphonylureas (346). Other studies support this increase of activity in the vasculature in sepsis but also suggest certain changes in pharmacology namely the lack of effect of sulphonylureas. Only direct pore blockers were able to inhibit activity (392). Furthermore, the expression of Kir6.1 is regulated via Toll-like receptors and nuclear factor kappa-light-chain-enhancer of activated B cells and the increase in expression of the current is postulated to underlie the poor response to vasoconstrictors with overwhelming sepsis (475). However, subsequent studies on mice and flies with global genetic deletion of Kir6.1 revealed that they have a substantial survival disadvantage in models of septic shock (97; 261). The precise mechanism has not been elucidated but a poor response to increased metabolic demand in the coronary circulation is one idea.

$\mathrm{K}_{\mathrm{ATP}}$ channels may be involved more broadly in immune function. Thus hydrogen 
sulphide promotes neutrophil migration into tissues and this response is sensitive to $\mathrm{K}_{\mathrm{ATP}}$ channel inhibitors (106). The exact mechanism was not defined but it was mediated via mechanisms involving chemokine receptor expression on the neutrophil and given some of these assays were in-vitro in nature a direct role of $\mathrm{K}_{\mathrm{ATP}}$ channels in neutrophil biology cannot be excluded. A second mechanism is endothelial injury promoting the release of mediators and a consequent inflammatory response (141). As we have discussed above $\mathrm{K}_{\mathrm{ATP}}$ channel may well be a component in that response. $\mathrm{K}_{\text {ATP }}$ channels within the cellular milieu can also modulate the inflammatory response. Thus in Drosophila infection by a cardiotropic virus is promoted by $\mathrm{K}_{\text {ATP }}$ channel knockout and inhibited by treatment with a $\mathrm{K}_{\text {ATP }}$ channel opener (126). Nicorandil can prevent monocyte to macrophage transition and promotes an anti-inflammatory macrophage phenotype (607). Thus in summary, $\mathrm{K}_{\mathrm{ATP}}$ channels may be involved in inflammatory responses through classic actions in cardiac and vascular tissues however there are also indications that they may have direct actions in modulating immune cell biology. This is an area for future research.

\section{Mitochondrial $\mathbf{K}_{\mathrm{ATP}}$ channels}

There has been considerable interest in whether a $\mathrm{K}_{\mathrm{ATP}}$ channel is resident in mitochondrial membranes ("mitoK $\mathrm{ATP}_{\text {") }}(244 ; 410)$. The earliest study directly recorded channel activity using patch-clamp in the mitochondrial inner membrane by fusing rat live mitochondria to form giant mitoplasts. They measured a $10 \mathrm{pS}$ single channel conductance for a potassium-selective conductance. Critically single channel open probability was reduced by ATP and glibenclamide (244). Later work focussed on cardiac tissues and specifically tried to define a distinctive pharmacology for the mitochondrial channel over that of the sarcolemmal channel. On the basis of more indirect measurements of mitochondrial function, specifically mitochondrial swelling induced by water accompanying the $\mathrm{K}^{+}$flux, it was 
proposed that 5-hydoxydecanoate was a specific inhibitor and mito $_{\text {ATP }}$ was activated by diazoxide unlike the sarcolemmal channel (189). However this pharmacology may not be so clear cut $(104 ; 312)$ and it is notable the number of publications that have made use of this


(598).

These questions and ambiguities could be resolved by the cloning of the relevant channel subunits. Initially Kir6.1 was suggested as a candidate $(324 ; 510)$ however this relied on the use of antibodies that may be recognising unrelated mitochondrial proteins (157). A proteomic study isolated succinate dehydrogenase, mitochondrial ATP-binding cassette protein 1, phosphate carrier, adenine nucleotide translocator, and ATP synthase as a complex (8). However none of these proteins is a recognised sulphonylurea like subunit or inwardly rectifying potassium channel subunit. It is becoming clear that 5-hyroxydecanoate and diazoxide also have direct interactions with the components of the mitochondrial respiratory chain $(108 ; 202)$. However one more recent study is potentially plausible (156). In bovine hearts an inward rectifier subunit (Kir1.2) was isolated from inner mitochondrial membranes. Kir1.2 is a member of the "ROMK" family originally expression cloned from kidney and these channels do show some intrinsic ATP sensitivity (223). Furthermore, short SUR2 variants may localise to mitochondria (131). Finally in C elegans, deletion of all three inward rectifier genes did not affect potassium flux across mitochondria or hypoxic preconditioning $(575)$.

In summary, it is clear that drugs traditionally affecting $\mathrm{K}_{\mathrm{ATP}}$ channels can change mitochondrial function however whether these observations definitively indicate the existence of a $\mathrm{K}_{\mathrm{ATP}}$ channel can be contested. The ambiguities would be much clarified by the isolation and in-vivo validation of a channel subunit encoding mitoK $\mathrm{ATP}_{\mathrm{AT}}$ 


\section{Other tissues}

There are reports of $\mathrm{K}_{\mathrm{ATP}}$ channels in joint tissues such as articular chondrocytes and also in bone cells such as osteoclasts $(249 ; 364)$. Interestingly, nicorandil inhibits osteoclast differentiation: an effect that is dependent both on its ability to act as an NO donor and also to activate $\mathrm{K}_{\text {ATP }}$ channels (249). $\mathrm{K}_{\text {ATP }}$ channel subunits are also expressed in the hair follicle and may be involved in regulating the follicle growth cycle (482).

\section{$\mathrm{K}_{\mathrm{ATP}}$ channels in disease}

Human disease can be directly caused by defects in ion channel function particularly neurological, cardiac and endocrine disease. This occurs most commonly as a result of a mutation in an ion channel gene or subunit that occurs either spontaneously or is inherited in a Mendelian fashion within a family. The resultant mutant channels may then not be transcribed or if the protein is produced the channel may not reach the plasma membrane. Finally, if mutant channels do reach the plasma membrane they may then fail to gate or conduct properly or more rarely have enhanced function ("gain of function mutations"). These different mechanisms are summarised in Figure 9. "Channelopathies" can also be acquired in nature for example because of the production of auto-antibodies to channels such as with myasthenia gravis and the muscle endplate acetylcholine receptor. These conditions can give substantial insight into the physiological function of ion channels in man. Secondly, ion channels may be implicated in the genetic architecture of human traits in large scale genome wide association studies (370). Furthermore, ion channels may play a role in complex pathophysiological mechanisms and appropriate pharmacological intervention may ameliorate or reverse disease progression. $\mathrm{K}_{\mathrm{ATP}}$ channels have been implicated in a range of human pathologies and this is discussed below. Table 7 summarises the association of mutations or genomic variants in $\mathrm{K}_{\mathrm{ATP}}$ channels with human diseases or traits. 


\section{Congenital Hyperinsulinism}

Congenital hyperinsulinism describes a disease in which there are inappropriate and high levels of insulin secretion from pancreatic $\beta$ cells. This leads to low blood glucose and can result in loss of consciousness and neurological damage if left untreated. The disease can present at any time, even into adulthood, but the more severe forms present in the neonate and young child. It occurs in 1 to 50,000 births but is much higher in areas of the middle-east with high levels of consanguinity $(122 ; 381)$. There are a variety of genetic causes including a abnormalities in a number of metabolic enzymes, such as glutamate dehydrogenase and glucokinase, but those presenting early in life are generally due to mutations in $A B C C 8$ (SUR1) and $K C N J 11($ Kir6.2) $(123 ; 381 ; 531)$. Morphologically a number of different patterns of disease are seen. In diffuse disease, which is the commonest, all pancreatic $\beta$ cells are affected but the islet histology is normal. In general patients have a recessive inheritance pattern with homozygous or compound heterozygous mutations in the $\mathrm{K}_{\mathrm{ATP}}$ channel genes $(259 ; 383 ; 592)$. In focal disease one or more areas of the pancreas are affected and the cells in these regions are histologically abnormal. The genetics of this disease are more complex with a paternally inherited mutation in $A B C C 8$ or $K C N J 11$ and the loss of a corresponding maternal allele (558). Furthermore, the imbalanced imprinting in the focal areas results in the expression of genes which promote islet cell hyperplasia (insulin-like growth factor 2 and various tumour suppressor genes) (158). Though rarer than the diffuse pattern it still constitutes up to $30-40 \%$ of cases and is an important differential in the diagnosis as surgical resection can be curative. Finally there is an atypical histological pattern that does not fit into either of the above (381).

In congenital hyperinsulinism a large number of mutations have been described through-out the $A B C C 8$ and $K C N J 11$ genes $(123 ; 383 ; 531 ; 538)$. In general the mutations are 
missense leading to a loss of channel function and this can occur in two ways. Figure 10 illustrates the disease pathogenesis. The first is that the channels no longer reach the plasma membrane due to defects in cellular trafficking $(65 ; 471 ; 519 ; 592)$. They may be retained in the endoplasmic reticulum and $\backslash$ or retrieved from the golgi apparatus where they are likely recognised as abnormal and degraded by the proteasome. Alternatively, they may be rapidly endocytosed on reaching the plasma membrane and degraded in lysosomes (336). In a second class of mutation, the SUR1 subunit is delivered to the plasma membrane but the ability of the channel complex to be stimulated by MgADP is impaired (486). This results in membrane resident but inhibited $\mathrm{K}_{\mathrm{ATP}}$ channels that no longer respond to metabolism in the normal way. These mechanisms have been elucidated generally in heterologous expression systems but have also been confirmed in patient derived samples obtained after pancreatectomy (123; 259). In addition, studies of patient-derived pancreatectomy samples also showed that $\beta$ cells were depolarised and calcium overloaded.

The disease can be treated using diazoxide but this is only successful in a proportion of cases. In focal disease, the lesion or lesions can be surgically removed resulting in cure. In severe diffuse disease, partial pancreatectomy is ultimately necessary and may in later life lead to diabetes mellitus (502). There has been preclinical interest in whether trafficking deficient mutants can be rescued and trafficked to the plasma membrane using various pharmacological agents. There have been cellular studies showing that diazoxide and sulphonylureas can act as chemical chaperones resulting in improved delivery of channels to the plasma membrane $(408 ; 591 ; 592)$. Whilst there are obvious practical issues with using sulphonyureas it suggests it is possible to find pharmacophores that can perform this function. For example recent studies have suggested that carbamazepine can act in this fashion (341). The recent clinical success of mutation-specific therapy in cystic fibrosis also means that other channelopathies may be amenable to similar approaches $(425 ; 561)$. 
The majority of congenital hyperinsulinism is autosomal recessive in inheritance. Interestingly however autosomal dominant disease is described and is generally milder often presenting later and is well managed by medical therapy especially diazoxide $(235 ; 268$; 413). It appears that the majority of these mutations have impaired function: an effect that is dominant in the assembled octamers. Some dominant mutations do not respond to medical therapy and these appear to be a dominant negative trafficking deficit (380). Furthermore there are some indications that these patients may develop diabetes mellitus in later life (235). It is thought the excess calcium entry ultimately leads to pancreatic $\beta$ cell apoptosis as in mice (see above).

\section{Neonatal Diabetes Mellitus}

Neonatal diabetes mellitus is generally defined as diabetes mellitus occurring within the first six months of life though this has recently been extended by some investigators to nine months $(451 ; 452)$. Type 1 diabetes is very rare in this age group and these patients have a unique genetic aetiology. A large number of genes have been implicated in causing the disease and these are involved in beta cell function, insulin release, pancreatic development and beta cell death (451). The three most commonly affected genes are KCNJ11, INS which encodes the proinsulin protein and $A B C C 8$ (451). The discussion will be confined to disease causing genes in the pancreatic $\mathrm{K}_{\mathrm{ATP}}$ channel subunits. The disease is rare occurring in 1 to 100,000 of births (451).

Mutations in $K C N J 11$ and $A B C C 8$ generally occur de-novo in outbred populations and are heterozygotic $(178 ; 451 ; 533)$. There are spectrums of presentation from transient neonatal diabetes, and permanent neonatal diabetes through to much severer syndromes involving neurological manifestations which make up about $20 \%$ of cases $(152 ; 177)$. These include developmental delay, autism and epilepsy (developmental delay, epilepsy and 
neonatal diabetes; DEND syndrome) and in some patients the epilepsy is absent (intermediate DEND; iDEND syndrome) $(177 ; 451)$. In addition motor delay, ataxia, anxiety and attention deficit hyperactivity disorder can also be features of the neurological disease. SUR1 and Kir6.2 constitute a large population of widely distributed neuronal channels and thus it is not surprising that the central nervous system is involved (82). A murine model has been developed in which it was possible to selectively express the V59M Kir6.2 mutation in a variety of tissues using various tissue selective cre recombinases and these models offer insight into human disease pathogenesis. Expression of V59M Kir6.2 in the pancreas leads to impaired insulin release and diabetes (176). Furthermore, it seems that the muscle weakness is related to expression of mutant $\mathrm{K}_{\mathrm{ATP}}$ channels in the central nervous system and not in muscle myocytes $(81 ; 82)$. The expression of V59M Kir6.2 in the central nervous system as well as muscle weakness also leads to reduced anxiety (301). Interestingly, it appears that "neonatal diabetes" can present later in life due to $\mathrm{K}_{\text {ATP }}$ channel mutations either around adolescence or during pregnancy (152). In KCNJ11 the mutations often cluster on select residues particularly R201 and V59 whilst they are more widely distributed in $A B C C 8$ (13). When the mutations are expressed in heterologous expression systems they lead to channels that have a "gain of function" phenotype and that are, to varying extents, insensitive to ATP inhibition $(26 ; 175 ; 178)$. Figure 10 illustrates the disease pathogenesis. The severity of phenotype correlates with the degree of ATP insensitivity: DEND mutations lead to a severe loss of ATP inhibition whilst in neonatal diabetes the impairment can be modest (13). In this regard, a recessive KCNJ11 mutation has been described (G324R) which in the homozygous form leads to transient neonatal diabetes mellitus whilst the parents as heterozygous carriers show no evidence of impaired glucose homeostasis (556). When the mutation is expressed in heterologous expression systems the $\mathrm{IC}_{50}$ for channel inhibition is only modestly shifted from $30 \mu \mathrm{M}$ to $38 \mu \mathrm{M}$ with the mutant (556). It is interesting that even with KCNJ11 mutations 
there is little evidence for cardiac or muscle disease that is independent of nervous innervation (81). Indeed in expression studies with SUR2A, KCNJ11 mutations do not affect ATP sensitivity to the same degree (517).

The discovery of the genetic basis of this disease has led to a revolution in the management of the patients and is a genuine example of precision medicine (411). Traditionally these patients were treated with insulin but the discovery of the over-activity of pancreatic $K_{\text {ATP }}$ channels as central in the disease pathogenesis led to the use of sulphonylureas. The responses were dramatic with glucose homeostasis becoming normalised in many patients with normal responses of insulin release following eating due to preservation of the response of pancreatic $\beta$ cells to incretins (411). High doses are necessary particularly when neurological disease is present and with severe disease and ATP-insensitive mutants the use of sulphonylureas may fail $(13 ; 27)$. The neurological deficits are often only partially ameliorated by sulphonylurea treatment as their origins may, to a degree, be developmental $(13 ; 39 ; 138 ; 286 ; 470 ; 490)$. Another interesting feature is that in contrast to type II diabetes mellitus, where with time sulphonylurea therapy fails, in neonatal diabetes the opposite occurs with a reduction in dose often necessary (237). However it is important to begin therapy as early as possible, as with time there is a decline in the success of sulphonylureas in neonatal diabetes (27). Expression of V59M Kir6.2 in the murine model above in the endocrine pancreas leads to additional morphological changes with glycogen accumulation in islets suggesting that high glucose can itself lead to $\beta$ cell damage $(55 ; 433)$. These morphological changes can be reversed by restoration of a normal blood glucose. The study of these naturally occurring mutations has also supported the molecular models of sulphonylurea action. Sulphonylureas inhibit MgADP activation and binding but this does not lead to complete closure and the antagonism is partial with a maximum of $70-80 \%$ inhibition (416). In intact cells the remaining inhibition is postulated to arise from MgADP now being 
able to act as an inhibitor of Kir6.2 in the presence of sulphonylureas. However if the mechanism of ATP inhibition by the mutant Kir6.2 subunit is severely attenuated then sulphonylureas may lead to incomplete block (416). This may account for why therapy for very severe forms of neonatal diabetes, with or without the neurological sequelae, is less effective.

\section{Type 2 diabetes and genome wide association studies}

Type 2 diabetes is usually thought of as a disease of peripheral insulin resistance however it is clear that pancreatic $\beta$ cell mass is reduced and insulin secretion impaired. In addition to the role of $\mathrm{K}_{\mathrm{ATP}}$ channels in Mendelian diseases of blood glucose homeostasis, genome wide association studies in type 2 diabetes have implicated loci in and around the $A B C C 8-K C N J 11$ genes in addition to numerous other associations (171). In general the exact mechanism by which such genomic changes result in changes in $\beta$ cell physiology are not clear. It is complicated by the fact that the tag single nucleotide polymorphism is often in linkage disequilibrium with a number of other variants any of which may be causative. However in the case of the $K_{\text {ATP }}$ channel complex there is a coding variant (E23K) in KCNJ11 that drives the association (179). The E23K mutant when expressed in heterologous expression systems leads to modest reductions in ATP sensitivity $(197 ; 559)$. Furthermore, it is interesting that the $\mathrm{E} 23 \mathrm{~K}$ mutation is in linkage disequilibrium with another coding mutation in ABCC8 (S1369A) and co-expression of the two variants may potentiate the functional phenotype (197). The E23K mutant channels are also more susceptible to activation by long chain fatty acyl CoA species (436).

\section{Cardiac Arrhythmia}

A variety of different arrhythmic mechanisms can be distinguished including re-entry, 
abnormal automaticity and abnormal electrical events such as early and delayed afterdepolarisations (146). In guinea pig ventricular myocytes action potential duration (APD) was reduced by as much as $50 \%$ when as little as $0.7 \%$ of the maximum $\mathrm{K}_{\mathrm{ATP}}$ conductance was active (387) and the opening of $\mathrm{K}_{\mathrm{ATP}}$ channels leads to foreshortened repolarisation and QT interval on the surface ECG $(165 ; 294)$. In turn this gives a reduced effective refractory period, which in principle can predispose to re-entrant circuits and a pro-fibrillatory state. Pro-fibrillatory effects of $\mathrm{K}_{\text {ATP }}$ openers have been shown in numerous animal models and a major factor in this is likely to involve heterogeneous dispersion of action potential duration both in an interventricular, and intraventricular manner between layers of the myocardium $(72 ; 116 ; 163 ; 549 ; 577 ; 578)$. The corollary is that blocking $\mathrm{K}_{\mathrm{ATP}}$ channels would be antiarrhythmic. Studies in rat and canine models have looked at ventricular fibrillatory potential in the context of ischaemia and shown that this is reduced in the presence of $\mathrm{K}_{\mathrm{ATP}}$ blocking drugs $(44 ; 267 ; 578)$. This has been replicated in a Langendorff-perfused explanted cardiomyopathic human heart model (133).

Studies have also investigated arrhythmia inducibility in atrial preparations. In a rat model $\beta$-adrenergic induced metabolic stress caused reduced intracellular ATP concentration and led to inducible atrial tachyarrhythmia that was reversed with glibenclamide (279). In a murine model with salt-induced hypertension, atrial $\mathrm{K}_{\mathrm{ATP}}$ channel upregulation was seen coinciding with a shortened effective refractory period and increased atrial arrhythmia inducibility (300). In human hearts obtained at transplantation, potassium channel openers were seen to increase atrial arrhythmia inducibility that was then terminated with a $\mathrm{K}_{\text {ATP }}$ inhibitor (133). Interestingly, in clinical trials with nicorandil there was no increased arrhythmic risk (529). Atrial electrophysiology remodels as a consequence of atrial fibrillation (571) but conflicting evidence exists for remodelling of $\mathrm{K}_{\mathrm{ATP}}$ current in human chronic AF. Two studies have looked at differences in $\mathrm{K}_{\text {ATP }}$ current density in isolated right 
atrial appendage myocytes between sinus rhythm and chronic AF patients and showed opposing results $(28 ; 580)$.

The significance of an early repolarisation pattern ("J wave") on the ECG is controversial. For example, it is commonly observed in healthy males and athletes but in other circumstances it may presage something more malignant and the early repolarisation pattern ("J wave syndromes") may predispose individuals to ventricular fibrillation and sudden death (6). A rare variant in KCNJ8 (S422L) has been associated with prominent early repolarisation and ventricular fibrillation (193). Other groups subsequently described similar findings with the same mutation $(32 ; 349)$. In functional studies in heterologous expression systems this mutation led to an increase in current-density when the mutant Kir6.1 subunit was expressed with a SUR caused by a decrease in ATP sensitivity $(32 ; 193 ; 349)$. ABCC9 mutations have also been reported in Brugada syndrome and these too led to gain of function phenotypes in expression systems (228). Sudden infant death syndrome has also been reported to be associated with mutations in KCNJ8. An in frame deletion E332del and a missense mutation V346I have been associated with this condition and both led to some loss of $\mathrm{K}_{\mathrm{ATP}}$ channel function in heterologous expression systems (527). It is worth bearing in mind that the ExAc project is discovering a large number of missense mutations present in the population at large and has resulted in re-interpretation of the pathogenicity of missense mutations in a number of diseases (269).

Whilst $\mathrm{K}_{\text {ATP }}$ channel opening might lead to an increased likelihood of re-entry, in the case of abnormal automaticity or triggered activity it is also possible that hyperpolarisation of the membrane will lead to the arrhythmia being extinguished. Thus in isolated Purkinje fibre preparations $\mathrm{K}_{\mathrm{ATP}}$ channel opening slows spontaneous firing rate and suppresses automaticity (239) whilst hypoxia-induced spontaneous cycle length prolongation was blunted in Kir6.2 knockout mice suggesting a role in sinus node automaticity (161). Pinacidil has been shown 
to abolish early and delayed after-depolarisations (497). Indeed, nicorandil can abolish transmural dispersion of repolarisation and triggered activity in canine long QT models (479) and when given intravenously, has been shown to abolish EADs and ventricular fibrillation in a patient with long QT syndrome (460). Loss of $\mathrm{K}_{\mathrm{ATP}}$ channel function has also been shown to promote triggered activity: for example, Kir6.2 knockout mice developed early afterdepolarisations after isoproterenol challenge (322). A similar mechanism was proposed in a patient with lone atrial fibrillation emanating from the vein of Marshall who was found to have a missense mutation in the $A B C C 9$ gene encoding the SUR2A subunit (397). Thus the exact role of $\mathrm{K}_{\text {ATP }}$ channels in arrhythmia is complex and dependent on the substrate.

\section{Heart failure, hypertrophy and cardiomyopathy}

Adult cardiac cells do not divide and respond to a prolonged increase in workload with cell hypertrophy. This can be physiological as occurs with exercise training but can also be the response to cardiac disease such as in hypertension and heart failure (84). The pathological hypertrophy can contribute significantly to the disease pathobiology. Aortic banding is a commonly used approach to generate hypertrophy in animal models and in Kir6.2 knockout mice it leads to increased hypertrophy compared to littermate controls (589). However, the interpretation of these results is complicated by the paradoxical observation that this also occurs in mice with transgenic overexpression of SUR1 (230). The suggestion is that the SUR1 transgenic mouse also has disrupted cardiac sarcolemmal currents (230). Hypertrophy also occurs following myocardial infarction and Kir6.1 expression has been shown to be increased around the infarct border zone (246). Furthermore, this increase in Kir6.1 expression correlated with increased angiotensin II and tumour necrosis factor $\alpha$ expression (245; 246). In contrast Kir6.2 expression decreased. The cells also become responsive to diazoxide and have significantly upregulated $\mathrm{K}_{\mathrm{ATP}}$ currents. Although under 
resting conditions the action potential duration is prolonged, after the application of diazoxide it significantly shortens (246). Similar observations have been made in human samples (136). Cardiomegaly is also a feature of the Cantu syndrome (see below).

There are also some indications that $\mathrm{K}_{\mathrm{ATP}}$ channels might lead to rare forms of heart muscle disease. A group of patients with dilated cardiomyopathy were subjected to sequencing of the $\mathrm{K}_{\mathrm{ATP}}$ channel genes. A missense mutation A1513T and a frameshift mutation leading to a premature stop codon at Leu1524 were discovered in ABCC9. In functional studies these mutations impaired nucleotide hydrolysis at NBD2 (43). We have already discussed the non-synonymous polymorphism in Kir6.2 which generates a coding change (E23K) in relation to predisposition to type II diabetes mellitus. It is interesting that this polymorphism is also associated with increased left ventricular size in hypertensive patients and is also over-represented in heat failure patients $(434 ; 435)$. Furthermore, homozygous carriers have reduced exercise capacity with an attenuated heart rate response and lower maximal oxygen consumption (434).

\section{Cardioprotection}

Cardioprotection is a broad term which includes protection from cardiac ischaemia, ischaemia-reperfusion injury and phenomena such as early and late preconditioning (599). $\mathrm{K}_{\mathrm{ATP}}$ channels have a long history of being implicated in these various processes. These include as both an initiator andlor a downstream effector of the response whether present in cardiac sarcolemmal or mitochondrial membranes $(153 ; 598)$. For example, ischaemic preconditioning was eliminated in Kir6.2 global knockout mice and diazoxide was no longer able to mimic ischaemic preconditioning $(190 ; 512 ; 513)$. It is thought that the action potential shortening due to $\mathrm{K}_{\mathrm{ATP}}$ channel opening leads to reduced calcium entry and attenuated contractile function as illustrated in Figure 11 and also discussed above $(304 ; 557)$. 
The net effect is to reduce the energy demands on the cell and prevent calcium overload both of which, if unchecked, would lead to cell death. Thus $\mathrm{K}_{\text {ATP }}$ inhibitors prevent the action potential shortening whilst potassium channel openers potentiate the effect preserving cellular ATP levels $(348 ; 557)$. In the Kir6.2 knockout mouse there was a failure of action potential shortening and prolonged contractile dysfunction (513). Application of potassium channel openers also reduced the amount of calcium entering the cell during reperfusion: a possible central event in ischaemia-reperfusion injury. Transgenic mice, with over-expression of SUR2A in cardiac myocytes, have increased cardiac $\mathrm{K}_{\mathrm{ATP}}$ currents and this protects the cardiac myocytes from subsequent ischaemic challenge (119). There may even be a reservoir of $\mathrm{K}_{\mathrm{ATP}}$ channels that can translocate from intracellular sites to the plasma membrane under conditions of metabolic strain $(30 ; 58)$. Recent studies have shown that eps15 homology domain-containing protein 2 increases $\mathrm{K}_{\mathrm{ATP}}$ channel trafficking and currents by inhibiting endocytosis. Furthermore expression of a dominant-negative mutant sensitised increased cardiac damage to ischaemia (595). Latest observations also suggest that activation of Kir6.2containing channel complexes occurs relatively late during ischaemic challenge in ventricular myocytes and other channels perhaps even those containing Kir6.1 subunits might also be important in the initial phase (54). It is also worth remembering that vascular $\mathrm{K}_{\mathrm{ATP}}$ channels can have a significant influence on cardiac protection. Ischaemia-reperfusion injury was significantly increased in mice with both endothelial and smooth muscle deletion of Kir6.1 (20).

Thus the comprehensive available data using pharmacological agents and molecular approaches do indicate a potential role for $\mathrm{K}_{\mathrm{ATP}}$ channels in a variety of cardioprotective processes. A host of second messengers and receptor pathways have been invoked either upstream or downstream of the channels and these include protein kinase C, adenosine receptors and reactive oxygen species to name but a few. However recent trends have 
focussed on new pathways including opening of the mitochondrial permeability transition pore and various protein kinases including protein kinase B and janus kinase pathways (191; 447). It is not yet clear how these new paradigms integrate with the body of older literature to give a coherent view of these processes. Furthermore, the critical issue is whether cardioprotection can be used to benefit patients in common clinical scenarios. Human tissue preconditions in the same way that animal hearts do and thus this may be potentially feasible (495). Preconditioning can also be evoked remotely for example by repeatedly inflating a blood pressure cuff and this is much easier to use safely in patients in the hospital setting (331). $\mathrm{K}_{\text {ATP }}$ channels have a role in the effect and it likely resembles the phenomena invoked by local ischaemia though the full transduction pathway is not clear $(35 ; 331 ; 345)$. However clinical trials have so far failed to show benefit: for example, remote ischaemic preconditioning was disappointingly unable to improve outcomes in the well-controlled setting of cardiac surgery $(208 ; 352)$. The cardioprotection field is currently under a cloud as the best path to realising clinical benefit is not clear.

\section{Cantu syndrome}

Cantu syndrome is a very rare disease characterised by hypertrichosis, abnormal facial features with similarities to that occurring in acromegaly, macrosomia, skeletal abnormalities and an enlarged heart $(62 ; 439 ; 448)$. A number of other clinical features have been noted to occur in some individuals and these include pericardial effusion, patent ductus arteriosus, conduction system abnormalities, pulmonary hypertension and coarse lax skin (466). The genetic basis of the disease was initially obscure though sporadic autosomal dominant mutations were suspected. The advance came from the use of exonic sequencing in parent patient trios and led to the discovery of novel missense mutations in $A B C C 9(205 ; 552)$. Subsequently a few missense mutations were also described in $\operatorname{KCNJ8}(57 ; 91)$. Using 
standard heterologous expression techniques these mutations were expressed and shown to lead to increased $\mathrm{K}_{\mathrm{ATP}}$ channel activity $(92 ; 205)$. This occurs in two ways: the first is to impair inhibition to ATP and the second to increase activation by MgADP (92). A murine model has been developed in which Kir6.1 gain of function mutations can be transgenically expressed in various tissues and this can replicate features of the disease (306). However, this approach allows such mutant channels to be expressed ectopically where they may not under normal circumstances be expressed and does not replicate possible developmental aspects of the disease. In both Cantu syndrome and neonatal diabetes there is an argument for making true knock-in models to phenocopy the disease especially as this is easier now with CRISPR $\backslash$ cas9 technologies. As in neonatal diabetes sulphonylureas may significantly influence the course of the adult disease though they may not be effective in every case (90). To date there are no clinical data on the efficacy of this approach. One intriguing feature is that the clinical phonotype seems to be equivalent in $A B C C 9$ and $K C N J 8$ mutation carriers. $A B C C 9$ mutations would be thought to influence both Kir6.1 and Kir6.2 channel populations. This suggests that Kir6.1 might have a wider role in tissue physiology than is commonly appreciated and particularly during development.

\section{$K_{\mathrm{ATP}}$ channels and neurological disease}

The $\mathrm{K}_{\text {ATP }}$ channel mutations that underlie congenital hyperinsulinism, neonatal diabetes and the Cantu syndrome can all have varying degrees of neurological pathology. It seems that these are due to primary abnormalities associated with $\mathrm{K}_{\mathrm{ATP}}$ channel expression in neurones and not simply a secondary consequence of metabolic changes. Thus $\mathrm{K}_{\mathrm{ATP}}$ channels can directly influence brain function in man but the he exploitation of this for wider neurological disease is very much at an experimental stage.

There has been interest in the involvement of $\mathrm{K}_{\text {ATP }}$ channels in neuroprotection and 
stroke (217). The arguments are similar to those invoked for cardioprotection in that hyperpolarisation leads to neuronal silencing thus reducing metabolic demands. In addition the hyperpolarisation prevents the terminal depolarisation and large rise in intracellular calcium that is a prelude to neuronal death. A number of studies have shown such effects in several different neuronal populations $(160 ; 168 ; 590)$. In CA1 hippocampal neurones five minutes of hypoxia induces hyperpolarisation whilst in the same neurones from Kir6.2 knockout mice there is a rapid depolarisation (509). Furthermore middle cerebral artery occlusion resulted in greater brain injury in an in-vivo model in mice lacking Kir6.2 compared to control mice (508). Finally, transgenic mice overexpressing Kir6.2 in the forebrain were resistant to ischaemic injury due to neuronal silencing (216).

Neurones vary in their sensitivity to damage by anoxia. For example dorsal vagal neurones are highly resistant and this is attributed to prominent expression of $\mathrm{K}_{\mathrm{ATP}}$ channel currents (29). However this is not a universal phenomenon and there has been focus on dopaminergic neurones in the substantia nigra given their relevance for Parkinson's disease. In an interesting study the behaviour of ventral tegmental neurones with those in the substantia nigra was compared. The neurones in the substantia nigra were particularly susceptible to toxins known to lead to dopaminergic neuronal death and Parkinson's disease. The application of these known toxins provoked $\mathrm{K}_{\mathrm{ATP}}$ channel firing and cell death in the substantia nigra but not in the ventral tegmental area. The cell death and degeneration was prevented in the Kir6.2 knockout mouse (320).

Neuronal $\mathrm{K}_{\text {ATP }}$ channel also seem to be important in determining seizure threshold. Kir6.2 knockout mice are predisposed to hypoxia induced seizures and this was thought to arise from abnormal excitability of substantia nigral neurones in the genetically modified mice (586). In addition, mice transgenically overexpressing SUR1 in the forebrain were resistant to kainic acid induced seizures (215). 


\section{The current clinical use of drugs modulating $\mathrm{K}_{\mathrm{ATP}}$ channels}

Sulphonylureas are still used in the treatment of type II diabetes however they can lead to counterproductive weight gain and also a risk of hypoglycaemia particularly in the elderly (393). In addition, it is recommended that the newer classes of sulphonylurea and related agents are used because of the potential for drugs such as glibenclamide to inhibit $\mathrm{K}_{\mathrm{ATP}}$ channels in cardiac cells. The more modern trend is to use metformin instead though suphonylureas still have a place in those intolerant of metformin and in combination therapy (393). In addition to fewer problems with weight gain there is also evidence that metformin is associated with a lower risk of dementia (399).

Nicorandil is used as a second line agent for the treatment of stable angina with $\beta$ adrenoreceptor blockers and calcium channel antagonists the agents of choice. Nicorandil can also be used in combination treatment with these drugs however if more than two drugs fail to control symptoms some form of coronary revascularisation is generally recommended. The drug has been associated with gastrointestinal and skin ulceration and this has limited its use (200). Nicorandil has been tested in clinical trials to see if it can prevent acute coronary syndromes in patients with stable angina (529). There was some evidence of efficacy and also in a subsequent meta-analysis (333). However in the UK nicorandil is not recommended for secondary prevention after myocardial infarction (https://www.nice.org.uk/guidance/cg172).

Very high levels of blood pressure represent a medical emergency and need urgent pharmacological intervention. Diazoxide and minoxidil are potent anti-hypertensives and can be used in these situations. However they are second line drugs with labetolol and nicardipine preferred in modern clinical practice (412). Monoxidil is also known to promote hypertrichosis and this has been exploited as a topical preparation for male pattern baldness (395). Hair follicles express $\mathrm{K}_{\mathrm{ATP}}$ channel subunits but it is unclear what the mechanism is 
with direct effects on the follicle growth cycle or increases in blood flow being plausible (482). It is interesting that hypertrichosis is a feature of Cantu syndrome and suggests there is a direct effect of $\mathrm{K}_{\mathrm{ATP}}$ channel in the hair follicle.

\section{Conclusions}

$\mathrm{K}_{\mathrm{ATP}}$ channels are potassium channels that are directly sensitive to cell metabolism. They are complex molecular machines constituted of an octamer of four sulphonylurea receptors and four Kir6.0 inward rectifier potassium channel subunits. The channels are widely distributed in a number of tissues and differential functional and pharmacological properties are accounted for by distinct subunit expression. The combination of structure function studies and recent high resolution structural information, means we understand in much greater molecular detail how the channels select for potassium and respond to ATP, $\mathrm{MgADP}, \mathrm{PIP}_{2}$ and various pharmacological agents. The use of pharmacology, genetically engineered murine strains and the study of human disease have supported a number of physiological and pathological roles for $\mathrm{K}_{\mathrm{ATP}}$ channels. The best characterised are $\mathrm{K}_{\mathrm{ATP}}$ channels in pancreatic $\beta$ cells that are central in supporting stimulus secretion coupling between blood glucose and insulin secretion. Furthermore, glibenclamide and derivatives are used to treat type II diabetes mellitus and mutations in SUR1 and Kir6.2 can result in congenital hyperinsulinism and diabetes. However the physiological role of $\mathrm{K}_{\mathrm{ATP}}$ channels is broader and includes regulation of muscle excitability and contraction, neuronal excitability and vascular and non-vascular smooth muscle contractility. $\mathrm{K}_{\mathrm{ATP}}$ channels are also involved in cellular protection in a number of tissues and there may be ways of harnessing this for use in human disease.

It is likely that further definition of molecular function, such as nucleotide regulation and $\mathrm{K}_{\mathrm{ATP}}$ channel drug interactions, will come through additional structural studies and this 
may help develop new therapeutic approaches. The trafficking and regulation of the channel are still poorly defined particularly in native cells. Proteomic techniques are likely to reveal novel interactions and give clues to similarities and differences in different tissues. The use of increasingly sophisticated genetically modified mouse lines such as those that allow temporal and tissue-specific deletion is likely to further refine our integrated understanding of $\mathrm{K}_{\mathrm{ATP}}$ channel function in the whole organism. Modern human genomics including genome wide association studies in various physiological and disease traits, and exome and genome wide sequencing technologies are likely to further reveal the role of these channels and associated

pathways in human disease. Furthermore, the transcriptional control of expression in development and disease are little investigated and again modern epigenetic techniques could have an impact in this area.

\section{Acknowledgements}

This work was supported by the British Heart Foundation (RG/15/15/31742), Medical Research Council (MR/L016230/1) and was facilitated by the NIHR Biomedical Research Centre at Barts. The authors have no conflicts of interest to declare. 


\section{Tables}

Table 1 - Pharmacology of drugs acting on $\mathrm{K}_{\mathrm{ATP}}$ channels

\begin{tabular}{|c|c|c|c|c|c|}
\hline & Drug & Chemical class & Type of $K_{\text {ATP }}$ channel & Mechanism of action & Drugs of same class \\
\hline \multirow{11}{*}{$\begin{array}{l}n \\
0 \\
u\end{array}$} & \multicolumn{5}{|c|}{ First Generation } \\
\hline & Pinacidil & Cyanoguanidines & Cardiac $\mathrm{K}_{\mathrm{ATP}}$, Smooth muscle $\mathrm{K}_{\mathrm{ATP}}$ & $\begin{array}{l}\downarrow \text { Sensitivity to ATP } \\
\uparrow \mathrm{K}_{\text {ATP }} \text { opening }\end{array}$ & $\begin{array}{l}\text { P-1075, PNU-99963, PNU- } \\
9470\end{array}$ \\
\hline & Diazoxide & Benzothiadiazines & $\begin{array}{l}\text { Cardiac } \mathrm{K}_{\mathrm{ATP}} \text {, Smooth muscle } \mathrm{K}_{\mathrm{ATP}} \text {, } \\
\text { Mitochondrial } \mathrm{K}_{\mathrm{ATP}} \text {, Pancreatic } \mathrm{K}_{\mathrm{ATP}}\end{array}$ & Require ADP for activity & LN-5330 \\
\hline & Cromakalim & Benzopyrans & Cardiac $\mathrm{K}_{\text {ATP }}$, Smooth muscle $\mathrm{K}_{\text {ATP }}$ & $\begin{array}{l}\downarrow \text { Sensitivity to ATP } \\
\uparrow \mathrm{K}_{\text {ATP }} \text { opening }\end{array}$ & $\begin{array}{l}\text { Levcromakalim, Blmakalim, } \\
\text { Cellkalim, Rilmakalim, Y- } \\
27152\end{array}$ \\
\hline & Nicorandil & Pyridyl Nitrates & Cardiac $\mathrm{K}_{\mathrm{ATP}}$ & $\begin{array}{l}\text { Require ADP for activity } \\
\text { Exhibit nitrate-like effect }\end{array}$ & KRN-2391 \\
\hline & Minoxidil & Pyrimidine Sulfate & Cardiac $\mathrm{K}_{\mathrm{ATP}}$ & ND & LP-805 \\
\hline & Aprikalim & Carbothiamides & Cardiac $\mathrm{K}_{\text {ATP }}$ & ND & MCC-134 \\
\hline & \multicolumn{5}{|c|}{ Second Generation } \\
\hline & WAY-151616 & Cyclobutenediones & Smooth muscle $\mathrm{K}_{\mathrm{ATP}}$ & ND & WAY-133537 \\
\hline & ZM-244085 & Dihydropyridine & Smooth muscle $\mathrm{K}_{\mathrm{ATP}}$ & ND & ZD-0947 \\
\hline & ZD-6169 & Tertiary carbinols & Smooth muscle $\mathrm{K}_{\mathrm{ATP}}$ & ND & A-151892 \\
\hline \multirow{7}{*}{$\begin{array}{l}\frac{n}{0} \\
\frac{0}{0} \\
\frac{0}{c} \\
\frac{1}{c}\end{array}$} & \multicolumn{5}{|l|}{ First Generation } \\
\hline & Tolbutamide & Sulfonylureas & Pancreatic $\mathrm{K}_{\text {ATP }}$ & Binding with lower affinity & $\begin{array}{l}\text { Chlorpropamide, } \\
\text { Acetohexamide, Tolazamide }\end{array}$ \\
\hline & \multicolumn{5}{|c|}{ Second Generation } \\
\hline & Glibenclamide & Sulfonylureas & $\begin{array}{l}\text { Cardiac } K_{\text {ATP }} \text {, Smooth muscle } K_{\text {ATP }}, \\
\text { Mitochondrial } K_{\text {ATP }} \text {, Pancreatic } K_{\text {ATP }}\end{array}$ & Binding with higher affinity & $\begin{array}{l}\text { Glipizide, Glimepiride, } \\
\text { Glipizide }\end{array}$ \\
\hline & \multicolumn{5}{|l|}{ Third generation } \\
\hline & Meglitinide & Benzoic acid derivatives & Pancreatic $\mathrm{K}_{\mathrm{ATP}}$ & $\begin{array}{l}\text { Nonsulfonylurea insulin secretagogues } \\
\text { Binding with lower affinity }\end{array}$ & $\begin{array}{l}\text { Repaglinide, Nateglinide, } \\
\text { Mitiglinide }\end{array}$ \\
\hline & HMR-1098 & Sulfonylureas & Cardiac $\mathrm{K}_{\mathrm{ATP}}$ & Binding with higher affinity & HMR-1883 \\
\hline
\end{tabular}



Table 2 - A summary of genetically modified mouse models used in investigating the biology of $\mathrm{K}_{\mathrm{ATP}}$ channels

\begin{tabular}{|c|c|c|c|c|c|c|}
\hline Mouse Genotype & $\begin{array}{c}\text { Functional effect on } \\
\mathbf{K}_{\mathrm{ATP}}\end{array}$ & $\begin{array}{l}\text { Premature } \\
\text { Death }\end{array}$ & $\begin{array}{c}\text { Blood } \\
\text { Pressure } \\
\text { Effects }\end{array}$ & $\begin{array}{l}\text { Cardiac } \\
\text { Effects }\end{array}$ & Mouse Phenotype & References \\
\hline \multicolumn{7}{|c|}{ Whole animal } \\
\hline Kir6.1-/- & $\begin{array}{l}\text { Loss of current in } \\
\text { vascular smooth muscle }\end{array}$ & Yes & Increased & Yes & $\begin{array}{l}\text { Coronary artery vasospasm, hypertension, } \\
\text { heart block and premature death }\end{array}$ & $(22 ; 309 ; 358)$ \\
\hline Kir6.2-/- & $\begin{array}{l}\text { Loss of current in } \\
\text { striated muscle and } \beta \text { - } \\
\text { cells }\end{array}$ & No & No & Yes & $\begin{array}{l}\text { Defective glucose-induced insulin secretion. } \\
\text { Loss of current in ventricular myocytes. } \\
\text { Action potential shortening and depressed } \\
\text { cardiac contractility in response to KCOs. } \\
\text { Enhanced glucose uptake in skeletal muscle. } \\
\text { Impaired glucagon secretion. Impaired } \\
\text { exercise tolerance with muscle damage and } \\
\text { arrhythmia under stress. No neuroprotection } \\
\text { after seizure. }\end{array}$ & $\begin{array}{l}(322 ; 355 ; 357 \\
511-513 ; 528 \\
586 ; 616)\end{array}$ \\
\hline $\begin{array}{c}\text { Kir6.2 Y12X ENU } \\
\text { mutagenesis }\end{array}$ & $\begin{array}{l}\text { Loss of current in } \\
\text { pancreatic } \beta \text {-cells }\end{array}$ & ND & ND & ND & $\begin{array}{l}\text { Impaired insulin secretion and no } \\
\text { hypoglycaemia }\end{array}$ & (232) \\
\hline SUR1-/- & $\begin{array}{l}\text { Loss of current in atrial } \\
\text { cardiomyocytes and } \beta \text { - } \\
\text { cells }\end{array}$ & No & No & ND & $\begin{array}{l}\text { Glucose intolerance and impaired insulin } \\
\text { secretion. Protected against ischemic insult. }\end{array}$ & $\begin{array}{l}(127 ; 149 ; 467 ; \\
481)\end{array}$ \\
\hline SUR1 E1506K knock-in & $\begin{array}{l}\text { Loss of current in } \\
\text { pancreatic } \beta \text {-cells }\end{array}$ & ND & ND & ND & $\begin{array}{l}\text { Initially hyperinsulinism but later followed by } \\
\text { reduced } \beta \text { cell insulin content and diabetes } \\
\text { mellitus }\end{array}$ & $(480)$ \\
\hline SUR2-/- & $\begin{array}{l}\text { Loss of current in } \\
\text { smooth, cardiac and } \\
\text { skeletal muscles }\end{array}$ & Yes & Increased & Yes & $\begin{array}{l}\text { Coronary artery vasospasm, hypertension, } \\
\text { heart block and premature death. Increased } \\
\text { glucose uptake in skeletal muscle. Impaired } \\
\text { exercise tolerance and skeletal muscle } \\
\text { myopathy. Resistant to cardiovascular stress. }\end{array}$ & $(74 ; 75 ; 504 ; 505)$ \\
\hline \multicolumn{7}{|c|}{ Smooth muscle } \\
\hline sm22 $\alpha$ cre-Kir6.1 (flx, flx) & $\begin{array}{l}\text { Loss of current in } \\
\text { vascular smooth muscle }\end{array}$ & No & Increased & No & Hypertension & (22) \\
\hline sm22 $\alpha-S U R 2 B / S U R 2-/-$ & $\begin{array}{l}\text { SM-specific expression } \\
\text { of SUR2B in SUR2 KO }\end{array}$ & Yes & ND & Yes & $\begin{array}{l}\text { Coronary artery vasospasm, hypertension, } \\
\text { heart block and premature death }\end{array}$ & $(257)$ \\
\hline
\end{tabular}




\begin{tabular}{|c|c|c|c|c|c|c|}
\hline & mice & & & & & \\
\hline smMHC-Kir6.1-AAA & $\begin{array}{l}\text { Dominant-negative } \\
\text { suppression of Kir6.1 in } \\
\text { smooth muscle }\end{array}$ & No & Increased & No & Hypertension & (309) \\
\hline smMHC-Kir6.1[G343D] & $\begin{array}{l}\text { Gain of function in } \\
\text { smooth muscle }\end{array}$ & No & Decreased & No & 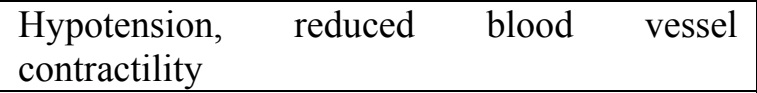 & $(309)$ \\
\hline $\begin{array}{c}\text { smMHC- } \\
\text { Kir6.1[G343D,Q53R] }\end{array}$ & $\begin{array}{l}\text { Gain of function in } \\
\text { smooth muscle }\end{array}$ & No & Decreased & No & $\begin{array}{l}\begin{array}{l}\text { Hypotension, reduced blood } \\
\text { contractility }\end{array} \\
\end{array}$ & (309) \\
\hline \multicolumn{7}{|c|}{ Endothelium } \\
\hline $\begin{array}{c}\text { Tie2 cre, Tg STOP Kir6.1- } \\
\text { AAA }\end{array}$ & $\begin{array}{l}\text { Dominant-negative } \\
\text { suppression of Kir6.1 in } \\
\text { endothelium }\end{array}$ & No & No & Yes & $\begin{array}{l}\text { Coronary vasospasm. Increased coronary } \\
\text { perfusion pressure }\end{array}$ & (335) \\
\hline Tie2 cre -Kir6.1 (flx, flx) & $\begin{array}{l}\text { Loss of current in } \\
\text { endothelium }\end{array}$ & No & No & No & $\begin{array}{l}\begin{array}{l}\text { Protective against ischemia-reperfusion } \\
\text { damage }\end{array} \\
\end{array}$ & (20) \\
\hline \multicolumn{7}{|c|}{ Cardiac Tissue } \\
\hline CMV-SUR2A & $\begin{array}{l}\text { Increased expression in } \\
\text { Cardiac muscle }\end{array}$ & No & ND & ND & $\begin{array}{l}\text { Resistant to hypoxia, ischemia and ischemia- } \\
\text { reperfusion injury }\end{array}$ & (119) \\
\hline $\begin{array}{l}\alpha \mathrm{MHC}-\mathrm{Kir} 6.1[\mathrm{G} 343 \mathrm{D}]- \\
\text { AAA }\end{array}$ & $\begin{array}{l}\text { Increased expression in } \\
\text { Cardiac muscle }\end{array}$ & No & ND & Yes & $\begin{array}{l}\text { Decreased ATP sensitivity, AV nodal } \\
\begin{array}{l}\text { abnormalities, Increased tolerance to } \\
\text { cardioplegic stress }\end{array}\end{array}$ & $(213 ; 307)$ \\
\hline $\begin{array}{l}\alpha \text {-MHC cre, Tg STOP } \\
\text { Kir6.1-AAA }\end{array}$ & $\begin{array}{l}\text { Dominant-negative } \\
\text { suppression of Kir6.1 in } \\
\text { cardiac muscle }\end{array}$ & No & ND & Yes & $\begin{array}{l}\text { Loss of current in ventricular myocytes, } \\
\text { Increased heart rate, Prolonged APD, } \\
\text { Compromised exercise tolerance. }\end{array}$ & $(537)$ \\
\hline $\begin{array}{l}\alpha \text {-MHC cre, Tg STOP } \\
\text { Kir6.2-AAA }\end{array}$ & $\begin{array}{l}\text { Dominant-negative } \\
\text { suppression of Kir6.1 in } \\
\text { cardiac muscle }\end{array}$ & No & ND & Yes & $\begin{array}{l}\text { Loss of current in ventricular myocytes. } \\
\text { Prolonged APD }\end{array}$ & $(537)$ \\
\hline$\alpha$-MHC-FLAG-SUR1 & $\begin{array}{l}\text { Overexpression in } \\
\text { cardiac muscle }\end{array}$ & Yes & ND & No & PR Prolongation. Reduced $\mathrm{K}_{\mathrm{ATP}}$ conductance & $(151)$ \\
\hline $\begin{array}{c}\alpha-\mathrm{MHC}-\mathrm{Kir} 6.2[\Delta \mathrm{N} 2- \\
30, \mathrm{~K} 185 \mathrm{Q}]\end{array}$ & $\begin{array}{l}\text { Overexpression in } \\
\text { cardiac muscle }\end{array}$ & Yes & ND & Yes & $\begin{array}{l}\text { Increased incidence of AV block. Reduced } \\
\mathrm{K}_{\text {ATP }} \text { conductance. Prolonged APD }\end{array}$ & $(147 ; 287)$ \\
\hline $\begin{array}{c}\alpha-\text { MHC-FLAG-SUR1/ } \alpha- \\
\text { MHC-Kir6.2[ } \Delta \mathrm{N} 2- \\
\text { 30,K185Q }\end{array}$ & $\begin{array}{l}\text { Overexpression in } \\
\text { cardiac muscle }\end{array}$ & Yes & ND & Yes & $\begin{array}{l}\text { PR Prolongation, Ventricular tachycardia, AV } \\
\text { block, Atrial fibrillation, atrial flutter }\end{array}$ & $(150)$ \\
\hline$\alpha$-MHC-FLAG-SUR2A & Overexpression in & No & ND & No & Reduced $\mathrm{K}_{\text {ATP }}$ current-density & $(151)$ \\
\hline
\end{tabular}




\begin{tabular}{|c|c|c|c|c|c|c|}
\hline & cardiac muscle & & & & & \\
\hline $\begin{array}{l}\text { Mck-cre, Rosa26STOP } \\
\text { Kir6.2 V59M }\end{array}$ & $\begin{array}{l}\text { Gain of function in } \\
\text { muscle cells }\end{array}$ & No & ND & No & $\begin{array}{l}\text { Impaired ATP sensitivity of channels in } \\
\text { skeletal and cardiac muscle. No discernible } \\
\text { phenotype }\end{array}$ & (81) \\
\hline \multicolumn{7}{|c|}{  } \\
\hline $\begin{array}{l}\text { Rip-cre, Rosa26STOP } \\
\text { Kir6.2 V59M }\end{array}$ & $\begin{array}{l}\text { Gain of function in } \\
\text { pancreatic islets }\end{array}$ & ND & ND & ND & $\begin{array}{l}\text { Reduced insulin secretion and diabetes } \\
\text { mellitus }\end{array}$ & (176) \\
\hline Rip-Kir6.1[G343D] & $\begin{array}{l}\text { Gain of function in } \\
\text { pancreatic islets }\end{array}$ & No & ND & ND & Glucose intolerance & $(432)$ \\
\hline Rip-Kir6.1[G343D,Q53R] & $\begin{array}{l}\text { Gain of function in } \\
\text { pancreatic islets }\end{array}$ & No & ND & ND & $\begin{array}{l}\text { Reduced plasma insulin and severe diabetes } \\
\text { mellitus }\end{array}$ & $(432)$ \\
\hline \multicolumn{7}{|c|}{ Neuronal } \\
\hline CMK-SUR1 & $\begin{array}{l}\text { Increased expression in } \\
\text { forebrain }\end{array}$ & No & ND & ND & $\begin{array}{l}\text { Protective against seizures and neuronal } \\
\text { damage }\end{array}$ & $(215)$ \\
\hline $\begin{array}{c}\text { Nestin-cre, Rosa26STOP } \\
\text { Kir6.2 V59M } \\
\end{array}$ & $\begin{array}{l}\text { Gain of function in } \\
\text { central neurones }\end{array}$ & ND & ND & ND & Muscle weakness and reduced anxiety & $(82 ; 301)$ \\
\hline
\end{tabular}


Table 3 - Summary of the properties of $K_{\text {ATP }}$ channel populations in the pancreas and gut

\begin{tabular}{|c|c|c|c|c|c|}
\hline Location & $\begin{array}{c}\text { Subunit } \\
\text { Composition }\end{array}$ & $\begin{array}{c}\text { Conductance } \\
\text { (pS) }\end{array}$ & $\begin{array}{c}\operatorname{ATP~IC}_{50} \\
(\mu \mathrm{M})\end{array}$ & Physiological Function & Refs \\
\hline$\alpha$-cells & Kir6.2\SUR1 & $45-70$ & 17 & $\begin{array}{l}\text { Regulation of glucagon secretion } \\
\text { in response changes in blood } \\
\text { glucose }\end{array}$ & $\begin{array}{l}(36 ; 48 ; \\
445 ; 609)\end{array}$ \\
\hline$\beta$-cells & Kir6.2\SUR1 & $70-80$ & $15-160$ & $\begin{array}{l}\text { Regulation of insulin release in } \\
\text { response to changes in } \\
\text { metabolism }\end{array}$ & $\begin{array}{l}(14 ; 241 ; \\
243) \\
(359)\end{array}$ \\
\hline $\begin{array}{c}\text { Enteroendocrine } \\
\text { cells }\end{array}$ & Kir6.2\SUR1 & ND & ND & $\begin{array}{l}\text { Involved the stimulus-secretion } \\
\text { coupling of gut hormones such as } \\
\text { GIP, GLP-1 and PYY }\end{array}$ & $\begin{array}{l}(334 ; 388 ; \\
428)\end{array}$ \\
\hline
\end{tabular}

GIP - gluco-insulinotropic peptide, GLP-1 - glucagon-like peptide-1, PYY - peptide tyrosine tyrosine 
Table 4 - Summary of the properties of the major $\mathrm{K}_{\mathrm{ATP}}$ channel populations in striated muscle

\begin{tabular}{|c|c|c|c|c|c|}
\hline Location & $\begin{array}{c}\text { Subunit } \\
\text { Composition }\end{array}$ & $\begin{array}{c}\text { Conductance } \\
\text { (pS) }\end{array}$ & $\begin{array}{c}\operatorname{ATP~IC~}_{50} \\
(\mu \mathrm{M})\end{array}$ & Physiological Function & Refs \\
\hline Atria & Kir6.2\SUR1 & $52-90$ & $39-100$ & $\begin{array}{l}\text { Action potential repolarisation. } \\
\text { Adaptation to cell swelling }\end{array}$ & $\begin{array}{l}(33 ; 149 ; \\
248 ; 553 ; \\
619)\end{array}$ \\
\hline Ventricles & Kir6.2\SUR2A & $70-90$ & $10-100$ & $\begin{array}{l}\text { Protection against } \mathrm{Ca}^{2+} \text { overload } \\
\text { during hypoxia, } \\
\text { Adaptation response to stress }\end{array}$ & $\begin{array}{l}(31 ; 148 ; \\
240 ; 391 ; \\
526)\end{array}$ \\
\hline $\begin{array}{l}\text { Conduction } \\
\text { System }\end{array}$ & $\begin{array}{c}\text { Kir6.1\Kir6.2 } \\
\text { SUR2B }\end{array}$ & $52-60$ & $16-120$ & $\begin{array}{l}\text { Adaptation to stress, regulation of } \\
\text { pacemaker activity }\end{array}$ & $\begin{array}{l}(31 ; 162 ; \\
201 ; 314)\end{array}$ \\
\hline $\begin{array}{l}\text { Skeletal } \\
\text { Muscle }\end{array}$ & $\begin{array}{c}\text { Kir6.2\SUR2A } \\
\text { Kir6.2 \SUR1 }\end{array}$ & $60-71$ & $13-123$ & $\begin{array}{l}\text { Adaptation to strenuous exercise } \\
\text { and prevention of muscle fibre } \\
\text { damage during exercise. } \\
\text { Regulation of glucose uptake and } \\
\text { metabolism. }\end{array}$ & $\begin{array}{l}(22 ; 74 ; \\
75 ; 351 ; \\
356 ; 358 ; \\
420 ; 488 ; \\
528 ; 543 ; \\
545 ; 587 ; \\
614)\end{array}$ \\
\hline
\end{tabular}


Table 5 - Summary of the properties of the major $\mathrm{K}_{\mathrm{ATP}}$ channel populations in smooth muscle

\begin{tabular}{|c|c|c|c|c|c|}
\hline Location & $\begin{array}{c}\text { Subunit } \\
\text { Composition }\end{array}$ & $\begin{array}{c}\text { Conductance } \\
\text { (pS) }\end{array}$ & $\begin{array}{c}\operatorname{ATP~IC}_{50} \\
(\mu \mathrm{M})\end{array}$ & Physiological Function & Refs \\
\hline Endothelium & $\begin{array}{l}\text { Kir6.1\Kir6.2 } \\
\text { SUR2B }\end{array}$ & $25-40$ and 150 & ND & Protective during ischemia & $\begin{array}{l}(20 ; 252 ; \\
273 ; 274 ; \\
335 ; 600)\end{array}$ \\
\hline $\begin{array}{l}\text { Vascular } \\
\text { Smooth } \\
\text { Muscle }\end{array}$ & Kir6.1\SUR2B & $15-50$ & $29-200$ & $\begin{array}{l}\text { Vasodilation } \\
\text { Blood pressure regulation }\end{array}$ & $\begin{array}{l}(22 ; 74 ; \\
358 ; 420 ; \\
587)\end{array}$ \\
\hline $\begin{array}{c}\text { Non-vascular } \\
\text { Smooth } \\
\text { Muscle }\end{array}$ & \begin{tabular}{l} 
Kir6.1\Kir6.2\} $\\
{\text { SUR2B }}$ & $18-80$ & & Relaxation/Contraction & $(284 ; 522)$ \\
\hline
\end{tabular}
\end{tabular}


Table 6 - Summary of the $\mathrm{K}_{\text {ATP }}$ channel expression profile and function in the central and peripheral nervous systems.

\begin{tabular}{|c|c|c|c|c|c|}
\hline Location & $\begin{array}{c}\text { Subunit } \\
\text { Composition }\end{array}$ & $\begin{array}{c}\text { Conductance } \\
\text { (pS) }\end{array}$ & $\begin{array}{c}\operatorname{ATP~IC}_{50} \\
(\mu \mathrm{M})\end{array}$ & Physiological Function & Refs \\
\hline Hypothalamus & Kir6.2\SUR1 & $13-86,149$ & ND & $\begin{array}{l}\text { Expressed in AgRP/NPY- and } \\
\text { POMC-positive neurons. } \\
\text { Regulation of neuronal } \\
\text { excitability in response to } \\
\text { glucose. Activity regulated by } \\
\text { insulin and leptin. }\end{array}$ & $\begin{array}{l}(238 ; 414 ; \\
493)\end{array}$ \\
\hline Pituitary & $\begin{array}{l}\text { Kir6.2\SUR2B } \\
\text { Kir6.2\SUR1 }\end{array}$ & 74 & 30 & Regulation of hormone secretion & $(59 ; 582)$ \\
\hline $\begin{array}{l}\text { Substantia } \\
\text { Nigra }\end{array}$ & Kir6.2\SUR1 & 77 & 12 & $\begin{array}{l}\text { Neuroprotection from stress and } \\
\text { against seizures, Regulation of } \\
\text { excitability, Release of } \\
\text { neurotransmitters such as } \\
\text { dopamine, GABA and glutamate } \\
\text { in response to changes } \\
\text { metabolism. Play a role in } \\
\text { memory, locomotion and } \\
\text { behaviour }\end{array}$ & $\begin{array}{l}(19 ; 121 ; \\
283 ; 461 ; \\
473 ; 586)\end{array}$ \\
\hline $\begin{array}{c}\text { Dorsal Root } \\
\text { Ganglion }\end{array}$ & $\begin{array}{c}\text { Kir6.2\SUR1 } \\
\text { SUR2 }\end{array}$ & $72-78$ & ND & Suppression of hyperalgesia. & $(275 ; 618)$ \\
\hline Glial Cells & \begin{tabular}{l} 
Kir6.1\Kir6.2\} $\\
{\text { SUR1 }}$ & ND & ND & $\begin{array}{l}\text { Neuroprotective } \\
\text { Potassium siphoning }\end{array}$ & $\begin{array}{l}(532 ; 603 ; \\
611)\end{array}$ \\
\hline
\end{tabular}
\end{tabular}

AgRP/NPY-agouti-related peptide/neuropeptide Y, POMC-proopiomelanocortin 
Table 7 - A summary of human diseases associated with mutations in $\mathrm{K}_{\text {ATP }}$ channel subunits.

\begin{tabular}{|c|c|c|c|}
\hline Gene & $\begin{array}{l}\text { Clinical } \\
\text { Condition }\end{array}$ & Mechanisms of disease & Reference \\
\hline \multirow[t]{3}{*}{ KCNJ8 } & Cantu Syndrome & $\begin{array}{l}\text { Missense non-synonymous } \\
\text { variant V65M, functional } \\
\text { characteristics not confirmed }\end{array}$ & $(57)$ \\
\hline & $\begin{array}{l}\text { Sudden Infant } \\
\text { Death Syndrome }\end{array}$ & $\begin{array}{l}\text { In frame deletion E332del and } \\
\text { missense mutation V346I each } \\
\text { cause loss of function and have } \\
\text { been associated with this } \\
\text { condition }\end{array}$ & $(527)$ \\
\hline & $\begin{array}{l}\text { Brugada } \\
\text { syndrome, Early } \\
\text { repolarisation ("J } \\
\text { wave") syndrome, } \\
\text { atrial and } \\
\text { ventricular } \\
\text { fibrillation }\end{array}$ & $\begin{array}{l}\text { S422L GOF has been } \\
\text { associated with these } \\
\text { conditions }\end{array}$ & $(32 ; 114 ; 193 ; 349)$ \\
\hline \multirow[t]{7}{*}{ KCNJ11 } & $\begin{array}{l}\text { Congenital } \\
\text { Hyperinsulinism }\end{array}$ & $\begin{array}{l}\text { Recessive mutations leading to } \\
\text { loss of } \mathrm{K}_{\text {ATP }} \text { channels at the } \\
\text { membrane and ER retention } \\
\text { eg. } \mathrm{H} 259 \mathrm{R}\end{array}$ & $(340)$ \\
\hline & & $\begin{array}{l}\text { Recessive mutations producing } \\
\text { non-functional protein eg. } \\
\text { Y12X, L147P }\end{array}$ & $(382 ; 530)$ \\
\hline & & $\begin{array}{l}\text { Dominant mutation causing } \\
\text { impaired pore-opening e.g. in- } \\
\text { frame deletion I } 284 \mathrm{del}\end{array}$ & $(268 ; 380)$ \\
\hline & Neonatal Diabetes & $\begin{array}{l}\text { Missense mutations causing } \\
\text { ATP insensitivity and GOF eg. } \\
\text { E227K, E229K }\end{array}$ & $(175 ; 177 ; 556)$ \\
\hline & & $\begin{array}{l}\text { In-frame deletion Kir6.2- } \\
28 \Delta 32 \text { causing ATP } \\
\text { insensitivity and GOF }\end{array}$ & $(93)$ \\
\hline & Type 2 Diabetes & $\begin{array}{l}\text { E23K mutant causing modest } \\
\text { ATP insensitivity and GOF }\end{array}$ & $(179)$ \\
\hline & $\begin{array}{l}\text { Increased LV size } \\
\text { and Heart Failure }\end{array}$ & $\begin{array}{l}\text { E23K mutant appears over- } \\
\text { represented in heart failure } \\
\text { patients }\end{array}$ & $(434 ; 435)$ \\
\hline \multirow[t]{2}{*}{ ABCC8 } & $\begin{array}{l}\text { Congenital } \\
\text { Hyperinsulinism }\end{array}$ & $\begin{array}{l}\text { Recessive mutations leading to } \\
\text { loss of } K_{\text {ATP }} \text { channels at the } \\
\text { membrane and ER retention } \\
\text { e.g. F1388del }\end{array}$ & $(65 ; 471 ; 519 ; 592)$ \\
\hline & & $\begin{array}{l}\text { Recessive mutations causing } \\
\text { loss of MgADP and drug } \\
\text { sensitivity despite membrane } \\
\text { resident channels e.g. T1139M, }\end{array}$ & $(486)$ \\
\hline
\end{tabular}




\begin{tabular}{|c|c|c|c|}
\hline & & R1215Q & \\
\hline & & $\begin{array}{l}\text { Dominant mutations causing } \\
\text { reduced sensitivity to } \\
\text { metabolic inhibition and drug } \\
\text { activation eg. V187D, E1506K }\end{array}$ & $(235 ; 268 ; 401)$ \\
\hline & Neonatal Diabetes & $\begin{array}{l}\text { Missense mutations causing } \\
\text { ATP insensitivity and GOF eg. } \\
\text { L213R, I1424V }\end{array}$ & (26) \\
\hline & Type 2 Diabetes & $\begin{array}{l}\text { S1369A variant when co- } \\
\text { expressed with KCNJ11 E23K } \\
\text { variant causes ATP } \\
\text { insensitivity and GOF }\end{array}$ & (197) \\
\hline АВСС9 & Cantu Syndrome & $\begin{array}{l}\text { Missense mutations leading to } \\
\text { reduced ATP sensitivity or } \\
\text { increased MgADP activation } \\
\text { and GOF eg. P432L, A478V, } \\
\text { C1043Y }\end{array}$ & $(92 ; 205 ; 552)$ \\
\hline & $\begin{array}{l}\text { Dilated } \\
\text { Cardiomyopathy }\end{array}$ & $\begin{array}{l}\text { Missense mutation A1513T or } \\
\text { frameshift mutation and stop } \\
\text { codon introduction at L1524 - } \\
\text { both impair nucleotide } \\
\text { hydrolysis at NBF2 causing } \\
\text { reduced function and } \\
\text { associated with DCM patients }\end{array}$ & (43) \\
\hline & Atrial Fibrillation & $\begin{array}{l}\text { Missense mutation T1547I } \\
\text { leading to loss of function and } \\
\text { implicated in AF initiating } \\
\text { from the Vein of Marshall }\end{array}$ & (397) \\
\hline & $\begin{array}{l}\text { Brugada and } \\
\text { Early } \\
\text { Repolarisation } \\
\text { Syndromes } \\
\end{array}$ & $\begin{array}{l}\text { V734I and S1402C GOF } \\
\text { mutations implicated }\end{array}$ & (228) \\
\hline & $\begin{array}{l}\text { Coronary spasm } \\
\text { and Myocardial } \\
\text { Infarction }\end{array}$ & $\begin{array}{l}\text { Association with V734I } \\
\text { mutation which causes both } \\
\text { reduced ATP inhibition and } \\
\text { reduced MgNDP activation } \\
\text { when mutant co-expressed } \\
\text { with SUR2B }\end{array}$ & (491) \\
\hline
\end{tabular}




\section{Figure Legends}

Figure 1 - Recordings of single $K_{A T P}$ channels. Cell-attached single channel recordings of Kir6.2 \SUR2B channels expressed in HEK293 cells. Co-expression of Kir6.2 \SUR2B forms a channel with a single channel conductance of $\sim 70 \mathrm{pS}$.

Figure 1 Teaching points: Ion channels have an open and closed conformation and when open pass a current with a characteristic conductance. The figure illustrates such high resolution single channel recordings of $\mathrm{K}_{\mathrm{ATP}}$ channels using the patch-clamp recording technique.

Figure 2 - The structure of drugs acting on $K_{A T P}$ channels.

Figure 2 Teaching points: $\mathrm{K}_{\mathrm{ATP}}$ channels have a rich pharmacology with a variety of pharmacophores able to selectively inhibit or activate the currents.

Figure 3 - A cartoon of the molecular composition of a $K_{A T P}$ channel. $\mathrm{K}_{\mathrm{ATP}}$ channels are formed from four pore-forming Kir6.x subunits and four regulatory sulphonylurea receptor subunits. Kir6x is a member of the inward-rectifying $\mathrm{K}^{+}$channel family (Kir) with 2 transmembrane domains (M1 and M2), a pore-forming region (H5) with the $\mathrm{K}^{+}$selectivity sequence and intracellular $\mathrm{N}$ and $\mathrm{C}$ termini. SUR belongs to the ATP binding cassette (ABC) family of proteins. SUR consists of 3 transmembrane domains (TMDs) composed of 5, 6 and 6 transmembrane segments respectively. The intracellular loop between TMD0 and TMD1, L0 provides the physical interaction with Kir6x. Two nucleotide binding domains (NBD1 and 
NDB2) comprised of Walker A and B nucleotide binding motifs provide the binding sites for magnesium complexed adenine nucleotides.

Figure 3 Teaching points: We understand the molecular composition of $\mathrm{K}_{\mathrm{ATP}}$ channels. They are composed of four inwardly rectifying potassium channel subunits (Kir6.1 and Kir6.2) and four sulphonylurea receptors (SUR1, SUR2A and SUR2B) which are a member of the large family of ATP binding cassette proteins. ATP inhibits the channel by binding to the channel pore forming subunit whilst MgADP, sulphonylureas and potassium channel openers act on the sulphonylurea receptors. The channels in different tissues have different properties and this is accounted for by selective expression of different Kir6.0 subunits and different SURs.

Figure 4 - The high resolution structure of the pancreatic $K_{A T P}$ channel. A. The linear sequence of Kir6.2 and SUR1 proteins. The various critical domains are coloured and the same scheme is used in the other panels. The numbers indicate amino acid residues defining the regions. B. A side view of the cryo-EM density map of the $\mathrm{K}_{\text {ATP }}$ channel $(3.6 \AA$ resolution). The position of the membrane is indicated by the gray bars. C. An extracellular view of the complex. D. A model of the $\mathrm{K}_{\mathrm{ATP}}$ channel complex with various ligands as indicated (ATP is green and glibenclamide is red). E. The model viewed from the extracellular side of membrane. This figure is reproduced from the recent study (342).

Figure 4 Teaching points: One of the major advances has been the determination of crystal structures of $\mathrm{K}_{\text {ATP }}$ channels using cryo EM. These have revealed their characteristic structural features and given insight into how glibenclamide might bind and inhibit the channel.

Figure 5 - The ATP binding pocket in Kir6.2 determined in the quatrefoil form. A. An EM 
density of the Kir6.2 tetramer with ATP molecules shown in yellow. B. A ribbon representation of Kir6.2 with two pore domains shown with important structural elements indicated. The ATP molecule is again shown in yellow. C The ATP binding site with residues contacting the yellow ATP as indicated. The The N-terminus from the neighbouring subunit interacts with the purine base of ATP. Dashed lines indicate hydrogen bonds. D. The EM density of the ATP molecule is outlined with a blue mesh and illustrates a horseshoe-shaped conformation. This figure is reproduced from the recent study (305).

Figure 5 Teaching points: The defining feature of $\mathrm{K}_{\mathrm{ATP}}$ channels is their sensitivity to nucleotide levels and ATP in particular thus enabling them to link cellular metabolism and membrane potential. The crystal structures show in exquisite molecular detail how ATP binds to the Kir6.2 subunit.

Figure 6 - Proposed sites of action of $K_{A T P}$ openers and inhibitors. The above schematics demonstrate the pharmaco-topology with respect to the different sulphonylurea receptor subtypes. The colour of the various segments of each SUR demonstrates broadly the homology between the subtypes. SUR2A and SUR2B (red) share almost 100\% homology and that which is different from SUR1 (blue). However, the terminal 42 amino acids of the C terminus of SUR2A and SUR2B differ, and in fact this segment in SUR1 shares almost 100\% homology with that in SUR2B as depicted by the colour coding in blue. Openers and their sites of action are depicted in green and inhibitors black. Capital letters denotes binding with high affinity and lower case with lower affinity. The action of diazoxide on SUR2A is shown in darker green given the fact that this interaction requires the presence of a high concentration of MgADP, and this probably results allosterically due to the differing terminal 42 amino acids at the $\mathrm{C}$ terminus of SUR2A (368). 
Figure 6 Teaching points: The drugs that work on $\mathrm{K}_{\text {ATP }}$ channels show some tissue selectivity accounted for by differential Kir6.0 and SUR expression.

Figure 7 - The regulation of vascular smooth muscle $K_{A T P}$ channels. Activation or inhibition of $\mathrm{K}_{\mathrm{ATP}}$ channels in the vascular smooth muscle cell determines its membrane potential. Vasoactive factors that activate $\mathrm{K}_{\mathrm{ATP}}$ channels either directly or indirectly cause membrane hyperpolarisation, closure of voltage-dependent calcium channels, reduced intracellular $\mathrm{Ca}^{2+}$ and dilation. Conversely factors that inhibit $\mathrm{K}_{\text {ATP }}$ channels cause depolarisation of the cell membrane leading to opening of voltage-dependent calcium channels, increased intracellular $\mathrm{Ca}^{2+}$ and contraction. Left, Dilation of VSM as a result of $\mathrm{K}_{\text {ATP }}$ channel activation initiated by vasodilators such as adrenaline, adenosine, calcitonin gene-related peptide (CGRP) and vasoactive intestinal peptide (VIP) via the G-protein (Gs)/Adenylate Cyclase (AC)/Protein Kinase A (PKA) signalling pathway. Hypoxia, ischemia and metabolic stress indirectly activate $\mathrm{K}_{\mathrm{ATP}}$ channels by inhibiting oxidative phosphorylation and therefore decreasing the ATP/ADP ratio. Right, endogenous mediators such as noradrenaline, angiotensin II, endothelin-1 and histamine inhibit $\mathrm{K}_{\text {ATP }}$ channels via the G-protein (Gi, q)/PKC signalling pathway leading to VSM contraction.

Figure 7 Teaching points: $\mathrm{K}_{\mathrm{ATP}}$ channels are critically involved in many physiological processes. In vascular smooth muscle cells they significantly influence vascular smooth tone and both vasodilators and vasoconstrictors can modulate activity through direct protein phosphorylation of the channel subunits. 
Figure $8-A$ cartoon of stimulus-secretion coupling in pancreatic $\beta$ cells. $\mathrm{K}_{\mathrm{ATP}}$ channels couple cellular metabolism to electrical activity. When blood glucose is low, ATP production is reduced allowing $\mathrm{K}_{\text {ATP }}$ channels to open thus hyperpolarising the membrane and preventing an increase intracellular $\mathrm{Ca}^{2+}$ and subsequent insulin release. When there is a high blood glucose concentration, ATP production increases leading to channel inhibition, an increase in intracellular $\mathrm{Ca}^{2+}$ and insulin release.

Figure 8 Teaching points: $\mathrm{K}_{\mathrm{ATP}}$ channels are critically involved in many physiological processes. The best described are their role in stimulus secretion coupling in the pancreas. Increases in blood glucose are tightly coupled to ATP production in pancreatic beta resulting in channel inhibition, membrane depolarisation and entry of calcium which promotes the release of insulin vesicles.

Figure 9 - Disease mechanisms in hereditary channelopathies. The route to delivery of fully and normally functioning ion channels at the cell membrane can be halted or disturbed at various checkpoints. Mutations can lead to: (1) Defective transcription or translation such that channel proteins are merely not synthesised at all. (2) Aberrant folding of channel proteins into their tertiary and quaternary structures that is recognised by chaperone proteins in the endoplasmic reticulum and leads to their degradation and failure to exit the endoplasmic reticulum. (3) Further quality control in the golgi complex where channels can still be recognised as faulty and retro-translocated back to the endoplasmic reticulum or assigned for degradation. (4) Defective cycling to and from the membrane through exo- and endocytosis. (5) Channels that pass through all the checkpoints and are delivered to the membrane but which display abnormal gating and/or kinetics, or abnormal responses to modulatory pathways. 
Figure 9 Teaching points: An emerging theme has been the involvement of ion channels in human disease known as "channelopathies". For example, defects in $\mathrm{K}_{\mathrm{ATP}}$ channels lead to disorders of insulin handling through gain and loss of function mutations. This can occur through many different mechanisms and not simply changes in the activity of the channel at the plasma membrane. Differences in channel trafficking through the secretory pathway and in endocytosis may also be involved.

Figure 10 - The pathogenesis of hereditary hyperinsulinism and diabetes due to mutations in $K_{A T P}$ channels. Loss of function mutations leads to excessive insulin release and hypoglycaemia. In contrast, gain of function mutation affect ATP sensitivity and impair insulin release from pancreatic beta cells resulting in diabetes.

Figure 10 Teaching points: The critical role of role of $\mathrm{K}_{\mathrm{ATP}}$ channels in insulin release is reinforced by human hereditary diseases of both excessive and reduced insulin release which result from mutations in the genes underlying subunits of $\mathrm{K}_{\mathrm{ATP}}$ channels.

Figure 11 - Protective role of $K_{A T P}$ channels in cardiomyocytes. Activation of $\mathrm{K}_{\mathrm{ATP}}$ channels by protein kinase $\mathrm{C}$ or metabolic insults such as ischemia and/or hypoxia stabilises the membrane potential, leads to shortening of the action potential duration and reduces the influx of calcium through voltage dependent calcium channels. This attenuates calciuminduced calcium release from the sarcoplasmic reticulum which reduces contractility, prevents calcium overload and decreases ATP demand. 
Figure 11 Teaching points: $\mathrm{K}_{\text {ATP }}$ channels in the heart and elsewhere are protective to the cell. One of the main ideas in the heart is that this limits calcium entry and release reducing muscle contraction, calcium overload and ATP demand.

\section{Cross-References to Comprehensive Physiology}

Ion channels in the heart (Cardiovascular Physiology) Daniel C. Bartos, Eleonora Grandi, Crystal M. Ripplinger 10.1002/cphy.c140069 Source: Volume 5, Issue 3, July 2015

Smooth Muscle Ion Channels and Regulation of Vascular Tone in Resistance Arteries and Arterioles Nathan R. Tykocki, Erika M. Boerman, William F. Jackson 10.1002/cphy.c160011 Source: Volume 7, Issue 2, April 2017

Substrate Control of Insulin Release Christopher B. Newgard, Franz M. Matschinsky 10.1002/cphy.cp070205 Source: Supplement 21: Handbook of Physiology, The Endocrine System, The Endocrine Pancreas and Regulation of Metabolism

K+ Channels: Function-Structural Overview Carlos González, David Baez-Nieto, Ignacio Valencia, Ingrid Oyarzún, Patricio Rojas, David Naranjo, Ramón Latorre 10.1002/cphy.c110047 Source: Volume 2, Issue 3, July 2012

Regulation of Ion Channels by Membrane Lipids Avia Rosenhouse-Dantsker, Dolly Mehta, Irena Levitan 10.1002/cphy.c110001 Source: Volume 2, Issue 1, January 2012 


\section{References}

1. Aguilar Bryan L, Nichols CG, Wechsler SW, Clement JP4, Boyd AE, Gonzalez G, Herrera Sosa H, Nguy K, Bryan J and Nelson DA. Cloning of the beta cell high-affinity sulfonylurea receptor: a regulator of insulin secretion. Science 268: 423 426, 1995.

2. Alekseev AE, Reyes S, Yamada S, Hodgson-Zingman DM, Sattiraju S, Zhu Z, Sierra A, Gerbin M, Coetzee WA, Goldhamer DJ, Terzic A and Zingman LV. Sarcolemmal ATP-sensitive $\mathrm{K}(+)$ channels control energy expenditure determining body weight. Cell Metab 11: 58-69, 2010.

3. Allen TG and Brown DA. Modulation of the excitability of cholinergic basal forebrain neurones by KATP channels. $J$ Physiol 554: 353-370, 2004.

4. Almond SC and Paterson DJ. Sulphonylurea-sensitive channels and NO-cGMP pathway modulate the heart rate response to vagal nerve stimulation in vitro. $J \mathrm{Mol}$ Cell Cardiol 32: 2065-2073, 2000.

5. Antcliff JF, Haidar S, Proks P, Sansom MS and Ashcroft FM. Functional analysis of a structural model of the ATP-binding site of the KATP channel Kir6.2 subunit. EMBO J 24: 229-239, 2005.

6. Antzelevitch C. Genetic, molecular and cellular mechanisms underlying the J wave syndromes. Circ J 76: 1054-1065, 2012. 
7. Arakel EC, Brandenburg S, Uchida K, Zhang H, Lin YW, Kohl T, Schrul B, Sulkin MS, Efimov IR, Nichols CG, Lehnart SE and Schwappach B. Tuning the electrical properties of the heart by differential trafficking of KATP ion channel complexes. J Cell Sci 127: 2106-2119, 2014.

8. Ardehali H, Chen Z, Ko Y, Mejia-Alvarez R and Marban E. Multiprotein complex containing succinate dehydrogenase confers mitochondrial ATP-sensitive $\mathrm{K}+$ channel activity. Proc Natl Acad Sci U S A 101: 11880-11885, 2004.

9. Ashcroft FM, Harrison DE and Ashcroft SJ. Glucose induces closure of single potassium channels in isolated rat pancreatic beta-cells. Nature 312: 446-448, 1984.

10. Ashcroft FM and Kakei M. ATP-sensitive $\mathrm{K}+$ channels in rat pancreatic beta-cells: modulation by ATP and Mg2+ ions. J Physiol 416: 349-367, 1989.

11. Ashcroft FM, Kakei M, Gibson JS, Gray DW and Sutton R. The ATP- and tolbutamide-sensitivity of the ATP-sensitive K-channel from human pancreatic B cells. Diabetologia 32: 591-598, 1989.

12. Ashcroft FM, Kakei M, Kelly RP and Sutton R. ATP-sensitive $\mathrm{K}+$ channels in human isolated pancreatic B-cells. FEBS Lett 215: 9-12, 1987.

13. Ashcroft FM, Puljung MC and Vedovato N. Neonatal Diabetes and the KATP Channel: From Mutation to Therapy. Trends Endocrinol Metab 28: 377-387, 2017.

14. Ashcroft FM and Rorsman P. K(ATP) channels and islet hormone secretion: new 
insights and controversies. Nat Rev Endocrinol 9: 660-669, 2013.

15. Ashcroft SJ and Ashcroft FM. Properties and functions of ATP-sensitive Kchannels. Cell Signal 2: 197-214, 1990.

16. Ashfield R, Gribble FM, Ashcroft SJ and Ashcroft FM. Identification of the highaffinity tolbutamide site on the SUR1 subunit of the K(ATP) channel. Diabetes 48 : 1341-1347, 1999.

17. Ashford ML, Boden PR and Treherne JM. Glucose-induced excitation of hypothalamic neurones is mediated by ATP-sensitive K+ channels. Pflugers Arch 415: 479-483, 1990.

18. Ashford ML, Sturgess NC, Trout NJ, Gardner NJ and Hales CN. Adenosine-5'triphosphate-sensitive ion channels in neonatal rat cultured central neurones. Pflugers Arch 412: 297-304, 1988.

19. Avshalumov MV and Rice ME. Activation of ATP-sensitive K+ (K(ATP)) channels by $\mathrm{H} 2 \mathrm{O} 2$ underlies glutamate-dependent inhibition of striatal dopamine release. Proc Natl Acad Sci U S A 100: 11729-11734, 2003.

20. Aziz Q, Li Y, Anderson N, Ojake L, Tsisanova E and Tinker A. Molecular and functional characterization of the endothelial ATP-sensitive potassium channel. J Biol Chem 292: 17587, 2017.

21. Aziz Q, Thomas A, Khambra T and Tinker A. Phenformin has a direct inhibitory 
effect on the ATP-sensitive potassium channel. Eur J Pharmacol 634: 26-32, 2010.

22. Aziz Q, Thomas AM, Gomes J, Ang R, Sones WR, Li Y, Ng KE, Gee L and Tinker A. The ATP-Sensitive Potassium Channel Subunit, Kir6.1, in Vascular Smooth Muscle Plays a Major Role in Blood Pressure Control. Hypertension 64: 523-529, 2014.

23. Aziz Q, Thomas AM, Khambra T and Tinker A. Regulation of the ATP-sensitive potassium channel subunit, Kir6.2, by a Ca2+-dependent protein kinase C. J Biol Chem 287: 6196-6207, 2012.

24. Babenko AP and Bryan J. A conserved inhibitory and differential stimulatory action of nucleotides on K(IR)6.0/SUR complexes is essential for excitation- metabolism coupling by K(ATP) channels. J Biol Chem 276: 49083-49092, 2001.

25. Babenko AP, Gonzalez G and Bryan J. Pharmaco-topology of sulfonylurea receptors. Separate domains of the regulatory subunits of K(ATP) channel isoforms are required for selective interaction with $\mathrm{K}(+)$ channel openers. $J$ Biol Chem 275: 717-720, 2000.

26. Babenko AP, Polak M, Cave H, Busiah K, Czernichow P, Scharfmann R, Bryan J, Aguilar-Bryan L, Vaxillaire $\mathbf{M}$ and Froguel $\mathbf{P}$. Activating mutations in the ABCC8 gene in neonatal diabetes mellitus. N Engl J Med 355: 456-466, 2006.

27. Babiker T, Vedovato N, Patel K, Thomas N, Finn R, Mannikko R, Chakera AJ, Flanagan SE, Shepherd MH, Ellard S, Ashcroft FM and Hattersley AT. 
Successful transfer to sulfonylureas in KCNJ11 neonatal diabetes is determined by the mutation and duration of diabetes. Diabetologia 59: 1162-1166, 2016.

28. Balana B, Dobrev D, Wettwer E, Christ T, Knaut M and Ravens U. Decreased ATP-sensitive $\mathrm{K}(+)$ current density during chronic human atrial fibrillation. $J$ Mol Cell Cardiol 35: 1399-1405, 2003.

29. Ballanyi K. Protective role of neuronal KATP channels in brain hypoxia. J Exp Biol 207: 3201-3212, 2004.

30. Bao L, Hadjiolova K, Coetzee WA and Rindler MJ. Endosomal KATP channels as a reservoir after myocardial ischemia: a role for SUR2 subunits. Am J Physiol Heart Circ Physiol 300: H262-H270, 2011.

31. Bao L, Kefaloyianni E, Lader J, Hong M, Morley G, Fishman GI, Sobie EA and Coetzee WA. Unique properties of the ATP-sensitive $\mathrm{K}(+)$ channel in the mouse ventricular cardiac conduction system. Circ Arrhythm Electrophysiol 4: 926-935, 2011.

32. Barajas-Martinez H, Hu D, Ferrer T, Onetti CG, Wu Y, Burashnikov E, Boyle M, Surman T, Urrutia J, Veltmann C, Schimpf R, Borggrefe M, Wolpert C, Ibrahim BB, Sanchez-Chapula JA, Winters S, Haissaguerre M and Antzelevitch C. Molecular genetic and functional association of Brugada and early repolarization syndromes with S422L missense mutation in KCNJ8. Heart Rhythm 9: 548-555, 2012. 
33. Baron A, van Bever L, Monnier D, Roatti A and Baertschi AJ. A novel K(ATP) current in cultured neonatal rat atrial appendage cardiomyocytes. Circ Res 85: 707$715,1999$.

34. Barwell J, Wheatley M, Conner AC, Taddese B, Vohra S, Reynolds CA and Poyner DR. The activation of the CGRP receptor. Biochem Soc Trans 41: 180-184, 2013.

35. Basalay MV, Mastitskaya S, Mrochek A, Ackland GL, Del Arroyo AG, Sanchez J, Sjoquist PO, Pernow J, Gourine AV and Gourine A. Glucagon-like peptide-1 (GLP-1) mediates cardioprotection by remote ischaemic conditioning. Cardiovasc Res 112: 669-676, 2016.

36. Basco D, Zhang Q, Salehi A, Tarasov A, Dolci W, Herrera P, Spiliotis I, Berney X, Tarussio D, Rorsman P and Thorens B. alpha-cell glucokinase suppresses glucoseregulated glucagon secretion. Nat Commun 9: 546, 2018.

37. Baukrowitz T, Schulte U, Oliver D, Herlitze S, Krauter T, Tucker SJ, Ruppersberg JP and Fakler B. PIP ${ }_{2}$ and PIP as Determinants for ATP Inhibition of $\mathrm{K}_{\mathrm{ATP}}$ Channels. Science 282: 1141-1144, 1998.

38. Beech DJ, Zhang H, Nakao K and Bolton TB. K channel activation by nucleotide diphosphates and its inhibition by glibenclamide in vascular smooth muscle cells. $\mathrm{Br} J$ Pharmacol 110: 573-582, 1993.

39. Beltrand J, Elie C, Busiah K, Fournier E, Boddaert N, Bahi-Buisson N, Vera M, 


\section{Bui-Quoc E, Ingster-Moati I, Berdugo M, Simon A, Gozalo C, Djerada Z, Flechtner I, Treluyer JM, Scharfmann R, Cave H, Vaivre-Douret L and Polak M.}

Sulfonylurea Therapy Benefits Neurological and Psychomotor Functions in Patients With Neonatal Diabetes Owing to Potassium Channel Mutations. Diabetes Care 38: 2033-2041, 2015.

40. Bennett PB and Begenisich TB. Catecholamines modulate the delayed rectifying potassium current (IK) in guinea pig ventricular myocytes. Pflugers Arch 410: 217 219, 1987.

41. Berridge MJ. Inositol trisphosphate and calcium signalling mechanisms. Biochim Biophys Acta 1793: 933-940, 2009.

42. Bienengraeber M, Alekseev AE, Abraham MR, Carrasco AJ, Moreau C, Vivaudou M, Dzeja PP and Terzic A. ATPase activity of the sulfonylurea receptor: a catalytic function for the KATP channel complex. FASEB J 14: 1943-1952, 2000.

43. Bienengraeber M, Olson TM, Selivanov VA, Kathmann EC, O'Cochlain F, Gao F, Karger AB, Ballew JD, Hodgson DM, Zingman LV, Pang YP, Alekseev AE and Terzic A. ABCC9 mutations identified in human dilated cardiomyopathy disrupt catalytic KATP channel gating. Nat Genet 36: 382-387, 2004.

44. Billman GE, Englert HC and Scholkens BA. HMR 1883, a novel cardioselective inhibitor of the ATP-sensitive potassium channel. Part II: effects on susceptibility to ventricular fibrillation induced by myocardial ischemia in conscious dogs. $J$ Pharmacol Exp Ther 286: 1465-1473, 1998. 
45. Birnbaumer L. Expansion of signal transduction by $\mathrm{G}$ proteins. The second 15 years or so: from 3 to 16 alpha subunits plus betagamma dimers. Biochim Biophys Acta 1768: 772-793, 2007.

46. Birnbaumer $\mathbf{L}$. The discovery of signal transduction by $\mathrm{G}$ proteins: a personal account and an overview of the initial findings and contributions that led to our present understanding. Biochim Biophys Acta 1768: 756-771, 2007.

47. Blanco-Rivero J, Gamallo C, Aras-Lopez R, Cobeno L, Cogolludo A, PerezVizcaino F, Ferrer M and Balfagon G. Decreased expression of aortic KIR6.1 and SUR2B in hypertension does not correlate with changes in the functional role of K(ATP) channels. Eur J Pharmacol 587: 204-208, 2008.

48. Bokvist K, Olsen HL, Hoy M, Gotfredsen CF, Holmes WF, Buschard K, Rorsman P and Gromada J. Characterisation of sulphonylurea and ATP-regulated $\mathrm{K}+$ channels in rat pancreatic A-cells. Pflugers Arch 438: 428-436, 1999.

49. Bolotina VM, Najibi S, Palacino JJ, Pagano PJ and Cohen RA. Nitric oxide directly activates calcium-dependent potassium channels in vascular smooth muscle. Nature 368: 850-853, 1994.

50. Bonev AD and Nelson MT. Vasoconstrictors inhibit ATP-sensitive K+ channels in arterial smooth muscle through protein kinase C. J Gen Physiol 108: 315-323, 1996.

51. Branstrom R, Corkey BE, Berggren PO and Larsson O. Evidence for a unique long chain acyl-CoA ester binding site on the ATP-regulated potassium channel in 
mouse pancreatic beta cells. J Biol Chem 272: 17390-17394, 1997.

52. Bray KM and Quast U. A specific binding site for $\mathrm{K}+$ channel openers in rat aorta. $J$ Biol Chem 267: 11689-11692, 1992.

53. Breen EG, Mulhall D and Keogh JA. Treatment of essential hypertension and hypertension associated with renal impairment with pinacidil: a new vasodilator. Eur J Clin Pharmacol 28: 381-386, 1985.

54. Brennan S, Jackson R, Patel M, Sims MW, Hudman D, Norman RI, Lodwick D and Rainbow RD. Early opening of sarcolemmal ATP-sensitive potassium channels is not a key step in PKC-mediated cardioprotection. J Mol Cell Cardiol 79: 42-53, 2015.

55. Brereton MF, Rohm M, Shimomura K, Holland C, Tornovsky-Babeay S, Dadon D, Iberl M, Chibalina MV, Lee S, Glaser B, Dor Y, Rorsman P, Clark A and Ashcroft FM. Hyperglycaemia induces metabolic dysfunction and glycogen accumulation in pancreatic beta-cells. Nat Commun 7: 13496, 2016.

56. Brown DA and Adams PR. Muscarinic suppression of a novel voltage-sensitive K+ current in a vertebrate neurone. Nature 283: 673-676, 1980.

57. Brownstein CA, Towne MC, Luquette LJ, Harris DJ, Marinakis NS, Meinecke P, Kutsche K, Campeau PM, Yu TW, Margulies DM, Agrawal PB and Beggs AH. Mutation of KCNJ8 in a patient with Cantu syndrome with unique vascular abnormalities - support for the role of K(ATP) channels in this condition. Eur J Med 
Genet 56: 678-682, 2013.

58. Budas GR, Jovanovic S, Crawford RM and Jovanovic A. Hypoxia-induced preconditioning in adult stimulated cardiomyocytes is mediated by the opening and trafficking of sarcolemmal KATP channels. FASEB J 2004.

59. Budzik J, Omer S, Morris JF and Christian HC. Vascular endothelial growth factor secretion from pituitary folliculostellate cells: role of KATP channels. $J$ Neuroendocrinol 26: 111-120, 2014.

60. Butt AM and Kalsi A. Inwardly rectifying potassium channels (Kir) in central nervous system glia: a special role for Kir4.1 in glial functions. J Cell Mol Med 10: 33-44, 2006.

61. Bylund DB, Eikenberg DC, Hieble JP, Langer SZ, Lefkowitz RJ, Minneman KP, Molinoff PB, Ruffolo RR, Jr. and Trendelenburg U. International Union of Pharmacology nomenclature of adrenoceptors. Pharmacol Rev 46: 121-136, 1994.

62. Cantu JM, Sanchez-Corona J, Hernandes A, Nazara Z and Garcia-Cruz D. Individualization of a syndrome with mental deficiency, macrocranium, peculiar facies, and cardiac and skeletal anomalies. Clin Genet 22: 172-179, 1982.

63. Carlsen JE, Kardel T, Jensen HA, Tango M and Trap-Jensen J. Pinacidil, a new vasodilator: pharmacokinetics and pharmacodynamics of a new retarded release tablet in essential hypertension. Eur J Clin Pharmacol 25: 557-561, 1983. 
64. Carrasco AJ, Dzeja PP, Alekseev AE, Pucar D, Zingman LV, Abraham MR, Hodgson D, Bienengraeber M, Puceat M, Janssen E, Wieringa B and Terzic A. Adenylate kinase phosphotransfer communicates cellular energetic signals to ATPsensitive potassium channels. Proc Natl Acad Sci U S A 98: 7623-7628, 2001.

65. Cartier EA, Conti LR, Vandenberg CA and Shyng SL. Defective trafficking and function of KATP channels caused by a sulfonylurea receptor 1 mutation associated with persistent hyperinsulinemic hypoglycemia of infancy. Proc Natl Acad Sci U S A 98: 2882-2887, 2001.

66. Chan KW, Zhang $\mathbf{H}$ and Logothetis DE. N-terminal transmembrane domain of the SUR controls trafficking and gating of Kir6 channel subunits. EMBO J 22: 38333843, 2003.

67. Chen L, Zhang J, Ding Y, Li H, Nie L, Yan X, Zhou H and Zheng Y. K(ATP) channels of parafacial respiratory group (pFRG) neurons are involved in H2Smediated central inhibition of respiratory rhythm in medullary slices of neonatal rats. Brain Res 1527: 141-148, 2013.

68. Chen PC, Bruederle CE, Gaisano HY and Shyng SL. Syntaxin 1A regulates surface expression of beta-cell ATP-sensitive potassium channels. Am J Physiol Cell Physiol 300: C506-C516, 2011.

69. Cheng KT, Rosenhouse-Dantsker A and Malik AB. Contribution and Regulation of Calcium Channels in Endothelial Cells. In: Vascular Ion Channels in Physiology and Disease, edited by Levitan I and Dopicko AM. Cham: Springer International 
Publishing, 2016, p. 37-62.

70. Cheng WW, Tong A, Flagg TP and Nichols CG. Random assembly of SUR subunits in K(ATP) channel complexes. Channels (Austin) 2: 34-38, 2008.

71. Cheng Y, Ndisang JF, Tang G, Cao K and Wang R. Hydrogen sulfide-induced relaxation of resistance mesenteric artery beds of rats. Am J Physiol Heart Circ Physiol 287: H2316-H2323, 2004.

72. Chi L, Uprichard AC and Lucchesi BR. Profibrillatory actions of pinacidil in a conscious canine model of sudden coronary death. J Cardiovasc Pharmacol 15: 452464, 1990.

73. Choeiri C, Staines WA, Miki T, Seino S, Renaud JM, Teutenberg K and Messier C. Cerebral glucose transporters expression and spatial learning in the K-ATP Kir6.2(/-) knockout mice. Behav Brain Res 172: 233-239, 2006.

74. Chutkow WA, Pu J, Wheeler MT, Wada T, Makielski JC, Burant CF and McNally EM. Episodic coronary artery vasospasm and hypertension develop in the absence of Sur2 K(ATP) channels. J Clin Invest 110: 203-208, 2002.

\section{Chutkow WA, Samuel V, Hansen PA, Pu J, Valdivia CR, Makielski JC and} Burant CF. Disruption of Sur2-containing K(ATP) channels enhances insulinstimulated glucose uptake in skeletal muscle. Proc Natl Acad Sci U S A 98: 1176011764, 2001. 
76. Chutkow WA, Simon MC, Le Beau MM and Burant CF. Cloning, tissue expression, and chromosomal localization of SUR2, the putative drug-binding subunit of cardiac, skeletal muscle, and vascular KATP channels. Diabetes 45: 1439-1445, 1996.

77. Cifelli C, Boudreault L, Gong B, Bercier JP and Renaud JM. Contractile dysfunctions in ATP-dependent $\mathrm{K}+$ channel-deficient mouse muscle during fatigue involve excessive depolarization and $\mathrm{Ca} 2+$ influx through L-type $\mathrm{Ca} 2+$ channels. Exp Physiol 93: 1126-1138, 2008.

78. Clapham JC, Trail BK and Hamilton TC. K+ channel activators, acute glucose tolerance and glibenclamide-induced hypoglycaemia in the hypertensive rat. Eur $J$ Pharmacol 257: 79-85, 1994.

79. Clapp LH and Tinker A. Potassium channels in the vasculature. Curr Opin Nephrol Hypertens 7: 91-98, 1998.

80. Claret M, Smith MA, Batterham RL, Selman C, Choudhury AI, Fryer LG, Clements M, Al-Qassab H, Heffron H, Xu AW, Speakman JR, Barsh GS, Viollet B, Vaulont S, Ashford ML, Carling D and Withers DJ. AMPK is essential for energy homeostasis regulation and glucose sensing by POMC and AgRP neurons. $J$ Clin Invest 117: 2325-2336, 2007.

81. Clark R, Mannikko R, Stuckey DJ, Iberl M, Clarke K and Ashcroft FM. Mice expressing a human K(ATP) channel mutation have altered channel ATP sensitivity but no cardiac abnormalities. Diabetologia 55: 1195-1204, 2012. 
82. Clark RH, McTaggart JS, Webster R, Mannikko R, Iberl M, Sim XL, Rorsman P, Glitsch M, Beeson D and Ashcroft FM. Muscle dysfunction caused by a KATP channel mutation in neonatal diabetes is neuronal in origin. Science 329: 458-461, 2010.

83. Clement JP4, Kunjilwar K, Gonzalez G, Schwanstecher M, Panten U, Aguilar Bryan L and Bryan J. Association and stoichiometry of K(ATP) channel subunits. Neuron 18: 827-838, 1997.

84. Clerk A, Cullingford TE, Fuller SJ, Giraldo A, Markou T, Pikkarainen S and Sugden PH. Signaling pathways mediating cardiac myocyte gene expression in physiological and stress responses. J Cell Physiol 212: 311-322, 2007.

85. Cole WC, Malcolm T, Walsh MP and Light PE. Inhibition by protein kinase $\mathrm{C}$ of the K(NDP) subtype of vascular smooth muscle ATP-sensitive potassium channel. Circ Res 87: 112-117, 2000.

86. Colquhoun D. Binding, gating, affinity and efficacy: the interpretation of structureactivity relationships for agonists and of the effects of mutating receptors. $\mathrm{Br} J$ Pharmacol 125: 924-947, 1998.

87. Conti LR, Radeke CM, Shyng SL and Vandenberg CA. Transmembrane topology of the sulfonylurea receptor SUR1. J Biol Chem 276: 41270-41278, 2001.

88. Cook DL and Hales CN. Intracellular ATP directly blocks $\mathrm{K}+$ channels in pancreatic B-cells. Nature 311: 271-273, 1984. 
89. Cook NS, Quast U, Hof RP, Baumlin Y and Pally C. Similarities in the mechanism of action of two new vasodilator drugs: pinacidil and BRL 34915. J Cardiovasc Pharmacol 11: 90-99, 1988.

90. Cooper PE, McClenaghan C, Chen X, Stary-Weinzinger A and Nichols CG. Conserved functional consequences of disease-associated mutations in the slide-helix of Kir6.1 and Kir6.2 subunits of the ATP-sensitive potassium channel. J Biol Chem 2017.

91. Cooper PE, Reutter H, Woelfle J, Engels H, Grange DK, van HG, van Bon BW, Hoischen A and Nichols CG. Cantu syndrome resulting from activating mutation in the KCNJ8 gene. Hum Mutat 35: 809-813, 2014.

92. Cooper PE, Sala-Rabanal M, Lee SJ and Nichols CG. Differential mechanisms of Cantu syndrome-associated gain of function mutations in the ABCC9 (SUR2) subunit of the KATP channel. J Gen Physiol 146: 527-540, 2015.

93. Craig TJ, Shimomura K, Holl RW, Flanagan SE, Ellard S and Ashcroft FM. An in-frame deletion in Kir6.2 (KCNJ11) causing neonatal diabetes reveals a site of interaction between Kir6.2 and SUR1. J Clin Endocrinol Metab 94: 2551-2557, 2009.

94. Crawford RM, Budas GR, Jovanovic S, Ranki HJ, Wilson TJ, Davies AM and Jovanovic A. M-LDH serves as a sarcolemmal K(ATP) channel subunit essential for cell protection against ischemia. EMBO J 21: 3936-3948, 2002.

95. Crawford RM, Ranki HJ, Botting CH, Budas GR and Jovanovic A. Creatine 
kinase is physically associated with the cardiac ATP-sensitive $\mathrm{K}+$ channel in vivo. FASEB J 16: 102-104, 2002.

96. Creba JA, Downes CP, Hawkins PT, Brewster G, Michell RH and Kirk CJ. Rapid breakdown of phosphatidylinositol 4-phosphate and phosphatidylinositol 4,5bisphosphate in rat hepatocytes stimulated by vasopressin and other $\mathrm{Ca} 2+$-mobilizing hormones. Biochem J 212: 733-747, 1983.

97. Croker B, Crozat K, Berger M, Xia Y, Sovath S, Schaffer L, Eleftherianos L, Imler JL and Beutler B. ATP-sensitive potassium channels mediate survival during infection in mammals and insects. Nat Genet 39: 1453-1460, 2007.

98. Cui N, Wu J, Xu H, Wang R, Rojas A, Piao H, Mao J, Abdulkadir L, Li L and Jiang C. A threonine residue (Thr71) at the intracellular end of the M1 helix plays a critical role in the gating of Kir6.2 channels by intracellular ATP and protons. $J$ Membr Biol 192: 111-122, 2003.

99. Cui Y, Giblin JP, Clapp LH and Tinker A. A mechanism for ATP-sensitive potassium channel diversity: functional coassembly of two pore forming subunits. Proc Natl Acad Sci U S A 98: 729-734, 2001.

100. Cui Y, Tinker A and Clapp LH. Different molecular sites of action for the KATP channel inhibitors, PNU-99963 and PNU-37883A. Br J Pharmacol 139: 122-128, 2003.

101. Cui Y, Tran S, Tinker A and Clapp LH. The molecular composition of K(ATP) 
channels in human pulmonary artery smooth muscle cells and their modulation by growth. Am J Respir Cell Mol Biol 26: 135-143, 2002.

102. Cullis PR, Fennske DB and Hope MJ. Physical properties and functional roles of lipids in membranes. In: Biochemistry of Lipids, Lipoproteins and Membranes, edited by Vance DE and Vance JE. Amsterdam: Elsevier, 1996, p. 1-33.

103. D'Avanzo N, Cheng WW, Doyle DA and Nichols CG. Direct and specific activation of human inward rectifier $\mathrm{K}+$ channels by membrane phosphatidylinositol 4,5bisphosphate. J Biol Chem 285: 37129-37132, 2010.

104. D'hahan N, Moreau C, Prost AL, Jacquet H, Alekseev AE, Terzic A and Vivaudou M. Pharmacological plasticity of cardiac ATP-sensitive potassium channels toward diazoxide revealed by ADP. Proc Natl Acad Sci U S A 96: 12162-12167, 1999.

105. Dadak S, Beall C, Vlachaki Walker JM, Soutar MP, McCrimmon RJ and Ashford ML. Oleate induces KATP channel-dependent hyperpolarization in mouse hypothalamic glucose-excited neurons without altering cellular energy charge. Neuroscience 346: 29-42, 2017.

106. Dal-Secco D, Cunha TM, Freitas A, Alves-Filho JC, Souto FO, Fukada SY, Grespan R, Alencar NM, Neto AF, Rossi MA, Ferreira SH, Hothersall JS and Cunha FQ. Hydrogen sulfide augments neutrophil migration through enhancement of adhesion molecule expression and prevention of CXCR2 internalization: role of ATPsensitive potassium channels. $J$ Immunol 181: 4287-4298, 2008. 
107. Dart C and Standen NB. Adenosine-activated potassium current in smooth muscle cells isolated from the pig coronary artery. J Physiol 471: 767-786, 1993.

108. Das M, Parker JE and Halestrap AP. Matrix volume measurements challenge the existence of diazoxide/glibencamide-sensitive KATP channels in rat mitochondria. $J$ Physiol 547: 893-902, 2003.

109. Daut J, Maier-Rudolph W, von Beckerath N, Mehrke G, Gunther K and GoedelMeinen L. Hypoxic dilation of coronary ateries is mediated by ATP-sensitive potassium channels. Science 247: 1341-1344, 1990.

110. Davidson MB, Molnar IG, Furman A and Yamaguchi D. Glyburide-stimulated glucose transport in cultured muscle cells via protein kinase C-mediated pathway requiring new protein synthesis. Diabetes 40: 1531-1538, 1991.

111. Davies NW. Modulation of ATP-sensitive K+ channels in skeletal muscle by intracellular protons. Nature 343: 375-377, 1990.

112. de WH, Mikhailov MV, Fotinou C, Dreger M, Craig TJ, Venien-Bryan C and Ashcroft FM. Studies of the ATPase activity of the ABC protein SUR1. FEBS J 274: 3532-3544, 2007.

113. Deacon RM, Brook RC, Meyer D, Haeckel O, Ashcroft FM, Miki T, Seino S and Liss B. Behavioral phenotyping of mice lacking the K ATP channel subunit Kir6.2. Physiol Behav 87: 723-733, 2006. 
114. Delaney JT, Muhammad R, Blair MA, Kor K, Fish FA, Roden DM and Darbar D. A KCNJ8 mutation associated with early repolarization and atrial fibrillation. Europace 14: 1428-1432, 2012.

115. Dhar-Chowdhury P, Harrell MD, Han SY, Jankowska D, Parachuru L, Morrissey A, Srivastava S, Liu W, Malester B, Yoshida H and Coetzee WA. The glycolytic enzymes, glyceraldehyde-3-phosphate dehydrogenase, triose-phosphate isomerase, and pyruvate kinase are components of the K(ATP) channel macromolecular complex and regulate its function. J Biol Chem 280: 38464-38470, 2005.

116. Di Diego JM and Antzelevitch C. Pinacidil-induced electrical heterogeneity and extrasystolic activity in canine ventricular tissues. Does activation of ATP-regulated potassium current promote phase 2 reentry? Circulation 88: 1177-1189, 1993.

117. Doring F, Wischmeyer E, Kuhnlein RP, Jackle $\mathbf{H}$ and Karschin A. Inwardly rectifying $\mathrm{K}+$ (Kir) channels in Drosophila. A crucial role of cellular milieu factors Kir channel function. J Biol Chem 277: 25554-25561, 2002.

118. Doyle DA, Cabral JM, Pfuetzner RA, Kuo A, Gulbis JM, Cohen SL, Chait BT and MacKinnon $\mathbf{R}$. The structure of the potassium channel: molecular basis of $\mathrm{K}+$ conduction and selectivity. Science 280: 69-77, 1998.

119. Du Q, Jovanovic S, Clelland A, Sukhodub A, Budas G, Phelan K, Murray-Tait V, Malone L and Jovanovic A. Overexpression of SUR2A generates a cardiac phenotype resistant to ischemia. FASEB J 20: 1131-1141, 2006. 
120. Duchen MR, Smith PA and Ashcroft FM. Substrate-dependent changes in mitochondrial function, intracellular free calcium concentration and membrane channels in pancreatic beta-cells. Biochem J 294 ( Pt 1): 35-42, 1993.

121. Dunn-Meynell AA, Rawson NE and Levin BE. Distribution and phenotype of neurons containing the ATP-sensitive K+ channel in rat brain. Brain Res 814: 41-54, 1998.

122. Dunne MJ, Cosgrove KE, Shepherd RM, Aynsley-Green A and Lindley KJ. Hyperinsulinism in infancy: from basic science to clinical disease. Physiol Rev 84: 239-275, 2004.

123. Dunne MJ, Kane C, Shepherd RM, Sanchez JA, James RF, Johnson PR, Aynsley Green A, Lu S, Clement JP4, Lindley KJ, Seino S and Aguilar Bryan L. Familial persistent hyperinsulinemic hypoglycemia of infancy and mutations in the sulfonylurea receptor. $N$ Engl J Med 336: 703-706, 1997.

124. Dzeja PP and Terzic A. Phosphotransfer networks and cellular energetics. J Exp Biol 206: 2039-2047, 2003.

125. Eaton MJ, Skatchkov SN, Brune A, Biedermann B, Veh RW and Reichenbach A. SURI and Kir6.1 subunits of K(ATP)-channels are co-localized in retinal glial (Muller) cells. Neuroreport 13: 57-60, 2002.

126. Eleftherianos I, Won S, Chtarbanova S, Squiban B, Ocorr K, Bodmer R, Beutler B, Hoffmann JA and Imler JL. ATP-sensitive potassium channel (K(ATP))- 
dependent regulation of cardiotropic viral infections. Proc Natl Acad Sci U S A 108: 12024-12029, 2011.

127. Elrod JW, Harrell M, Flagg TP, Gundewar S, Magnuson MA, Nichols CG, Coetzee WA and Lefer DJ. Role of sulfonylurea receptor type 1 subunits of ATPsensitive potassium channels in myocardial ischemia/reperfusion injury. Circulation 117: 1405-1413, 2008.

128. Emfinger CH, Welscher A, Yan Z, Wang Y, Conway H, Moss JB, Moss LG, Remedi MS and Nichols CG. Expression and function of ATP-dependent potassium channels in zebrafish islet beta-cells. $R$ Soc Open Sci 4: 160808, 2017.

129. Enkvetchakul D, Loussouarn G, Makhina E, Shyng SL and Nichols CG. The kinetic and physical basis of K(ATP) channel gating: toward a unified molecular understanding. Biophys $J$ 78: 2334-2348, 2000.

130. Enkvetchakul D and Nichols CG. Gating mechanism of KATP channels: function fits form. J Gen Physiol 122: 471-480, 2003.

131. Fahrenbach JP, Stoller D, Kim G, Aggarwal N, Yerokun B, Earley JU, Hadhazy M, Shi NQ, Makielski JC and McNally EM. Abcc9 is required for the transition to oxidative metabolism in the newborn heart. FASEB $J 2014$.

132. Fan Z and Makielski JC. Anionic phospholipids activate ATP-sensitive potassium channels. Journal of Biological Chemistry 272: 5388-5395, 1997. 
133. Farid TA, Nair K, Masse S, Azam MA, Maguy A, Lai PF, Umapathy K, Dorian P, Chauhan V, Varro A, Al-Hesayen A, Waxman M, Nattel S and Nanthakumar K. Role of KATP channels in the maintenance of ventricular fibrillation in cardiomyopathic human hearts. Circ Res 109: 1309-1318, 2011.

134. Farzaneh $\mathbf{T}$ and Tinker A. Differences in the mechanism of metabolic regulation of ATP-sensitive K+ channels containing Kir6.1 and Kir6.2 subunits. Cardiovasc Res 79: 621-631, 2008.

135. Fatehi M, Carter CC, Youssef $\mathbf{N}$ and Light PE. The mechano-sensitivity of cardiac ATP-sensitive potassium channels is mediated by intrinsic MgATPase activity. $J$ Mol Cell Cardiol 108: 34-41, 2017.

136. Fedorov VV, Glukhov AV, Ambrosi CM, Kostecki G, Chang R, Janks D, Schuessler RB, Moazami N, Nichols CG and Efimov IR. Effects of KATP channel openers diazoxide and pinacidil in coronary-perfused atria and ventricles from failing and non-failing human hearts. J Mol Cell Cardiol 51: 215-225, 2011.

137. Felsch H, Lange U, Hambrock A, Loffler-Walz C, Russ U, Carroll WA, Gopalakrishnan M and Quast U. Interaction of a novel dihydropyridine K+ channel opener, A-312110, with recombinant sulphonylurea receptors and KATP channels: comparison with the cyanoguanidine P1075. Br J Pharmacol 141: 1098-1105, 2004.

138. Fendler W, Pietrzak I, Brereton MF, Lahmann C, Gadzicki M, Bienkiewicz M, Drozdz I, Borowiec M, Malecki MT, Ashcroft FM and Mlynarski WM. Switching to sulphonylureas in children with iDEND syndrome caused by KCNJ11 mutations 
results in improved cerebellar perfusion. Diabetes Care 36: 2311-2316, 2013.

139. Fernandes VS, Ribeiro AS, Barahona MV, Orensanz LM, Martinez-Saenz A, Recio P, Martinez AC, Bustamante S, Carballido J, Garcia-Sacristan A, Prieto D and Hernandez M. Hydrogen sulfide mediated inhibitory neurotransmission to the pig bladder neck: role of KATP channels, sensory nerves and calcium signaling. $J$ Urol 190: 746-756, 2013.

140. Ficker E, Taglialatela M, Wible BA, Henley CM and Brown AM. Spermine and spermidine as gating molecules for inward rectifier K+ channels. Science 266: 10681072, 1994.

141. Figura M, Chilton L, Liacini A, Viskovic MM, Phan V, Knight D, Millar TM, Patel K, Kubes P, Giles WR and Tibbles LA. Blockade of K(ATP) channels reduces endothelial hyperpolarization and leukocyte recruitment upon reperfusion after hypoxia. Am J Transplant 9: 687-696, 2009.

142. Findlay I. ATP-sensitive $\mathrm{K}+$ channels in rat ventricular myocytes are blocked and inactivated by internal divalent cations. Pflugers Arch 410: 313-320, 1987.

143. Findlay I. The effects of magnesium upon adenosine triphosphate-sensitive potassium channels in a rat insulin-secreting cell line. J Physiol 391: 611-629, 1987.

144. Findlay I. Effects of ADP upon the ATP-sensitive K+ channel in rat ventricular myocytes. J Membr Biol 101: 83-92, 1988. 
145. Findlay I and Dunne MJ. ATP maintains ATP-inhibited K+ channels in an operational state. Pflugers Arch 407: 238-240, 1986.

146. Finlay M, Harmer SC and Tinker A. The control of cardiac ventricular excitability by autonomic pathways. Pharmacol Ther 174: 97-111, 2017.

147. Flagg TP, Charpentier F, Manning-Fox J, Remedi MS, Enkvetchakul D, Lopatin A, Koster $\mathbf{J}$ and Nichols $\mathbf{C}$. Remodeling of excitation-contraction coupling in transgenic mice expressing ATP-insensitive sarcolemmal KATP channels. Am J Physiol Heart Circ Physiol 286: H1361-H1369, 2004.

148. Flagg TP, Enkvetchakul D, Koster JC and Nichols CG. Muscle KATP channels: recent insights to energy sensing and myoprotection. Physiol Rev 90: 799-829, 2010.

149. Flagg TP, Kurata HT, Masia R, Caputa G, Magnuson MA, Lefer DJ, Coetzee WA and Nichols CG. Differential structure of atrial and ventricular KATP: atrial KATP channels require SUR1. Circ Res 103: 1458-1465, 2008.

150. Flagg TP, Patton B, Masia R, Mansfield C, Lopatin AN, Yamada KA and Nichols CG. Arrhythmia susceptibility and premature death in transgenic mice overexpressing both SUR1 and Kir6.2[DeltaN30,K185Q] in the heart. Am J Physiol Heart Circ Physiol 293: H836-H845, 2007.

151. Flagg TP, Remedi MS, Masia R, Gomes J, McLerie M, Lopatin AN and Nichols CG. Transgenic overexpression of SUR1 in the heart suppresses sarcolemmal K(ATP). J Mol Cell Cardiol 39: 647-656, 2005. 
152. Flanagan SE, Patch AM, Mackay DJ, Edghill EL, Gloyn AL, Robinson D, Shield JP, Temple K, Ellard S and Hattersley AT. Mutations in ATP-sensitive K+ channel genes cause transient neonatal diabetes and permanent diabetes in childhood or adulthood. Diabetes 56: 1930-1937, 2007.

153. Forbes RA, Steenbergen C and Murphy E. Diazoxide-Induced Cardioprotection Requires Signaling Through a Redox- Sensitive Mechanism. Circ Res 88: 802-809, 2001.

154. Fosset M, De Weille JR, Green RD, Schmid-Antomarchi $H$ and Lazdunski M. Antidiabetic sulfonylureas control action potential properties in heart cells via high affinity receptors that are linked to ATP-dependent $\mathrm{K}+$ channels. J Biol Chem 263: 7933-7936, 1988.

155. Foster CD, Fujii K, Kingdon $\mathbf{J}$ and Brading AF. The effect of cromakalim on the smooth muscle of the guinea-pig urinary bladder. Br J Pharmacol 97: 281-291, 1989.

156. Foster DB, Ho AS, Rucker J, Garlid AO, Chen L, Sidor A, Garlid KD and O'Rourke B. Mitochondrial ROMK Channel Is a Molecular Component of MitoKATP. Circ Res 111: 446-454, 2012.

157. Foster DB, Rucker JJ and Marban E. Is Kir6.1 a subunit of mitoK(ATP)? Biochem Biophys Res Commun 366: 649-656, 2008.

158. Fournet JC, Mayaud C, de Lonlay P, Gross-Morand MS, Verkarre V, Castanet M, Devillers M, Rahier J, Brunelle F, Robert JJ, Nihoul-Fekete C, Saudubray 
JM and Junien C. Unbalanced expression of 11p15 imprinted genes in focal forms of congenital hyperinsulinism: association with a reduction to homozygosity of a mutation in ABCC8 or KCNJ11. Am J Pathol 158: 2177-2184, 2001.

159. Fox JE, Magga J, Giles WR and Light PE. Acyl coenzyme A esters differentially activate cardiac and beta-cell adenosine triphosphate-sensitive potassium channels in a side-chain length-specific manner. Metabolism 52: 1313-1319, 2003.

160. Fujimura N, Tanaka E, Yamamoto S, Shigemori M and Higashi H. Contribution of ATP-sensitive potassium channels to hypoxic hyperpolarization in rat hippocampal CA1 neurons in vitro. J Neurophysiol 77: 378-385, 1997.

161. Fukuzaki K, Sato T, Miki T, Seino S and Nakaya H. Role of sarcolemmal ATPsensitive $\mathrm{K}+$ channels in the regulation of sinoatrial node automaticity: an evaluation using Kir6.2-deficient mice. J Physiol 586: 2767-2778, 2008.

162. Fukuzaki K, Sato T, Miki T, Seino S and Nakaya H. Role of sarcolemmal ATPsensitive $\mathrm{K}+$ channels in the regulation of sinoatrial node automaticity: an evaluation using Kir6.2-deficient mice. J Physiol 586: 2767-2778, 2008.

163. Furukawa T, Kimura S, Furukawa N, Bassett AL and Myerburg RJ. Role of cardiac ATP-regulated potassium channels in differential responses of endocardial and epicardial cells to ischemia. Circ Res 68: 1693-1702, 1991.

164. Furukawa T, Yamane T, Terai T, Katayama Y and Hiraoka M. Functional linkage of the cardiac ATP-sensitive K+ channel to the actin cytoskeleton. Pflugers Arch 431: 
504-512, 1996.

165. Gallacher DJ, Van de Water A, van der Linde H, Hermans AN, Lu HR, Towart R and Volders PG. In vivo mechanisms precipitating torsades de pointes in a canine model of drug-induced long-QT1 syndrome. Cardiovasc Res 76: 247-256, 2007.

166. Gallwitz B. Glucagon-like peptide-1 and gastric inhibitory polypeptide: new advances. Curr Opin Endocrinol Diabetes Obes 23: 23-27, 2016.

167. Gao S, Long CL, Wang RH and Wang H. K(ATP) activation prevents progression of cardiac hypertrophy to failure induced by pressure overload via protecting endothelial function. Cardiovasc Res 83: 444-456, 2009.

168. Garcia de AS, Franke H, Pissarek M, Nieber K and Illes P. Neuroprotection by ATP-dependent potassium channels in rat neocortical brain slices during hypoxia. Neurosci Lett 273: 13-16, 1999.

169. Garlid KD, Paucek P, Yarov-Yarovoy V, Murray HN, Darbenzio RB, D'Alonzo AJ, Lodge NJ, Smith MA and Grover GJ. Cardioprotective effect of diazoxide and its interaction with mitochondrial ATP-sensitive K+ channels. Possible mechanism of cardioprotection. Circ Res 81: 1072-1082, 1997.

170. Garratt KN, Brady PA, Hassinger NL, Grill DE, Terzic A and Holmes DR, Jr. Sulfonylurea drugs increase early mortality in patients with diabetes mellitus after direct angioplasty for acute myocardial infarction. J Am Coll Cardiol 33: 119-124, 1999. 
171. Gaulton KJ, Ferreira T, Lee Y, Raimondo A, Magi R, Reschen ME, Mahajan A, Locke A, Rayner NW, Robertson N, Scott RA, Prokopenko I, Scott LJ, Green T, Sparso T, Thuillier D, Yengo L, Grallert H, Wahl S, Franberg M, Strawbridge RJ, Kestler H, Chheda H, Eisele L, Gustafsson S, Steinthorsdottir V, Thorleifsson G, Qi L, Karssen LC, van Leeuwen EM, Willems SM, Li M, Chen H, Fuchsberger C, Kwan P, Ma C, Linderman M, Lu Y, Thomsen SK, Rundle JK, Beer NL, van de Bunt M, Chalisey A, Kang HM, Voight BF, Abecasis GR, Almgren P, Baldassarre D, Balkau B, Benediktsson R, Bluher M, Boeing H, Bonnycastle LL, Bottinger EP, Burtt NP, Carey J, Charpentier G, Chines PS, Cornelis MC, Couper DJ, Crenshaw AT, van Dam RM, Doney AS, Dorkhan M, Edkins S, Eriksson JG, Esko T, Eury E, Fadista J, Flannick J, Fontanillas P, Fox C, Franks PW, Gertow K, Gieger C, Gigante B, Gottesman O, Grant GB, Grarup N, Groves CJ, Hassinen M, Have CT, Herder C, Holmen OL, Hreidarsson AB, Humphries SE, Hunter DJ, Jackson AU, Jonsson A, Jorgensen ME, Jorgensen T, Kao WH, Kerrison ND, Kinnunen L, Klopp N, Kong A, Kovacs P, Kraft P, Kravic J, Langford C, Leander K, Liang L, Lichtner P, Lindgren CM, Lindholm E, Linneberg A, Liu CT, Lobbens S, Luan J, Lyssenko V, Mannisto S, McLeod O, Meyer J, Mihailov E, Mirza G, Muhleisen TW, Muller-Nurasyid M, Navarro C, Nothen MM, Oskolkov NN, Owen KR, Palli D, Pechlivanis S, Peltonen L, Perry JR, Platou CG, Roden M, Ruderfer D, Rybin D, van der Schouw YT, Sennblad B, Sigurethsson G, Stancakova A, Steinbach G, Storm P, Strauch K, Stringham HM, Sun Q, Thorand B, Tikkanen E, Tonjes A, Trakalo J, Tremoli E, Tuomi T, Wennauer R, Wiltshire S, Wood AR, Zeggini E, Dunham I, Birney E, Pasquali L, Ferrer J, Loos RJ, Dupuis J, Florez JC, Boerwinkle E, Pankow JS, van DC, Sijbrands E, Meigs JB, Hu FB, 
Thorsteinsdottir U, Stefansson K, Lakka TA, Rauramaa R, Stumvoll M, Pedersen NL, Lind L, Keinanen-Kiukaanniemi SM, Korpi-Hyovalti E, Saaristo TE, Saltevo J, Kuusisto J, Laakso M, Metspalu A, Erbel R, Jocke KH, Moebus S, Ripatti S, Salomaa V, Ingelsson E, Boehm BO, Bergman RN, Collins FS, Mohlke KL, Koistinen H, Tuomilehto J, Hveem K, Njolstad I, Deloukas P, Donnelly PJ, Frayling TM, Hattersley AT, de FU, Hamsten A, Illig T, Peters A, Cauchi S, Sladek R, Froguel P, Hansen T, Pedersen O, Morris AD, Palmer CN, Kathiresan S, Melander O, Nilsson PM, Groop LC, Barroso I, Langenberg C, Wareham NJ, O'Callaghan CA, Gloyn AL, Altshuler D, Boehnke M, Teslovich TM, McCarthy MI and Morris AP. Genetic fine mapping and genomic annotation defines causal mechanisms at type 2 diabetes susceptibility loci. Nat Genet 47: 1415-1425, 2015.

172. Giblin JP, Cui Y, Clapp LH and Tinker A. Assembly limits the pharmacological complexity of ATP-sensitive potassium channels. J Biol Chem 277: 13717-13723, 2002.

173. Giblin JP, Leaney JL and Tinker A. The Molecular Assembly of ATP-sensitive Potassium Channels: Determinants on the Pore Forming Subunit. J Biol Chem 274: 22652-22659, 1999.

174. Gilman AG. G proteins: transducers of receptor-generated signals. Annual Review of Biochemistry 56: 615-649, 1987.

175. Girard CA, Shimomura K, Proks P, Absalom N, Castano L, Perez de NG and Ashcroft FM. Functional analysis of six Kir6.2 (KCNJ11) mutations causing neonatal diabetes. Pflugers Arch 453: 323-332, 2006. 
176. Girard CA, Wunderlich FT, Shimomura K, Collins S, Kaizik S, Proks P, Abdulkader F, Clark A, Ball V, Zubcevic L, Bentley L, Clark R, Church C, Hugill A, Galvanovskis J, Cox R, Rorsman P, Bruning JC and Ashcroft FM. Expression of an activating mutation in the gene encoding the KATP channel subunit Kir6.2 in mouse pancreatic beta cells recapitulates neonatal diabetes. $J$ Clin Invest 119: 80-90, 2009.

177. Gloyn AL, Diatloff-Zito C, Edghill EL, Bellanne-Chantelot C, Nivot S, Coutant R, Ellard S, Hattersley AT and Robert JJ. KCNJ11 activating mutations are associated with developmental delay, epilepsy and neonatal diabetes syndrome and other neurological features. Eur J Hum Genet 14: 824-830, 2006.

178. Gloyn AL, Pearson ER, Antcliff JF, Proks P, Bruining GJ, Slingerland AS, Howard N, Srinivasan S, Silva JM, Molnes J, Edghill EL, Frayling TM, Temple IK, Mackay D, Shield JP, Sumnik Z, van Rhijn A, Wales JK, Clark P, Gorman S, Aisenberg J, Ellard S, Njolstad PR, Ashcroft FM and Hattersley AT. Activating mutations in the gene encoding the ATP-sensitive potassium-channel subunit Kir6.2 and permanent neonatal diabetes. N Engl J Med 350: 1838-1849, 2004.

179. Gloyn AL, Weedon MN, Owen KR, Turner MJ, Knight BA, Hitman G, Walker M, Levy JC, Sampson M, Halford S, McCarthy MI, Hattersley AT and Frayling TM. Large-scale association studies of variants in genes encoding the pancreatic betacell KATP channel subunits Kir6.2 (KCNJ11) and SUR1 (ABCC8) confirm that the KCNJ11 E23K variant is associated with type 2 diabetes. Diabetes 52: 568-572, 2003.

180. Gong B, Miki T, Seino S and Renaud JM. A K(ATP) channel deficiency affects 
resting tension, not contractile force, during fatigue in skeletal muscle. Am J Physiol Cell Physiol 279: C1351-C1358, 2000.

181. Gonoi T, Nagashima K, Nishimura M and Seino S. PKA-mediated phosphorylation of the human $\mathrm{K}_{\mathrm{ATP}}$ channel: separate roles of Kir6.2 and SUR1 subunit phosphorylation. EMBOJ 18: 4722-4732, 1999.

182. Gonzalez C, Baez-Nieto D, Valencia I, Oyarzun I, Rojas P, Naranjo D and Latorre R. K(+) channels: function-structural overview. Compr Physiol 2: 2087$2149,2012$.

183. Gooshe M, Tabaeizadeh M, Aleyasin AR, Mojahedi P, Ghasemi K, Yousefi F, Vafaei A, Amini-Khoei H, Amiri S and Dehpour AR. Levosimendan exerts anticonvulsant properties against PTZ-induced seizures in mice through activation of nNOS/NO pathway: Role for KATP channel. Life Sci 168: 38-46, 2017.

184. Gribble FM and Ashcroft FM. Differential sensitivity of beta-cell and extrapancreatic K(ATP) channels to gliclazide. Diabetologia 42: 845-848, 1999.

185. Gribble FM and Reimann F. Sulphonylurea action revisited: the post-cloning era. Diabetologia 46: 875-891, 2003.

186. Gribble FM and Reimann F. Enteroendocrine Cells: Chemosensors in the Intestinal Epithelium. Annu Rev Physiol 78: 277-299, 2016.

187. Gribble FM, Tucker SJ and Ashcroft FM. The essential role of the Walker A motifs 
of SUR1 in K-ATP channel activation by Mg-ADP and diazoxide. EMBO J 16: 1145 $1152,1997$.

188. Gribble FM, Tucker SJ and Ashcroft FM. The interaction of nucleotides with the tolbutamide block of cloned ATP-sensitive $\mathrm{K}+$ channel currents expressed in Xenopus oocytes: a reinterpretation. J Physiol Lond 504: 35-45, 1997.

189. Grover GJ and Garlid KD. ATP-Sensitive potassium channels: a review of their cardioprotective pharmacology. J Mol Cell Cardiol 32: 677-695, 2000.

190. Gumina RJ, Pucar D, Bast P, Hodgson DM, Kurtz CE, Dzeja PP, Miki T, Seino S and Terzic A. Knockout of Kir6.2 negates ischemic preconditioning-induced protection of myocardial energetics. Am J Physiol Heart Circ Physiol 284: H2106H2113, 2003.

191. Hadebe N, Cour M and Lecour S. The SAFE pathway for cardioprotection: is this a promising target? Basic Res Cardiol 113: 9, 2018.

192. Hagiwara S, Miyazaki S and Rosenthal NP. Potassium current and the effect of cesium on this current during anomalous rectification of the egg cell membrane of a starfish. J Gen Physiol 67: 621-638, 1976.

193. Haissaguerre M, Chatel S, Sacher F, Weerasooriya R, Probst V, Loussouarn G, Horlitz M, Liersch R, Schulze-Bahr E, Wilde A, Kaab S, Koster J, Rudy Y, Le MH and Schott JJ. Ventricular fibrillation with prominent early repolarization associated with a rare variant of KCNJ8/KATP channel. J Cardiovasc Electrophysiol 
20: 93-98, 2009.

194. Haller M, Mironov SL, Karschin A and Richter DW. Dynamic activation of K(ATP) channels in rhythmically active neurons. J Physiol 537: 69-81, 2001.

195. Hambrock A, Loffler-Walz C, Russ U, Lange U and Quast U. Characterization of a mutant sulfonylurea receptor SUR2B with high affinity for sulfonylureas and openers: differences in the coupling to Kir6.x subtypes. Mol Pharmacol 60: 190-199, 2001.

196. Hambrock A, Preisig-Muller R, Russ U, Piehl A, Hanley PJ, Ray J, Daut J, Quast U and Derst C. Four novel splice variants of sulfonylurea receptor 1. Am J Physiol Cell Physiol 283: C587-C598, 2002.

197. Hamming KS, Soliman D, Matemisz LC, Niazi O, Lang Y, Gloyn AL and Light PE. Coexpression of the type 2 diabetes susceptibility gene variants KCNJ11 E23K and ABCC8 S1369A alter the ATP and sulfonylurea sensitivities of the ATP-sensitive K(+) channel. Diabetes 58: 2419-2424, 2009.

198. Han J, Kim N, Joo H, Kim E and Earm YE. ATP-sensitive K(+) channel activation by nitric oxide and protein kinase $\mathrm{G}$ in rabbit ventricular myocytes. Am J Physiol Heart Circ Physiol 283: H1545-H1554, 2002.

199. Han J, Kim N, Kim E, Ho WK and Earm YE. Modulation of ATP-sensitive potassium channels by cGMP-dependent protein kinase in rabbit ventricular myocytes. J Biol Chem 276: 22140-22147, 2001. 
200. Han J, Lee SH, Giebisch G and Wang T. Potassium Channelopathies and Gastrointestinal Ulceration. Gut Liver 10: 881-889, 2016.

201. Han X, Light PE, Giles WR and French RJ. Identification and properties of an ATP-sensitive $\mathrm{K}+$ current in rabbit sino-atrial node pacemaker cells. J Physiol 490 ( Pt 2): 337-350, 1996.

202. Hanley PJ, Drose S, Brandt U, Lareau RA, Banerjee AL, Srivastava DK, Banaszak LJ, Barycki JJ, Van Veldhoven PP and Daut J. 5-Hydroxydecanoate is metabolised in mitochondria and creates a rate-limiting bottleneck for beta-oxidation of fatty acids. J Physiol 562: 307-318, 2005.

203. Hansen AM, Christensen IT, Hansen JB, Carr RD, Ashcroft FM and Wahl P. Differential interactions of nateglinide and repaglinide on the human beta-cell sulphonylurea receptor 1. Diabetes 51: 2789-2795, 2002.

204. Hansen SB, Tao X and MacKinnon R. Structural basis of PIP2 activation of the classical inward rectifier K+ channel Kir2.2. Nature 477: 495-498, 2011.

205. Harakalova M, van Harssel JJ, Terhal PA, van LS, Duran K, Renkens I, Amor DJ, Wilson LC, Kirk EP, Turner CL, Shears D, Garcia-Minaur S, Lees MM, Ross A, Venselaar H, Vriend G, Takanari H, Rook MB, van der Heyden MA, Asselbergs FW, Breur HM, Swinkels ME, Scurr IJ, Smithson SF, Knoers NV, van der Smagt JJ, Nijman IJ, Kloosterman WP, van Haelst MM, van HG and Cuppen E. Dominant missense mutations in ABCC9 cause Cantu syndrome. Nat Genet 44: 793-796, 2012. 
206. Harvey, J. and Ashford, M. L. J. Insulin occludes leptin activation of ATP-sensitive $\mathrm{K}+$ channels in rat CRI-G1 insulin secreting cells. Journal of Physiology 511, 695706. 1998.

Ref Type: Journal (Full)

207. Hatakeyama N, Wang Q, Goyal RK and Akbarali HI. Muscarinic suppression of ATP-sensitive $\mathrm{K}+$ channel in rabbit esophageal smooth muscle. Am J Physiol 268: C877-C885, 1995.

208. Hausenloy DJ, Candilio L, Evans R, Ariti C, Jenkins DP, Kolvekar S, Knight R, Kunst G, Laing C, Nicholas J, Pepper J, Robertson S, Xenou M, Clayton T and Yellon DM. Remote Ischemic Preconditioning and Outcomes of Cardiac Surgery. $N$ Engl J Med 373: 1408-1417, 2015.

209. Hayabuchi Y, Dart C and Standen NB. Evidence for involvement of A-kinase anchoring protein in activation of rat arterial K(ATP) channels by protein kinase A. $J$ Physiol 536: 421-427, 2001.

210. Hayabuchi Y, Davies NW and Standen NB. Angiotensin II inhibits rat arterial KATP channels by inhibiting steady- state protein kinase A activity and activating protein kinase Ce. J Physiol 530: 193-205, 2001.

211. Hayabuchi Y, Standen NB and Davies NW. Angiotensin II inhibits and alters kinetics of voltage-gated $\mathrm{K}(+)$ channels of rat arterial smooth muscle. Am J Physiol Heart Circ Physiol 281: H2480-H2489, 2001. 
212. Heginbotham L, Lu Z, Abramson T and MacKinnon R. Mutations in the $\mathrm{K}+$ channel signature sequence. Biophys J 66: 1061-1067, 1994.

213. Henn MC, Janjua MB, Zhang H, Kanter EM, Makepeace CM, Schuessler RB, Nichols CG and Lawton JS. Increased tolerance to stress in cardiac expressed gainof-function of adenosine triphosphate-sensitive potassium channel subunit Kir6.1. $J$ Surg Res 206: 460-465, 2016.

214. Henquin JC, Dufrane D and Nenquin M. Nutrient control of insulin secretion in isolated normal human islets. Diabetes 55: 3470-3477, 2006.

215. Hernandez-Sanchez C, Basile AS, Fedorova I, Arima H, Stannard B, Fernandez AM, Ito Y and LeRoith D. Mice transgenically overexpressing sulfonylurea receptor 1 in forebrain resist seizure induction and excitotoxic neuron death. Proc Natl Acad Sci U S A 98: 3549-3554, 2001.

216. Heron-Milhavet L, Xue-Jun Y, Vannucci SJ, Wood TL, Willing LB, Stannard B, Hernandez-Sanchez C, Mobbs C, Virsolvy A and LeRoith D. Protection against hypoxic-ischemic injury in transgenic mice overexpressing Kir6.2 channel pore in forebrain. Mol Cell Neurosci 25: 585-593, 2004.

217. Heurteaux C, Bertaina V, Widmann C and Lazdunski M. K+ channel openers prevent global ischemia-induced expression of c-fos, c-jun, heat shock protein, and amyloid beta-protein precursor genes and neuronal death in rat hippocampus. Proc Natl Acad Sci U S A 90: 9431-9435, 1993. 


\section{Heusser K, Yuan H, Neagoe I, Tarasov AI, Ashcroft FM and Schwappach B.}

Scavenging of 14-3-3 proteins reveals their involvement in the cell-surface transport of ATP-sensitive K+ channels. J Cell Sci 119: 4353-4363, 2006.

219. Higgins CF. ABC transporters: from microorganisms to man. Annu Rev Cell Biol 8: 67-113, 1992.

220. Hilgemann DW and Ball R. Regulation of cardiac $\mathrm{Na}+, \mathrm{Ca} 2+$ exchange and KATP potassium channels by PIP2. Science 273: 956-959, 1996.

221. Hille B, Dickson EJ, Kruse M, Vivas O and Suh BC. Phosphoinositides regulate ion channels. Biochim Biophys Acta 1851: 844-856, 2015.

222. Hille B and Schwarz W. Potassium channels as multi-ion single-file pores. J Gen Physiol 72: 409-442, 1978.

223. Ho K, Nichols CG, Lederer WJ, Lytton J, Vassilev PM, Kanazirska MV and Hebert SC. Cloning and expression of an inwardly rectifying ATP-regulated potassium channel. Nature 362: 31-38, 1993.

224. Holz GG, Chepurny OG and Leech CA. Leptin-stimulated KATP channel trafficking: a new paradigm for beta-cell stimulus-secretion coupling? Islets 5: 229232, 2013.

\section{Hong M, Kefaloyianni E, Bao L, Malester B, Delaroche D, Neubert TA and} Coetzee WA. Cardiac ATP-sensitive K+ channel associates with the glycolytic 
enzyme complex. FASEB J 25: 2456-2467, 2011.

226. Horinaka S. Use of nicorandil in cardiovascular disease and its optimization. Drugs 71: 1105-1119, 2011.

227. Hosoda C, Tanoue A, Shibano M, Tanaka Y, Hiroyama M, Koshimizu TA, Cotecchia S, Kitamura T, Tsujimoto G and Koike K. Correlation between vasoconstrictor roles and mRNA expression of alpha1-adrenoceptor subtypes in blood vessels of genetically engineered mice. Br J Pharmacol 146: 456-466, 2005.

228. Hu D, Barajas-Martinez H, Terzic A, Park S, Pfeiffer R, Burashnikov E, Wu Y, Borggrefe M, Veltmann C, Schimpf R, Cai JJ, Nam GB, Deshmukh P, Scheinman M, Preminger M, Steinberg J, Lopez-Izquierdo A, Ponce-Balbuena D, Wolpert C, Haissaguerre M, Sanchez-Chapula JA and Antzelevitch C. ABCC9 is a novel Brugada and early repolarization syndrome susceptibility gene. Int $J$ Cardiol 171: 431-442, 2014.

229. Hu K, Huang CS, Jan YN and Jan LY. ATP-sensitive potassium channel traffic regulation by adenosine and protein kinase C. Neuron 38: 417-432, 2003.

230. Hu X, Xu X, Huang Y, Fassett J, Flagg TP, Zhang Y, Nichols CG, Bache RJ and Chen Y. Disruption of sarcolemmal ATP-sensitive potassium channel activity impairs the cardiac response to systolic overload. Circ Res 103: 1009-1017, 2008.

231. Huang H, Liang L, Liu P, Wei H, Sachs F, Niu W and Wang W. Mechanical effects on KATP channel gating in rat ventricular myocytes. PLoS One 8: e63337, 
2013.

232. Hugill A, Shimomura K, Ashcroft FM and Cox RD. A mutation in KCNJ11 causing human hyperinsulinism (Y12X) results in a glucose-intolerant phenotype in the mouse. Diabetologia 53: 2352-2356, 2010.

233. Humphrey SJ, Smith MP, Cimini MG, Buchanan LV, Gibson JK, Khan SA and Meisheri KD. Cardiovascular effects of the K-ATP channel blocker U-37883A and structurally related morpholinoguanidines. Methods Find Exp Clin Pharmacol 18: 247-260, 1996.

234. Hunter M and Giebisch G. Calcium-activated K-channels of Amphiuma early distal tubule: inhibition by ATP. Pflugers Arch 412: 331-333, 1988.

235. Huopio H, Reimann F, Ashfield R, Komulainen J, Lenko HL, Rahier J, Vauhkonen I, Kere J, Laakso M, Ashcroft F and Otonkoski T. Dominantly inherited hyperinsulinism caused by a mutation in the sulfonylurea receptor type $1 . J$ Clin Invest 106: 897-906, 2000.

236. Hussain M, Wareham AC and Head SI. Mechanism of action of a $\mathrm{K}+$ channel activator BRL 38227 on ATP-sensitive K+ channels in mouse skeletal muscle fibres. $J$ Physiol 478 Pt 3: 523-532, 1994.

237. Iafusco D, Bizzarri C, Cadario F, Pesavento R, Tonini G, Tumini S, Cauvin V, Colombo C, Bonfanti R and Barbetti F. No beta cell desensitisation after a median of 68 months on glibenclamide therapy in patients with KCNJ11-associated 
permanent neonatal diabetes. Diabetologia 54: 2736-2738, 2011.

238. Ibrahim N, Bosch MA, Smart JL, Qiu J, Rubinstein M, Ronnekleiv OK, Low MJ and Kelly MJ. Hypothalamic proopiomelanocortin neurons are glucose responsive and express K(ATP) channels. Endocrinology 144: 1331-1340, 2003.

239. Imanishi S, Arita M, Aomine M and Kiyosue T. Antiarrhythmic effects of nicorandil on canine cardiac Purkinje fibers. J Cardiovasc Pharmacol 6: 772-779, 1984.

240. Inagaki N, Gonoi T, Clement JP, Wang CZ, Aguilar Bryan L, Bryan J and Seino S. A family of sulfonylurea receptors determines the pharmacological properties of ATP-sensitive K ${ }^{+}$channels. Neuron 16: 1011-1017, 1996.

\section{Inagaki N, Gonoi T, Clement JP4, Namba N, Inazawa J, Gonzalez G, Aguilar} Bryan L, Seino S and Bryan J. Reconstitution of IKATP: an inward rectifier subunit plus the sulfonylurea receptor. Science 270: 1166-1170, 1995.

242. Inagaki N, Inazawa J and Seino S. cDNA sequence, gene structure, and chromosomal localization of the human ATP-sensitive potassium channel, uKATP-1, gene (KCNJ8). Genomics 30: 102-104, 1995.

\section{Inagaki N, Tsuura Y, Namba N, Masuda K, Gonoi T, Horie M, Seino Y, Mizuta} $\mathbf{M}$ and Seino S. Cloning and functional characterization of a novel ATP-sensitive potassium channel ubiquitously expressed in rat tissues, including pancreatic islets, pituitary, skeletal muscle, and heart. J Biol Chem 270: 5691-5694, 1995. 
244. Inoue I, Nagase $\mathbf{H}$, Kishi $\mathbf{K}$ and Higuti T. ATP-sensitive $\mathrm{K}+$ channel in the mitochondrial inner membrane. Nature 352: 244-247, 1991.

245. Isidoro TN, Philip-Couderc P, Baertschi AJ, Lerch $\mathbf{R}$ and Montessuit C. Angiotensin II and tumour necrosis factor alpha as mediators of ATP-dependent potassium channel remodelling in post-infarction heart failure. Cardiovasc Res 83: 726-736, 2009.

246. Isidoro TN, Philip-Couderc P, Papageorgiou I, Baertschi AJ, Lerch R and Montessuit C. Expression and function of ATP-dependent potassium channels in late post-infarction remodeling. J Mol Cell Cardiol 42: 1016-1025, 2007.

\section{Isomoto S, Kondo C, Yamada M, Matsumoto S, Higashiguchi O, Horio Y,} Matsuzawa Y and Kurachi Y. A novel sulfonylurea receptor forms with BIR (Kir6.2) a smooth muscle type ATP-sensitive K+ channel. J Biol Chem 271: 2432124324, 1996.

248. Ito H, Tung RT, Sugimoto T, Kobayashi I, Takahashi K, Katada T, Ui M and Kurachi Y. On the mechanism of $G$ protein beta gamma subunit activation of the muscarinic $\mathrm{K}+$ channel in guinea pig atrial cell membrane. Comparison with the ATPsensitive K+ channel. J Gen Physiol 99: 961-983, 1992.

249. Iwaki F, Amano H and Ohura K. Nicorandil inhibits osteoclast differentiation in vitro. Eur J Pharmacol 793: 14-20, 2016.

250. Jackson WF, Konig A, Dambacher T and Busse R. Prostacyclin-induced 
vasodilation in rabbit heart is mediated by ATP-sensitive potassium channels. $\mathrm{Am} \mathrm{J}$ Physiol 264: H238-H243, 1993.

251. Jan LY and Jan YN. Potassium channels and their evolving gates. Nature 371: 119$122,1994$.

252. Janigro D, West GA, Gordon EL and Winn HR. ATP-sensitive K+ channels in rat aorta and brain microvascular endothelial cells. Am J Physiol 265: C812-C821, 1993.

253. Jiao J, Garg V, Yang B, Elton TS and Hu K. Protein kinase C-epsilon induces caveolin-dependent internalization of vascular adenosine 5'-triphosphate-sensitive $\mathrm{K}+$ channels. Hypertension 52: 499-506, 2008.

254. John SA, Weiss JN, Xie LH and Ribalet B. Molecular mechanism for ATPdependent closure of the K+ channel Kir6.2. J Physiol 552: 23-34, 2003.

255. Jun JY, Kong ID, Koh SD, Wang XY, Perrino BA, Ward SM and Sanders KM. Regulation of ATP-sensitive $\mathrm{K}(+)$ channels by protein kinase $\mathrm{C}$ in murine colonic myocytes. Am J Physiol Cell Physiol 281: C857-C864, 2001.

256. Kakei M, Noma A and Shibasaki T. Properties of adenosine-triphosphate-regulated potassium channels in guinea-pig ventricular cells. J Physiol 363: 441-462, 1985.

257. Kakkar R, Ye B, Stoller DA, Smelley M, Shi NQ, Galles K, Hadhazey M, Makielski JC and McNally EM. Spontaneous coronary vasospasm in KATP mutant mice arises from a smooth muscle-extrinsic process. Circ Res 98: 682-689, 2006. 
258. Kamei K, Yoshida S, Imagawa J, Nabata $\mathbf{H}$ and Kuriyama $\mathbf{H}$. Regional and species differences in glyburide-sensitive $\mathrm{K}+$ channels in airway smooth muscles as estimated from actions of KC 128 and levcromakalim. Br J Pharmacol 113: 889-897, 1994.

259. Kane C, Shepherd RM, Squires PE, Johnson PR, James RF, Milla PJ, AynsleyGreen A, Lindley KJ and Dunne MJ. Loss of functional KATP channels in pancreatic beta-cells causes persistent hyperinsulinemic hypoglycemia of infancy. Nat Med 2: 1344-1347, 1996.

260. Kane GC, Behfar A, Yamada S, Perez-Terzic C, O'Cochlain F, Reyes S, Dzeja PP, Miki T, Seino S and Terzic A. ATP-sensitive K+ channel knockout compromises the metabolic benefit of exercise training, resulting in cardiac deficits. Diabetes 53 Suppl 3: S169-S175, 2004.

261. Kane GC, Lam CF, O'Cochlain F, Hodgson DM, Reyes S, Liu XY, Miki T, Seino S, Katusic ZS and Terzic A. Gene knockout of the KCNJ8-encoded Kir6.1 K(ATP) channel imparts fatal susceptibility to endotoxemia. FASEB J 20: 2271-2280, 2006.

262. Kang G, Chepurny OG, Malester B, Rindler MJ, Rehmann H, Bos JL, Schwede F, Coetzee WA and Holz GG. cAMP sensor Epac as a determinant of ATP-sensitive potassium channel activity in human pancreatic beta cells and rat INS-1 cells. $J$ Physiol 573: 595-609, 2006.

263. Kang G, Leech CA, Chepurny OG, Coetzee WA and Holz GG. Role of the cAMP sensor Epac as a determinant of KATP channel ATP sensitivity in human pancreatic 
beta-cells and rat INS-1 cells. $J$ Physiol 586: 1307-1319, 2008.

264. Kang L, Dunn-Meynell AA, Routh VH, Gaspers LD, Nagata Y, Nishimura T, Eiki J, Zhang BB and Levin BE. Glucokinase is a critical regulator of ventromedial hypothalamic neuronal glucosensing. Diabetes 55: 412-420, 2006.

265. Kang L, Routh VH, Kuzhikandathil EV, Gaspers LD and Levin BE. Physiological and molecular characteristics of rat hypothalamic ventromedial nucleus glucosensing neurons. Diabetes 53: 549-559, 2004.

266. Kang M, Hashimoto A, Gade A and Akbarali HI. Interaction between hydrogen sulfide-induced sulfhydration and tyrosine nitration in the KATP channel complex. Am J Physiol Gastrointest Liver Physiol 308: G532-G539, 2015.

267. Kantor PF, Coetzee WA, Carmeliet EE, Dennis SC and Opie LH. Reduction of ischemic $\mathrm{K}+$ loss and arrhythmias in rat hearts. Effect of glibenclamide, a sulfonylurea. Circ Res 66: 478-485, 1990.

268. Kapoor RR, Flanagan SE, James CT, McKiernan J, Thomas AM, Harmer SC, Shield JP, Tinker A, Ellard S and Hussain K. Hyperinsulinaemic hypoglycaemia and diabetes mellitus due to dominant ABCC8/KCNJ11 mutations. Diabetologia 54: 2575-2583, 2011.

269. Karczewski KJ, Weisburd B, Thomas B, Solomonson M, Ruderfer DM, Kavanagh D, Hamamsy T, Lek M, Samocha KE, Cummings BB, Birnbaum D, Daly MJ and Macarthur DG. The ExAC browser: displaying reference data 
information from over 60000 exomes. Nucleic Acids Res 45: D840-D845, 2017.

270. Karschin A, Brockhaus $\mathbf{J}$ and Ballanyi K. KATP channel formation by the sulphonylurea receptors SUR1 with Kir6.2 subunits in rat dorsal vagal neurons in situ. J Physiol 509 ( Pt 2): 339-346, 1998.

271. Karschin C, Ecke C, Ashcroft FM and Karschin A. Overlapping distribution of K(ATP) channel-forming Kir6.2 subunit and the sulfonylurea receptor SUR1 in rodent brain. FEBS Lett 401: 59-64, 1997.

272. Kasai H, Hatakeyama H, Ohno M and Takahashi N. Exocytosis in islet beta-cells. Adv Exp Med Biol 654: 305-338, 2010.

273. Katnik C and Adams DJ. An ATP-sensitive potassium conductance in rabbit arterial endothelial cells. J Physiol 485 ( Pt 3): 595-606, 1995.

274. Katnik C and Adams DJ. Characterization of ATP-sensitive potassium channels in freshly dissociated rabbit aortic endothelial cells. Am J Physiol 272: H2507-H2511, 1997.

275. Kawano T, Zoga V, Gemes G, McCallum JB, Wu HE, Pravdic D, Liang MY, Kwok WM, Hogan Q and Sarantopoulos C. Suppressed Ca2+/CaM/CaMKIIdependent K(ATP) channel activity in primary afferent neurons mediates hyperalgesia after axotomy. Proc Natl Acad Sci U S A 106: 8725-8730, 2009.

276. Kawano T, Zoga V, McCallum JB, Wu HE, Gemes G, Liang MY, Abram S, 
Kwok WM, Hogan QH and Sarantopoulos CD. ATP-sensitive potassium currents in rat primary afferent neurons: biophysical, pharmacological properties, and alterations by painful nerve injury. Neuroscience 162: 431-443, 2009.

277. Kefaloyianni E, Lyssand JS, Moreno C, Delaroche D, Hong M, Fenyo D, Mobbs CV, Neubert TA and Coetzee WA. Comparative proteomic analysis of the ATPsensitive K+ channel complex in different tissue types. Proteomics 13: 368-378, 2013.

278. Khan SA, Higdon NR, Hester JB and Meisheri KD. Pharmacological characterization of novel cyanoguanidines as vascular KATP channel blockers. $J$ Pharmacol Exp Ther 283: 1207-1213, 1997.

279. Kim SJ, Zhang H, Khaliulin I, Choisy SC, Bond R, Lin H, El HS, Milnes JT, Hancox JC, Suleiman MS and James AF. Activation of glibenclamide-sensitive ATP-sensitive $\mathrm{K}+$ channels during beta-adrenergically induced metabolic stress produces a substrate for atrial tachyarrhythmia. Circ Arrhythm Electrophysiol 5: 11841192, 2012.

280. Kitazono T, Heistad DD and Faraci FM. Role of ATP-sensitive K+ channels in CGRP-induced dilatation of basilar artery in vivo. Am J Physiol 265: H581-H585, 1993.

281. Kleppisch T and Nelson MT. Adenosine activates ATP-sensitive potassium channels in arterial myocytes via A2 receptors and cAMP-dependent protein kinase. Proc Natl Acad Sci U S A 92: 12441-12445, 1995. 
282. Kline CF, Hund TJ and Mohler PJ. Ankyrin regulates KATP channel membrane trafficking and gating in excitable cells. Channels (Austin) 4: 55-57, 2010.

283. Knowlton C, Kutterer S, Roeper J and Canavier CC. Calcium dynamics control K-ATP channel-mediated bursting in substantia nigra dopamine neurons: a combined experimental and modeling study. J Neurophysiol 119: 84-95, 2018.

284. Koh SD, Bradley KK, Rae MG, Keef KD, Horowitz B and Sanders KM. Basal activation of ATP-sensitive potassium channels in murine colonic smooth muscle cell. Biophys J 75: 1793-1800, 1998.

285. Korchev YE, Negulyaev YA, Edwards CR, Vodyanoy I and Lab MJ. Functional localization of single active ion channels on the surface of a living cell. Nat Cell Biol 2: 616-619, 2000.

286. Koster JC, Cadario F, Peruzzi C, Colombo C, Nichols CG and Barbetti F. The G53D mutation in Kir6.2 (KCNJ11) is associated with neonatal diabetes and motor dysfunction in adulthood that is improved with sulfonylurea therapy. $J$ Clin Endocrinol Metab 93: 1054-1061, 2008.

287. Koster JC, Knopp A, Flagg TP, Markova KP, Sha Q, Enkvetchakul D, Betsuyaku T, Yamada KA and Nichols CG. Tolerance for ATP-insensitive K(ATP) channels in transgenic mice. Circ Res 89: 1022-1029, 2001.

288. Koster JC, Marshall BA, Ensor N, Corbett JA and Nichols CG. Targeted overactivity of beta cell K(ATP) channels induces profound neonatal diabetes. Cell 
100: 645-654, 2000.

289. Kovalev H, Quayle JM, Kamishima T and Lodwick D. Molecular analysis of the subtype-selective inhibition of cloned KATP channels by PNU-37883A. $B r J$ Pharmacol 141: 867-873, 2004.

290. Koyano T, Kakei M, Nakashima H, Yoshinaga M, Matsuoka T and Tanaka H. ATP-regulated $\mathrm{K}+$ channels are modulated by intracellular $\mathrm{H}+$ in guinea-pig ventricular cells. $J$ Physiol 463: 747-766, 1993.

291. Kruse M, Hammond GR and Hille B. Regulation of voltage-gated potassium channels by PI(4,5)P2. J Gen Physiol 140: 189-205, 2012.

292. Kubo M, Quayle JM and Standen NB. Angiotensin II inhibition of ATP-sensitive $\mathrm{K}+$ currents in rat arterial smooth muscle cells through protein kinase C. J Physiol 503 ( Pt 3): 489-496, 1997.

293. Kubo Y, Baldwin TJ, Jan YN and Jan LY. Primary structure and functional expression of a mouse inward rectifier potassium channel. Nature 362: 127-133, 1993.

294. Kubota I, Yamaki M, Shibata T, Ikeno E, Hosoya Y and Tomoike H. Role of ATPsensitive K+ channel on ECG ST segment elevation during a bout of myocardial ischemia. A study on epicardial mapping in dogs. Circulation 88: 1845-1851, 1993.

295. Kukovetz WR, Holzmann S, Braida C and Poch G. Dual mechanism of the 
relaxing effect of nicorandil by stimulation of cyclic GMP formation and by hyperpolarization. J Cardiovasc Pharmacol 17: 627-633, 1991.

296. Kunzelmann K, Pavenstadt H, Beck C, Unal O, Emmrich P, Arndt HJ and Greger R. Characterization of potassium channels in respiratory cells. I. General properties. Pflugers Arch 414: 291-296, 1989.

297. Kunzelmann K, Pavenstadt $\mathbf{H}$ and Greger R. Characterization of potassium channels in respiratory cells. II. Inhibitors and regulation. Pflugers Arch 414: 297303, 1989.

298. Kuo A, Gulbis JM, Antcliff JF, Rahman T, Lowe ED, Zimmer J, Cuthbertson J, Ashcroft FM, Ezaki T and Doyle DA. Crystal structure of the potassium channel KirBac1.1 in the closed state. Science 300: 1922-1926, 2003.

299. Kuo L and Chancellor JD. Adenosine potentiates flow-induced dilation of coronary arterioles by activating KATP channels in endothelium. Am J Physiol 269: H541H549, 1995.

300. Lader JM, Vasquez C, Bao L, Maass K, Qu J, Kefalogianni E, Fishman GI, Coetzee WA and Morley GE. Remodeling of atrial ATP-sensitive $\mathrm{K}(+)$ channels in a model of salt-induced elevated blood pressure. Am J Physiol Heart Circ Physiol 301: H964-H974, 2011.

301. Lahmann C, Clark RH, Iberl M and Ashcroft FM. A mutation causing increased KATP channel activity leads to reduced anxiety in mice. Physiol Behav 129: 79-84, 
2014.

302. Langheinrich $\mathbf{U}$, Schnitzler $\mathbf{M}$ and Daut $\mathbf{J}$. Ca2+-transients induced by $\mathrm{K}+$ channel openers in isolated coronary capillaries. Pflugers Arch 435: 435-438, 1998.

303. Lederer WJ and Nichols CG. Nucleotide modulation of the activity of rat heart ATPsensitive K+ channels in isolated membrane patches. J Physiol 419: 193-211, 1989.

304. Lederer WJ, Nichols CG and Smith GL. The mechanism of early contractile failure of isolated rat ventricular myocytes subjected to complete metabolic inhibition. $J$ Physiol 413: 329-349, 1989.

305. Lee KPK, Chen J and MacKinnon R. Molecular structure of human KATP in complex with ATP and ADP. Elife 6: 2017.

306. Levin MD, Singh GK, Zhang HX, Uchida K, Kozel BA, Stein PK, Kovacs A, Westenbroek RE, Catterall WA, Grange DK and Nichols CG. K(ATP) channel gain-of-function leads to increased myocardial L-type $\mathrm{Ca}(2+)$ current and contractility in Cantu syndrome. Proc Natl Acad Sci U S A 113: 6773-6778, 2016.

307. Levin MD, Zhang H, Uchida K, Grange DK, Singh GK and Nichols CG. Electrophysiologic consequences of KATP gain of function in the heart: Conduction abnormalities in Cantu syndrome. Heart Rhythm 12: 2316-2324, 2015.

308. Lezoualc'h F, Fazal L, Laudette $\mathbf{M}$ and Conte C. Cyclic AMP Sensor EPAC Proteins and Their Role in Cardiovascular Function and Disease. Circ Res 118: 881- 
897, 2016.

309. Li A, Knutsen RH, Zhang H, Osei-Owusu P, Moreno-Dominguez A, Harter TM, Uchida K, Remedi MS, Dietrich HH, Bernal-Mizrachi C, Blumer KJ, Mecham RP, Koster JC and Nichols CG. Hypotension Due to Kir6.1 Gain-of-Function in Vascular Smooth Muscle. J Am Heart Assoc 2: e000365, 2013.

310. Li N, Wu JX, Ding D, Cheng J, Gao N and Chen L. Structure of a Pancreatic ATPSensitive Potassium Channel. Cell 168: 101-110, 2017.

311. Li RA, Leppo M, Miki T, Seino S and Marban E. Molecular basis of electrocardiographic ST-segment elevation. Circ Res 87: 837-839, 2000.

312. Li X, Rapedius M, Baukrowitz T, Liu GX, Srivastava DK, Daut J and Hanley PJ. 5-Hydroxydecanoate and coenzyme A are inhibitors of native sarcolemmal KATP channels in inside-out patches. Biochim Biophys Acta 1800: 385-391, 2010.

313. Light PE, Allen BG, Walsh MP and French RJ. Regulation of adenosine triphosphate-sensitive potassium channels from rabbit ventricular myocytes by protein kinase C and type 2A protein phosphatase. Biochemistry 34: 7252-7257, 1995.

314. Light PE, Cordeiro JM and French RJ. Identification and properties of ATPsensitive potassium channels in myocytes from rabbit Purkinje fibres. Cardiovasc Res 44: 356-369, 1999.

315. Light PE, Manning Fox JE, Riedel MJ and Wheeler MB. Glucagon-like peptide-1 
inhibits pancreatic ATP-sensitive potassium channels via a protein kinase A- and ADP-dependent mechanism. Mol Endocrinol 16: 2135-2144, 2002.

316. Light PE, Sabir AA, Allen BG, Walsh MP and French RJ. Protein kinase Cinduced changes in the stoichiometry of ATP binding activate cardiac ATP-sensitive $\mathrm{K}+$ channels. A possible mechanistic link to ischemic preconditioning. Circ Res 79: 399-406, 1996.

317. Lin YF, Jan YN and Jan LY. Regulation of ATP-sensitive potassium channel function by protein kinase A-mediated phosphorylation in transfected HEK293 cells. EMBO J 19: 942-955, 2000.

318. Linton $\mathbf{K J}$ and Higgins $\mathbf{C F}$. Structure and function of ABC transporters: the ATP switch provides flexible control. Pflugers Arch 453: 555-567, 2007.

319. Liss B, Bruns R and Roeper J. Alternative sulfonylurea receptor expression defines metabolic sensitivity of K-ATP channels in dopaminergic midbrain neurons. EMBOJ 18: 833-846, 1999.

320. Liss B, Haeckel O, Wildmann J, Miki T, Seino S and Roeper J. K-ATP channels promote the differential degeneration of dopaminergic midbrain neurons. Nat Neurosci 8: 1742-1751, 2005.

321. Liu GX, Hanley PJ, Ray J and Daut J. Long-chain acyl-coenzyme A esters and fatty acids directly link metabolism to K(ATP) channels in the heart. Circ Res 88: 918-924, 2001. 


\section{Liu XK, Yamada S, Kane GC, Alekseev AE, Hodgson DM, O'Cochlain F,}

Jahangir A, Miki T, Seino S and Terzic A. Genetic disruption of Kir6.2, the poreforming subunit of ATP-sensitive K+ channel, predisposes to catecholamine-induced ventricular dysrhythmia. Diabetes 53 Suppl 3: S165-S168, 2004.

323. Liu Y, Cohen MV and Downey JM. Chelerythrine, a highly selective protein kinase $\mathrm{C}$ inhibitor, blocks the anti-infarct effect of ischemic preconditioning in rabbit hearts. Cardiovasc Drugs Ther 8: 881-882, 1994.

324. Liu Y, Ren G, O'Rourke B, Marban E and Seharaseyon J. Pharmacological comparison of native mitochondrial K(ATP) channels with molecularly defined surface K(ATP) channels. Mol Pharmacol 59: 225-230, 2001.

325. Liu Y, Tsuchida A, Cohen MV and Downey JM. Pretreatment with angiotensin II activates protein kinase $\mathrm{C}$ and limits myocardial infarction in isolated rabbit hearts. $J$ Mol Cell Cardiol 27: 883-892, 1995.

326. Liu Y, Ytrehus K and Downey JM. Evidence that translocation of protein kinase C is a key event during ischemic preconditioning of rabbit myocardium. $J$ Mol Cell Cardiol 26: 661-668, 1994.

327. Loffler-Walz C, Hambrock A and Quast U. Interaction of K(ATP) channel modulators with sulfonylurea receptor SUR2B: implication for tetramer formation and allosteric coupling of subunits. Mol Pharmacol 61: 407-414, 2002. 
Effects of L-type $\mathrm{Ca}(2+)$-channel blockade, $\mathrm{K}(+)(\mathrm{ATP})$-channel opening and nitric oxide on human uterine contractility in relation to gestational age and labour. $\mathrm{Mol}$ Hum Reprod 9: 159-164, 2003.

329. Lopatin AN, Makhina EN and Nichols CG. Potassium channel block by cytoplasmic polyamines as the mechanism of intrinsic rectification. Nature 372: 366369, 1994.

330. Lopatin AN, Makhina EN and Nichols CG. The mechanism of inward rectification of potassium channels: "long-pore plugging" by cytoplasmic polyamines. J Gen Physiol 106: 923-955, 1995.

331. Loukogeorgakis SP, Williams R, Panagiotidou AT, Kolvekar SK, Donald A, Cole TJ, Yellon DM, Deanfield JE and MacAllister RJ. Transient limb ischemia induces remote preconditioning and remote postconditioning in humans by a $\mathrm{K}(\mathrm{ATP})$-channel dependent mechanism. Circulation 116: 1386-1395, 2007.

332. Lu Z and MacKinnon R. Electrostatic tuning of Mg2+ affinity in an inward-rectifier K+ channel. Nature 371: 243-246, 1994.

333. Luo B, Wu P, Bu T, Zeng Z and Lu D. All-cause mortality and cardiovascular events with nicorandil in patients with IHD: systematic review and meta-analysis of the literature. Int J Cardiol 176: 661-669, 2014.

334. Mace OJ, Schindler M and Patel S. The regulation of K- and L-cell activity by GLUT2 and the calcium-sensing receptor CasR in rat small intestine. J Physiol 590: 
2917-2936, 2012.

\section{Malester B, Tong X, Ghiu I, Kontogeorgis A, Gutstein DE, Xu J, Hendricks-} Munoz KD and Coetzee WA. Transgenic expression of a dominant negative K(ATP) channel subunit in the mouse endothelium: effects on coronary flow and endothelin-1 secretion. FASEB J 21: 2162-2172, 2007.

336. Manna PT, Smith AJ, Taneja TK, Howell GJ, Lippiat JD and Sivaprasadarao A. Constitutive endocytic recycling and protein kinase C-mediated lysosomal degradation control K(ATP) channel surface density. J Biol Chem 285: 5963-5973, 2010.

337. Mannhold R. KATP channel openers: structure-activity relationships and therapeutic potential. Med Res Rev 24: 213-266, 2004.

338. Manning Fox JE, Kanji HD, French RJ and Light PE. Cardioselectivity of the sulphonylurea HMR 1098: studies on native and recombinant cardiac and pancreatic K(ATP) channels. Br J Pharmacol 135: 480-488, 2002.

339. Manning Fox JE, Nichols CG and Light PE. Activation of adenosine triphosphatesensitive potassium channels by acyl coenzyme A esters involves multiple phosphatidylinositol 4,5-bisphosphate-interacting residues. Mol Endocrinol 18: 679686, 2004.

340. Marthinet E, Bloc A, Oka Y, Tanizawa Y, Wehrle-Haller B, Bancila V, Dubuis JM, Philippe J and Schwitzgebel VM. Severe congenital hyperinsulinism caused by 
a mutation in the Kir6.2 subunit of the adenosine triphosphate-sensitive potassium channel impairing trafficking and function. J Clin Endocrinol Metab 90: 5401-5406, 2005.

341. Martin GM, Rex EA, Devaraneni P, Denton JS, Boodhansingh KE, DeLeon DD, Stanley CA and Shyng SL. Pharmacological Correction of Trafficking Defects in ATP-sensitive Potassium Channels Caused by Sulfonylurea Receptor 1 Mutations. $J$ Biol Chem 291: 21971-21983, 2016.

342. Martin GM, Yoshioka C, Rex EA, Fay JF, Xie Q, Whorton MR, Chen JZ and Shyng SL. Cryo-EM structure of the ATP-sensitive potassium channel illuminates mechanisms of assembly and gating. Elife 6: 2017.

343. Marx SO, Kurokawa J, Reiken S, Motoike H, D'Armiento J, Marks AR and Kass RS. Requirement of a macromolecular signaling complex for beta adrenergic receptor modulation of the KCNQ1-KCNE1 potassium channel. Science 295: 496499, 2002.

344. Masia R, Enkvetchakul D and Nichols CG. Differential nucleotide regulation of KATP channels by SUR1 and SUR2A. J Mol Cell Cardiol 39: 491-501, 2005.

345. Mastitskaya S, Marina N, Gourine A, Gilbey MP, Spyer KM, Teschemacher AG, Kasparov S, Trapp S, Ackland GL and Gourine AV. Cardioprotection evoked by remote ischaemic preconditioning is critically dependent on the activity of vagal preganglionic neurones. Cardiovasc Res 95: 487-494, 2012. 
346. Matsuda N and Hattori Y. Vascular biology in sepsis: pathophysiological and therapeutic significance of vascular dysfunction. J Smooth Muscle Res 43: 117-137, 2007.

347. McClenaghan NH, Flatt PR and Ball AJ. Actions of glucagon-like peptide-1 on KATP channel-dependent and -independent effects of glucose, sulphonylureas and nateglinide. J Endocrinol 190: 889-896, 2006.

348. McPherson CD, Pierce GN and Cole WC. Ischemic cardioprotection by ATPsensitive $\mathrm{K}+$ channels involves high-energy phosphate preservation. Am J Physiol 265: H1809-H1818, 1993.

349. Medeiros-Domingo A, Tan BH, Crotti L, Tester DJ, Eckhardt L, Cuoretti A, Kroboth SL, Song C, Zhou Q, Kopp D, Schwartz PJ, Makielski JC and Ackerman MJ. Gain-of-function mutation S422L in the KCNJ8-encoded cardiac K(ATP) channel Kir6.1 as a pathogenic substrate for J-wave syndromes. Heart Rhythm 7: 1466-1471, 2010.

350. Meisheri KD, Humphrey SJ, Khan SA, Cipkus-Dubray LA, Smith MP and Jones AW. 4-morpholinecarboximidine-N-1-adamantyl-N'-cyclohexylhydrochloride (U37883A): pharmacological characterization of a novel antagonist of vascular ATPsensitive K+ channel openers. J Pharmacol Exp Ther 266: 655-665, 1993.

351. Mele A, Camerino GM, Calzolaro S, Cannone M, Conte D and Tricarico D. Dual response of the KATP channels to staurosporine: a novel role of SUR2B, SUR1 and Kir6.2 subunits in the regulation of the atrophy in different skeletal muscle 
phenotypes. Biochem Pharmacol 91: 266-275, 2014.

352. Meybohm P, Bein B, Brosteanu O, Cremer J, Gruenewald M, Stoppe C, Coburn M, Schaelte G, Boning A, Niemann B, Roesner J, Kletzin F, Strouhal U, Reyher C, Laufenberg-Feldmann R, Ferner M, Brandes IF, Bauer M, Stehr SN, Kortgen A, Wittmann M, Baumgarten G, Meyer-Treschan T, Kienbaum P, Heringlake M, Schon J, Sander M, Treskatsch S, Smul T, Wolwender E, Schilling T, Fuernau G, Hasenclever D and Zacharowski K. A Multicenter Trial of Remote Ischemic Preconditioning for Heart Surgery. N Engl J Med 373: 1397-1407, 2015.

353. Mikhailov MV, Campbell JD, de WH, Shimomura K, Zadek B, Collins RF, Sansom MS, Ford RC and Ashcroft FM. 3-D structural and functional characterization of the purified KATP channel complex Kir6.2-SUR1. EMBO J 24: 4166-4175, 2005.

354. Mikhailov MV, Mikhailova EA and Ashcroft SJ. Molecular structure of the glibenclamide binding site of the beta-cell K(ATP) channel. FEBS Lett 499: 154-160, 2001.

355. Miki T, Iwanaga T, Nagashima K, Ihara Y and Seino S. Roles of ATP-sensitive K+ channels in cell survival and differentiation in the endocrine pancreas. Diabetes 50 Suppl 1: S48-S51, 2001.

356. Miki T, Minami K, Zhang L, Morita M, Gonoi T, Shiuchi T, Minokoshi Y, Renaud JM and Seino S. ATP-sensitive potassium channels participate in glucose uptake in skeletal muscle and adipose tissue. Am J Physiol Endocrinol Metab 283: 
E1178-E1184, 2002.

357. Miki T, Nagashima K, Tashiro F, Kotake K, Yoshitomi H, Tamamoto A, Gonoi T, Iwanaga T, Miyazaki J and Seino S. Defective insulin secretion and enhanced insulin action in KATP channel-deficient mice. Proc Natl Acad Sci U S A 95: 1040210406, 1998.

358. Miki T, Suzuki M, Shibasaki T, Uemura H, Sato T, Yamaguchi K, Koseki H, Iwanaga T, Nakaya $\mathbf{H}$ and Seino S. Mouse model of Prinzmetal angina by disruption of the inward rectifier Kir6.1. Nat Med 8: 466-472, 2002.

359. Minami K, Miki T, Kadowaki T and Seino S. Roles of ATP-sensitive K+ channels as metabolic sensors: studies of Kir6.x null mice. Diabetes 53 Suppl 3: S176-S180, 2004.

360. Mirshamsi S, Laidlaw HA, Ning K, Anderson E, Burgess LA, Gray A, Sutherland C and Ashford ML. Leptin and insulin stimulation of signalling pathways in arcuate nucleus neurones: PI3K dependent actin reorganization and KATP channel activation. BMC Neurosci 5: 54, 2004.

361. Miyoshi Y, Nakaya Y, Wakatsuki T, Nakaya S, Fujino K, Saito K and Inoue I. Endothelin blocks ATP-sensitive $\mathrm{K}+$ channels and depolarizes smooth muscle cells of porcine coronary artery. Circ Res 70: 612-616, 1992.

362. Mizutani S, Al-Dadah AS, Bloch JB, Prasad SM, Diodato MD, Schuessler RB, Damiano RJ, Jr. and Lawton JS. Hyperkalemic cardioplegia-induced myocyte 
swelling and contractile dysfunction: prevention by diazoxide. Ann Thorac Surg 81: 154-159, 2006.

363. Mizutani S, Prasad SM, Sellitto AD, Schuessler RB, Damiano RJ, Jr. and Lawton JS. Myocyte volume and function in response to osmotic stress: observations in the presence of an adenosine triphosphate-sensitive potassium channel opener. Circulation 112: I219-I223, 2005.

364. Mobasheri A, Gent TC, Nash AI, Womack MD, Moskaluk CA and Barrett-Jolley R. Evidence for functional ATP-sensitive (K(ATP)) potassium channels in human and equine articular chondrocytes. Osteoarthritis Cartilage 15: 1-8, 2007.

365. Mohan RM and Paterson DJ. Activation of sulphonylurea-sensitive channels and the NO-cGMP pathway decreases the heart rate response to sympathetic nerve stimulation. Cardiovasc Res 47: 81-89, 2000.

366. Moran BM, McKillop AM and O'Harte FP. Development of novel ligands for peptide GPCRs. Curr Opin Pharmacol 31: 57-62, 2016.

367. Moreau C, Jacquet H, Prost AL, D'hahan N and Vivaudou M. The molecular basis of the specificity of action of K(ATP) channel openers. EMBO J 19: 6644-6651, 2000.

368. Moreau C, Prost AL, Derand R and Vivaudou M. SUR, ABC proteins targeted by KATP channel openers. J Mol Cell Cardiol 38: 951-963, 2005. 
369. Muiesan G, Fariello R, Muiesan ML and Christensen OE. Effect of pinacidil on blood pressure, plasma catecholamines and plasma renin activity in essential hypertension. Eur J Clin Pharmacol 28: 495-499, 1985.

370. Munroe PB and Tinker A. Genome-wide association studies and contribution to cardiovascular physiology. Physiol Genomics 47: 365-375, 2015.

371. Murray MA, Boyle JP and Small RC. Cromakalim-induced relaxation of guinea-pig isolated trachealis: antagonism by glibenclamide and by phentolamine. $\mathrm{Br} J$ Pharmacol 98: 865-874, 1989.

372. Mustafa AK, Gadalla MM, Sen N, Kim S, Mu W, Gazi SK, Barrow RK, Yang G, Wang R and Snyder SH. H2S signals through protein S-sulfhydration. Sci Signal 2: ra72, 2009.

373. Mustafa AK, Gadalla MM and Snyder SH. Signaling by gasotransmitters. Sci Signal 2: re2, 2009.

374. Nasonkin I, Alikasifoglu A, Ambrose C, Cahill P, Cheng M, Sarniak A, Egan M and Thomas PM. A novel sulfonylurea receptor family member expressed in the embryonic Drosophila dorsal vessel and tracheal system. J Biol Chem 274: 29420$29425,1999$.

375. Nasuhoglu C, Feng S, Mao Y, Shammat I, Yamamato M, Earnest S, Lemmon M and Hilgemann DW. Modulation of cardiac PIP2 by cardioactive hormones and other physiologically relevant interventions. Am J Physiol Cell Physiol 283: C223- 
C234, 2002.

\section{Nazari SK, Nikoui V, Ostadhadi S, Chegini ZH, Oryan S and Bakhtiarian A.} Possible involvement of ATP-sensitive potassium channels in the antidepressant-like effect of baclofen in mouse forced swimming test. Pharmacol Rep 68: 1214-1220, 2016.

377. Nelson DA, Bryan J, Wechsler S, Clement JP4 and Aguilar Bryan L. The highaffinity sulfonylurea receptor: distribution, glycosylation, purification, and immunoprecipitation of two forms from endocrine and neuroendocrine cell lines. Biochemistry 35: 14793-14799, 1996.

378. Nelson MT, Huang Y, Brayden JE, Hescheler J and Standen NB. Arterial dilations in response to calcitonin gene-related peptide involve activation of $\mathrm{K}+$ channels. Nature 344: 770-773, 1990.

379. Nelson MT and Quayle JM. Physiological roles and properties of potassium channels in arterial smooth muscle. Am J Physiol 268: C799-C822, 1995.

380. Nessa A, Aziz QH, Thomas AM, Harmer SC, Tinker A and Hussain K. Molecular mechanisms of congenital hyperinsulinism due to autosomal dominant mutations in ABCC8. Hum Mol Genet 24: 5142-5153, 2015.

381. Nessa A, Rahman SA and Hussain K. Hyperinsulinemic Hypoglycemia - The Molecular Mechanisms. Front Endocrinol (Lausanne) 7: 29, 2016. 
382. Nestorowicz A, Inagaki N, Gonoi T, Schoor KP, Wilson BA, Glaser B, Landau H, Stanley CA, Thornton PS, Seino S and Permutt MA. A nonsense mutation in the inward rectifier potassium channel gene, Kir6.2, is associated with familial hyperinsulinism. Diabetes 46: 1743-1748, 1997.

383. Nestorowicz A, Wilson BA, Schoor KP, Inoue H, Glaser B, Landau H, Stanley CA, Thornton PS, Clement JP4, Bryan J, Aguilar Bryan L and Permutt MA. Mutations in the sulonylurea receptor gene are associated with familial hyperinsulinism in Ashkenazi Jews. Hum Mol Genet 5: 1813-1822, 1996.

384. Ng B, Kang Y, Elias CL, He Y, Xie H, Hansen JB, Wahl P and Gaisano HY. The actions of a novel potent islet beta-cell specific ATP-sensitive $\mathrm{K}+$ channel opener can be modulated by syntaxin-1A acting on sulfonylurea receptor 1. Diabetes 56: 21242134, 2007.

385. Nichols CG, Ho K and Hebert S. $\operatorname{Mg}(2+)$-dependent inward rectification of ROMK1 potassium channels expressed in Xenopus oocytes. J Physiol Lond 476: 399409, 1994.

386. Nichols CG and Lopatin AN. Inward rectifier potassium channels. Annu Rev Physiol 59: 171-191, 1997.

387. Nichols CG, Ripoll C and Lederer WJ. ATP-sensitive potassium channel modulation of the guinea pig ventricular action potential and contraction. Circ Res 68: 280-287, 1991. 
388. Nielsen LB, Ploug KB, Swift P, Orskov C, Jansen-Olesen I, Chiarelli F, Holst JJ, Hougaard P, Porksen S, Holl R, de BC, Gammeltoft S, Rorsman P, Mortensen HB and Hansen L. Co-localisation of the Kir6.2/SUR1 channel complex with glucagon-like peptide-1 and glucose-dependent insulinotrophic polypeptide expression in human ileal cells and implications for glycaemic control in new onset type 1 diabetes. Eur J Endocrinol 156: 663-671, 2007.

389. Niki I, Kelly RP, Ashcroft SJ and Ashcroft FM. ATP-sensitive K-channels in HIT T15 beta-cells studied by patch-clamp methods, $86 \mathrm{Rb}$ efflux and glibenclamide binding. Pflugers Arch 415: 47-55, 1989.

390. Nilius B and Droogmans G. Ion channels and their functional role in vascular endothelium. Physiol Rev 81: 1415-1459, 2001.

391. Noma A. ATP-regulated K+ channels in cardiac muscle. Nature 305: 147-148, 1983.

392. O'Brien A, Stidwill RP, Clapp LH and Singer M. Variable effects of inhibiting iNOS and closing the vascular ATP-sensitive potassium channel (via its pore-forming and sulfonylurea receptor subunits) in endotoxic shock. Shock 31: 535-541, 2009.

393. O'Hare JP, Hanif W, Millar-Jones D, Bain S, Hicks D, Leslie RD and Barnett AH. NICE guidelines for Type 2 diabetes: revised but still not fit for purpose. Diabet Med 32: 1398-1403, 2015.

394. Ohno-Shosaku T, Zunkler BJ and Trube G. Dual effects of ATP on K+ currents of mouse pancreatic beta-cells. Pflugers Arch 408: 133-138, 1987. 
395. Olsen EA, Weiner MS, Delong ER and Pinnell SR. Topical minoxidil in early male pattern baldness. J Am Acad Dermatol 13: 185-192, 1985.

396. Olsen ML, Khakh BS, Skatchkov SN, Zhou M, Lee CJ and Rouach N. New Insights on Astrocyte Ion Channels: Critical for Homeostasis and Neuron-Glia Signaling. J Neurosci 35: 13827-13835, 2015.

397. Olson TM, Alekseev AE, Moreau C, Liu XK, Zingman LV, Miki T, Seino S, Asirvatham SJ, Jahangir A and Terzic A. KATP channel mutation confers risk for vein of Marshall adrenergic atrial fibrillation. Nat Clin Pract Cardiovasc Med 4: 110116, 2007.

398. Orie NN, Thomas AM, Perrino BA, Tinker A and Clapp LH. Ca2+/calcineurin regulation of cloned vascular K ATP channels: crosstalk with the protein kinase A pathway. Br J Pharmacol 157: 554-564, 2009.

399. Orkaby AR, Cho K, Cormack J, Gagnon DR and Driver JA. Metformin vs sulfonylurea use and risk of dementia in US veterans aged $>/=65$ years with diabetes. Neurology 2017.

400. Ortiz D, Gossack L, Quast U and Bryan J. Reinterpreting the action of ATP analogs on KATP channels. J Biol Chem 288: 18894-18902, 2013.

401. Otonkoski T, Ammala C, Huopio H, Cote GJ, Chapman J, Cosgrove K, Ashfield R, Huang E, Komulainen J, Ashcroft FM, Dunne MJ, Kere J and Thomas PM. A point mutation inactivating the sulfonylurea receptor causes the severe form of 
persistent hyperinsulinemic hypoglycemia of infancy in Finland. Diabetes 48: 408$415,1999$.

402. Ozaki N, Shibasaki T, Kashima Y, Miki T, Takahashi K, Ueno H, Sunaga Y, Yano H, Matsuura Y, Iwanaga T, Takai Y and Seino S. cAMP-GEFII is a direct target of cAMP in regulated exocytosis. Nat Cell Biol 2: 805-811, 2000.

403. Paajanen $\mathbf{V}$ and Vornanen $\mathbf{M}$. The induction of an ATP-sensitive $\mathrm{K}(+)$ current in cardiac myocytes of air- and water-breathing vertebrates. Pflugers Arch 444: 760-770, 2002.

404. Paajanen V and Vornanen M. Regulation of action potential duration under acute heat stress by I(K,ATP) and I(K1) in fish cardiac myocytes. Am J Physiol Regul Integr Comp Physiol 286: R405-R415, 2004.

\section{Pagliaro P, Paolocci N, Isoda T, Saavedra WF, Sunagawa G and Kass DA.} Reversal of glibenclamide-induced coronary vasoconstriction by enhanced perfusion pulsatility: possible role for nitric oxide. Cardiovasc Res 45: 1001-1009, 2000.

406. Park SH, Ho WK and Jeon JH. AMPK regulates K(ATP) channel trafficking via PTEN inhibition in leptin-treated pancreatic beta-cells. Biochem Biophys Res Commun 440: 539-544, 2013.

407. Park SH, Ryu SY, Yu WJ, Han YE, Ji YS, Oh K, Sohn JW, Lim A, Jeon JP, Lee H, Lee KH, Lee SH, Berggren PO, Jeon JH and Ho WK. Leptin promotes K(ATP) channel trafficking by AMPK signaling in pancreatic beta-cells. Proc Natl Acad Sci U 
$S A$ 110: 12673-12678, 2013.

408. Partridge CJ, Beech DJ and Sivaprasadarao A. Identification and pharmacological correction of a membrane trafficking defect associated with a mutation in the sulphonylurea receptor causing familial hyperinsulinism. J Biol Chem 276: 3594735952, 2001.

409. Pasyk EA, Kang Y, Huang X, Cui N, Sheu L and Gaisano HY. Syntaxin-1A binds the nucleotide-binding folds of sulphonylurea receptor 1 to regulate the KATP channel. J Biol Chem 279: 4234-4240, 2004.

410. Paucek P, Mironova G, Mahdi F, Beavis AD, Woldegiorgis G and Garlid KD. Reconstitution and partial purification of the glibenclamide-sensitive, ATP-dependent $\mathrm{K}+$ channel from rat liver and beef heart mitochondria. J Biol Chem 267: 2606226069, 1992.

411. Pearson ER, Flechtner I, Njolstad PR, Malecki MT, Flanagan SE, Larkin B, Ashcroft FM, Klimes I, Codner E, Iotova V, Slingerland AS, Shield J, Robert JJ, Holst JJ, Clark PM, Ellard S, Sovik O, Polak M and Hattersley AT. Switching from insulin to oral sulfonylureas in patients with diabetes due to Kir6.2 mutations. $N$ Engl J Med 355: 467-477, 2006.

412. Perez MI and Musini VM. Pharmacological interventions for hypertensive emergencies. Cochrane Database Syst Rev CD003653, 2008.

413. Pinney SE, MacMullen C, Becker S, Lin YW, Hanna C, Thornton P, Ganguly A, 
Shyng SL and Stanley CA. Clinical characteristics and biochemical mechanisms of congenital hyperinsulinism associated with dominant KATP channel mutations. J Clin Invest 118: 2877-2886, 2008.

\section{Plum L, Ma X, Hampel B, Balthasar N, Coppari R, Munzberg H, Shanabrough} M, Burdakov D, Rother E, Janoschek R, Alber J, Belgardt BF, Koch L, Seibler J, Schwenk F, Fekete C, Suzuki A, Mak TW, Krone W, Horvath TL, Ashcroft FM and Bruning JC. Enhanced PIP3 signaling in POMC neurons causes KATP channel activation and leads to diet-sensitive obesity. J Clin Invest 116: 1886-1901, 2006.

\section{Prasad SM, Al-Dadah AS, Byrd GD, Flagg TP, Gomes J, Damiano RJ, Jr.,} Nichols CG and Lawton JS. Role of the sarcolemmal adenosine triphosphatesensitive potassium channel in hyperkalemic cardioplegia-induced myocyte swelling and reduced contractility. Ann Thorac Surg 81: 148-153, 2006.

416. Proks P, de WH and Ashcroft FM. Molecular mechanism of sulphonylurea block of K(ATP) channels carrying mutations that impair ATP inhibition and cause neonatal diabetes. Diabetes 62: 3909-3919, 2013.

417. Pu JL, Ye B, Kroboth SL, McNally EM, Makielski JC and Shi NQ. Cardiac sulfonylurea receptor short form-based channels confer a glibenclamide-insensitive KATP activity. J Mol Cell Cardiol 44: 188-200, 2008.

418. Purves GI, Kamishima T, Davies LM, Quayle JM and Dart C. Exchange protein activated by cAMP (Epac) mediates cAMP-dependent but protein kinase Ainsensitive modulation of vascular ATP-sensitive potassium channels. $J$ Physiol 587: 
3639-3650, 2009.

419. Quast U. Do the $\mathrm{K}+$ channel openers relax smooth muscle by opening $\mathrm{K}+$ channels? Trends Pharmacol Sci 14: 332-337, 1993.

420. Quayle JM, Nelson MT and Standen NB. ATP-sensitive and inwardly rectifying potassium channels in smooth muscle. Physiol Rev 77: 1165-1232, 1997.

421. Quayle JM, Standen NB and Stanfield PR. The voltage-dependent block of ATPsensitive potassium channels of frog skeletal muscle by caesium and barium ions. $J$ Physiol 405: 677-697, 1988.

422. Quinn KV, Cui Y, Giblin JP, Clapp LH and Tinker A. Do anionic phospholipids serve as cofactors or second messengers for the regulation of activity of cloned ATPsensitive K+ channels? Circ Res 93: 646-655, 2003.

423. Quinn KV, Giblin JP and Tinker A. Multisite Phosphorylation Mechanism for Protein Kinase A Activation of the Smooth Muscle ATP-Sensitive K+ Channel. Circ Res 94: 1359-1366, 2004.

424. Rainbow RD, Norman RI, Everitt DE, Brignell JL, Davies NW and Standen NB. Endothelin-I and angiotensin II inhibit arterial voltage-gated $\mathrm{K}+$ channels through different protein kinase C isoenzymes. Cardiovasc Res 83: 493-500, 2009.

425. Ramsey BW, Davies J, McElvaney NG, Tullis E, Bell SC, Drevinek P, Griese M, McKone EF, Wainwright CE, Konstan MW, Moss R, Ratjen F, Sermet-Gaudelus 
I, Rowe SM, Dong Q, Rodriguez S, Yen K, Ordonez C and Elborn JS. A CFTR potentiator in patients with cystic fibrosis and the G551D mutation. $N$ Engl J Med 365: 1663-1672, 2011.

426. Randall MD. The involvement of ATP-sensitive potassium channels and adenosine in the regulation of coronary flow in the isolated perfused rat heart. Br J Pharmacol 116: 3068-3074, 1995.

427. Reimann F, Dabrowski M, Jones P, Gribble FM and Ashcroft FM. Analysis of the differential modulation of sulphonylurea block of beta-cell and cardiac ATP-sensitive $\mathrm{K}+(\mathrm{K}(\mathrm{ATP}))$ channels by Mg-nucleotides. J Physiol 547: 159-168, 2003.

428. Reimann F and Gribble FM. Glucose-sensing in glucagon-like peptide-1-secreting cells. Diabetes 51: 2757-2763, 2002.

429. Reimann F, Habib AM, Tolhurst G, Parker HE, Rogers GJ and Gribble FM. Glucose sensing in L cells: a primary cell study. Cell Metab 8: 532-539, 2008.

430. Reimann F, Proks P and Ashcroft FM. Effects of mitiglinide (S 21403) on Kir6.2/SUR1, Kir6.2/SUR2A and Kir6.2/SUR2B types of ATP-sensitive potassium channel. Br J Pharmacol 132: 1542-1548, 2001.

431. Reimann F, Ryder TJ, Tucker SJ and Ashcroft FM. The role of lysine 185 in the kir6.2 subunit of the ATP- sensitive channel in channel inhibition by ATP. J Physiol Lond 520 Pt 3: 661-669, 1999. 
432. Remedi MS, Friedman JB and Nichols CG. Diabetes induced by gain-of-function mutations in the Kir6.1 subunit of the KATP channel. J Gen Physiol 149: 75-84, 2017.

\section{Remedi MS, Kurata HT, Scott A, Wunderlich FT, Rother E, Kleinridders A,} Tong A, Bruning JC, Koster JC and Nichols CG. Secondary consequences of beta cell inexcitability: identification and prevention in a murine model of K(ATP)-induced neonatal diabetes mellitus. Cell Metab 9: 140-151, 2009.

434. Reyes S, Park S, Johnson BD, Terzic A and Olson TM. KATP channel Kir6.2 E23K variant overrepresented in human heart failure is associated with impaired exercise stress response. Hum Genet 126: 779-789, 2009.

\section{Reyes S, Terzic A, Mahoney DW, Redfield MM, Rodeheffer RJ and Olson TM.} $\mathrm{K}$ (ATP) channel polymorphism is associated with left ventricular size in hypertensive individuals: a large-scale community-based study. Hum Genet 123: 665-667, 2008.

436. Riedel MJ, Boora P, Steckley D, de VG and Light PE. Kir6.2 polymorphisms sensitize beta-cell ATP-sensitive potassium channels to activation by acyl CoAs: a possible cellular mechanism for increased susceptibility to type 2 diabetes? Diabetes 52: 2630-2635, 2003.

437. Rjasanow A, Leitner MG, Thallmair V, Halaszovich CR and Oliver D. Ion channel regulation by phosphoinositides analyzed with VSPs-PI(4,5)P2 affinity, phosphoinositide selectivity, and PI(4,5)P2 pool accessibility. Front Pharmacol 6: $127,2015$. 
438. Robbins J, Marsh SJ and Brown DA. Probing the regulation of M (Kv7) potassium channels in intact neurons with membrane-targeted peptides. J Neurosci 26: 79507961, 2006.

439. Robertson SP, Kirk E, Bernier F, Brereton J, Turner A and Bankier A. Congenital hypertrichosis, osteochondrodysplasia, and cardiomegaly: Cantu syndrome. Am J Med Genet 85: 395-402, 1999.

440. Rogers BJ, Standaert ML and Pollet RJ. Direct effects of sulfonylurea agents on glucose transport in the BC3H-1 myocyte. Diabetes 36: 1292-1296, 1987.

441. Rohacs T, Chen J, Prestwich GD and Logothetis DE. Distinct specificities of inwardly rectifying $\mathrm{K}(+)$ channels for phosphoinositides. J Biol Chem 274: 36065 36072, 1999.

442. Rorsman P and Braun M. Regulation of insulin secretion in human pancreatic islets. Annu Rev Physiol 75: 155-179, 2013.

443. Rorsman P, Eliasson L, Kanno T, Zhang Q and Gopel S. Electrophysiology of pancreatic beta-cells in intact mouse islets of Langerhans. Prog Biophys Mol Biol 107: 224-235, 2011.

444. Rorsman P, Ramracheya R, Rorsman NJ and Zhang Q. ATP-regulated potassium channels and voltage-gated calcium channels in pancreatic alpha and beta cells: similar functions but reciprocal effects on secretion. Diabetologia 57: 1749-1761, 2014. 
445. Rorsman P, Salehi SA, Abdulkader F, Braun M and MacDonald PE. K(ATP)channels and glucose-regulated glucagon secretion. Trends Endocrinol Metab 19: 277-284, 2008.

446. Rorsman P and Trube G. Glucose dependent K+-channels in pancreatic beta-cells are regulated by intracellular ATP. Pflugers Arch 405: 305-309, 1985.

447. Rossello X and Yellon DM. The RISK pathway and beyond. Basic Res Cardiol 113: $2,2017$.

448. Rosser EM, Kaariainen H, Hurst JA, Baraitser M, Hall CM, Clayton P and Leonard JV. Three patients with the osteochondrodysplasia and hypertrichosis syndrome--Cantu syndrome. Clin Dysmorphol 7: 79-85, 1998.

449. Rother E, Konner AC and Bruning JC. Neurocircuits integrating hormone and nutrient signaling in control of glucose metabolism. Am J Physiol Endocrinol Metab 294: E810-E816, 2008.

450. RUBIN AA, ROTH FE, TAYLOR RM and ROSENKILDE H. Pharmacology of diazoxide, an antihypertensive, nondiuretic benzothiadiazine. J Pharmacol Exp Ther 136: 344-352, 1962.

451. Rubio-Cabezas $\mathbf{O}$ and Ellard S. Diabetes mellitus in neonates and infants: genetic heterogeneity, clinical approach to diagnosis, and therapeutic options. Horm Res Paediatr 80: 137-146, 2013. 
452. Rubio-Cabezas O, Flanagan SE, Damhuis A, Hattersley AT and Ellard S. KATP channel mutations in infants with permanent diabetes diagnosed after 6 months of life. Pediatr Diabetes 13: 322-325, 2012.

453. Saegusa N, Sato T, Saito T, Tamagawa M, Komuro I and Nakaya H. Kir6.2deficient mice are susceptible to stimulated ANP secretion: K(ATP) channel acts as a negative feedback mechanism? Cardiovasc Res 67: 60-68, 2005.

454. Sakura H, Ammala C, Smith PA, Gribble FM and Ashcroft FM. Cloning and functional expression of the cDNA encoding a novel ATP-sensitive potassium channel subunit expressed in pancreatic beta-cells, brain, heart and skeletal muscle. FEBS Lett 377: 338-344, 1995.

455. Salkoff L, Wei AD, Baban B, Butler A, Fawcett G, Ferreira G and Santi CM. Potassium channels in C. elegans. WormBook 1-15, 2005.

456. Sampson LJ, Davies LM, Barrett-Jolley R, Standen NB and Dart C. Angiotensin II-activated protein kinase $\mathrm{C}$ targets caveolae to inhibit aortic ATP-sensitive potassium channels. Cardiovasc Res 76: 61-70, 2007.

457. Sampson LJ, Hayabuchi Y, Standen NB and Dart C. Caveolae localize protein kinase A signaling to arterial ATP-sensitive potassium channels. Circ Res 95: 1012$1018,2004$.

458. Sampson LJ, Plane F and Garland CJ. Involvement of cyclic GMP and potassium channels in relaxation evoked by the nitric oxide donor, diethylamine NONOate, in 
the rat small isolated mesenteric artery. Naunyn Schmiedebergs Arch Pharmacol 364: 220-225, 2001.

459. Sanguinetti MC, Jurkiewicz NK, Scott A and Siegl PK. Isoproterenol antagonizes prolongation of refractory period by the class III antiarrhythmic agent E-4031 in guinea pig myocytes. Mechanism of action. Circ Res 68: 77-84, 1991.

460. Sato T, Hata Y, Yamamoto M, Morita H, Mizuo K, Yamanari H, Saito D and Ohe T. Early afterdepolarization abolished by potassium channel opener in a patient with idiopathic long QT syndrome. J Cardiovasc Electrophysiol 6: 279-282, 1995.

461. Schiemann J, Schlaudraff F, Klose V, Bingmer M, Seino S, Magill PJ, Zaghloul KA, Schneider G, Liss B and Roeper J. K-ATP channels in dopamine substantia nigra neurons control bursting and novelty-induced exploration. Nat Neurosci 15: 1272-1280, 2012.

462. Schnitzler M, Derst C, Daut J and Preisig-Muller R. ATP-sensitive potassium channels in capillaries isolated from guinea-pig heart. $J$ Physiol 525 Pt 2: 307-317, 2000

463. Schubert R, Serebryakov VN, Mewes H and Hopp HH. Iloprost dilates rat small arteries: role of $\mathrm{K}(\mathrm{ATP})-$ and $\mathrm{K}(\mathrm{Ca})$-channel activation by cAMP-dependent protein kinase. Am J Physiol 272: H1147-H1156, 1997.

464. Schulze D, Rapedius M, Krauter T and Baukrowitz T. Long-chain acyl-CoA esters and phosphatidylinositol phosphates modulate ATP inhibition of KATP channels by 
the same mechanism. J Physiol 552: 357-367, 2003.

465. Schwappach B, Zerangue N, Jan YN and Jan LY. Molecular basis for K(ATP) assembly: transmembrane interactions mediate association of a $\mathrm{K}+$ channel with an ABC transporter. Neuron 26: 155-167, 2000.

466. Scurr I, Wilson L, Lees M, Robertson S, Kirk E, Turner A, Morton J, Kidd A, Shashi V, Stanley C, Berry M, Irvine AD, Goudie D, Turner C, Brewer C and Smithson S. Cantu syndrome: report of nine new cases and expansion of the clinical phenotype. Am J Med Genet A 155A: 508-518, 2011.

467. Seghers V, Nakazaki M, DeMayo F, Aguilar-Bryan L and Bryan J. Sur1 knockout mice. A model for K(ATP) channel-independent regulation of insulin secretion. J Biol Chem 275: 9270-9277, 2000.

468. Sellitto AD, Al-Dadah AS, Schuessler RB, Nichols CG and Lawton JS. An open sarcolemmal adenosine triphosphate-sensitive potassium channel is necessary for detrimental myocyte swelling secondary to stress. Circulation 124: S70-S74, 2011.

469. Shafaroodi H, Barati S, Ghasemi M, Almasirad A and Moezi L. A role for ATPsensitive potassium channels in the anticonvulsant effects of triamterene in mice. Epilepsy Res 121: 8-13, 2016.

470. Shah RP, Spruyt K, Kragie BC, Greeley SA and Msall ME. Visuomotor performance in KCNJ11-related neonatal diabetes is impaired in children with DEND-associated mutations and may be improved by early treatment with 
sulfonylureas. Diabetes Care 35: 2086-2088, 2012.

471. Sharma N, Crane A, Clement JP, Gonzalez G, Babenko AP, Bryan J and AguilarBryan L. The C terminus of SUR1 is required for trafficking of KATP channels. $J$ Biol Chem 274: 20628-20632, 1999.

472. Sheikhi M, Shirzadian A, Dehdashtian A, Amiri S, Ostadhadi S, Ghasemi M and Dehpour AR. Involvement of ATP-sensitive potassium channels and the opioid system in the anticonvulsive effect of zolpidem in mice. Epilepsy Behav 62: 291-296, 2016.

473. Shen KZ, Wu YN, Munhall AC and Johnson SW. AMP kinase regulates ligandgated K-ATP channels in substantia nigra dopamine neurons. Neuroscience 330: 219$228,2016$.

474. Shi L, Xu M, Liu J, Zhang Z, Bao Z, Wang Y, Wang C and Wang J. K(ATP) channels are involved in regulatory volume decrease in rat cardiac myocytes. Physiol Res 58: 645-652, 2009.

475. Shi W, Cui N, Wu Z, Yang Y, Zhang S, Gai H, Zhu D and Jiang C. Lipopolysaccharides up-regulate Kir6.1/SUR2B channel expression and enhance vascular KATP channel activity via NF-kappaB-dependent signaling. J Biol Chem 285: 3021-3029, 2010.

476. Shi Y, Cui N, Shi W and Jiang C. A short motif in Kir6.1 consisting of four phosphorylation repeats underlies the vascular KATP channel inhibition by protein 
kinase C. J Biol Chem 283: 2488-2494, 2008.

477. Shi Y, Wu Z, Cui N, Shi W, Yang Y, Zhang X, Rojas A, Ha BT and Jiang C. PKA phosphorylation of SUR2B subunit underscores vascular KATP channel activation by beta-adrenergic receptors. Am J Physiol Regul Integr Comp Physiol 293: R1205R1214, 2007.

478. Shigeto M, Ramracheya R, Tarasov AI, Cha CY, Chibalina MV, Hastoy B, Philippaert K, Reinbothe T, Rorsman N, Salehi A, Sones WR, Vergari E, Weston C, Gorelik J, Katsura M, Nikolaev VO, Vennekens R, Zaccolo M, Galione A, Johnson PR, Kaku K, Ladds G and Rorsman P. GLP-1 stimulates insulin secretion by PKC-dependent TRPM4 and TRPM5 activation. J Clin Invest 125: 4714-4728, 2015.

479. Shimizu W and Antzelevitch C. Effects of a $\mathrm{K}(+)$ channel opener to reduce transmural dispersion of repolarization and prevent torsade de pointes in LQT1, LQT2, and LQT3 models of the long-QT syndrome. Circulation 102: 706-712, 2000.

480. Shimomura K, Tusa M, Iberl M, Brereton MF, Kaizik S, Proks P, Lahmann C, Yaluri N, Modi S, Huopio H, Ustinov J, Otonkoski T, Laakso M and Ashcroft FM. A mouse model of human hyperinsulinism produced by the E1506K mutation in the sulphonylurea receptor SUR1. Diabetes 62: 3797-3806, 2013.

481. Shiota C, Larsson O, Shelton KD, Shiota M, Efanov AM, Hoy M, Lindner J, Kooptiwut S, Juntti-Berggren L, Gromada J, Berggren PO and Magnuson MA. Sulfonylurea receptor type 1 knock-out mice have intact feeding-stimulated insulin 
secretion despite marked impairment in their response to glucose. $J$ Biol Chem 277: 37176-37183, 2002.

482. Shorter K, Farjo NP, Picksley SM and Randall VA. Human hair follicles contain two forms of ATP-sensitive potassium channels, only one of which is sensitive to minoxidil. FASEB J 22: 1725-1736, 2008.

483. Shyng S, Ferrigni T and Nichols CG. Regulation of KATP channel activity by diazoxide and MgADP. Distinct functions of the two nucleotide binding folds of the sulfonylurea receptor. J Gen Physiol 110: 643-654, 1997.

484. Shyng S and Nichols CG. Membrane Phospholipid Control of Nucleotide Sensitivity of $\mathrm{K}_{\text {ATP }}$ Channels. Science 282: 1138-1141, 1998.

485. Shyng SL, Cukras CA, Harwood J and Nichols CG. Structural Determinants of PIP(2) Regulation of Inward Rectifier K(ATP) Channels. J Gen Physiol 116: 599-608, 2000.

486. Shyng SL, Ferrigni T, Shepard JB, Nestorowicz A, Glaser B, Permutt MA and Nichols CG. Functional analyses of novel mutations in the sulfonylurea receptor 1 associated with persistent hyperinsulinemic hypoglycemia of infancy. Diabetes 47: 1145-1151, 1998

487. Shyng SL and Nichols CG. Octameric stoichiometry of the K-ATP channel complex. J Gen Physiol 110: 655-664, 1997. 
488. Sierra A, Subbotina E, Zhu Z, Gao Z, Koganti SR, Coetzee WA, Goldhamer DJ, Hodgson-Zingman DM and Zingman LV. Disruption of ATP-sensitive potassium channel function in skeletal muscles promotes production and secretion of musclin. Biochem Biophys Res Commun 471: 129-134, 2016.

489. Sikka P, Kapoor S, Bindra VK, Saini M and Saxena KK. Iptakalim: A novel multiutility potassium channel opener. J Pharmacol Pharmacother 3: 12-14, 2012.

490. Slingerland AS, Hurkx W, Noordam K, Flanagan SE, Jukema JW, Meiners LC, Bruining GJ, Hattersley AT and Hadders-Algra M. Sulphonylurea therapy improves cognition in a patient with the V59M KCNJ11 mutation. Diabet Med 25: 277-281, 2008.

491. Smith KJ, Chadburn AJ, Adomaviciene A, Minoretti P, Vignali L, Emanuele E and Tammaro P. Coronary spasm and acute myocardial infarction due to a mutation (V734I) in the nucleotide binding domain 1 of ABCC9. Int J Cardiol 168: 3506-3513, 2013.

492. Socala K, Nieoczym D, Pierog $\mathbf{M}$ and Wlaz P. Role of the adenosine system and glucose restriction in the acute anticonvulsant effect of caprylic acid in the $6 \mathrm{~Hz}$ psychomotor seizure test in mice. Prog Neuropsychopharmacol Biol Psychiatry 57: 44-51, 2015.

493. Spanswick D, Smith MA, Groppi VE, Logan SD and Ashford ML. Leptin inhibits hypothalamic neurons by activation of ATP-sensitive potassium channels. Nature 390: $521-525,1997$. 
494. Spanswick D, Smith MA, Mirshamsi S, Routh VH and Ashford ML. Insulin activates ATP-sensitive $\mathrm{K}+$ channels in hypothalamic neurons of lean, but not obese rats. Nat Neurosci 3: 757-758, 2000.

495. Speechly-Dick ME, Grover GJ and Yellon DM. Does ischemic preconditioning in the human involve protein kinase C and the ATP-dependent $\mathrm{K}+$ channel? Studies of contractile function after simulated ischemia in an atrial in vitro model. Circ Res 77: 1030-1035, 1995.

496. Speechly-Dick ME, Mocanu MM and Yellon DM. Protein kinase C. Its role in ischemic preconditioning in the rat. Circ Res 75: 586-590, 1994.

497. Spinelli W, Sorota S, Siegal M and Hoffman BF. Antiarrhythmic actions of the ATP-regulated K+ current activated by pinacidil. Circ Res 68: 1127-1137, 1991.

498. Spruce AE, Standen NB and Stanfield PR. Voltage-dependent ATP-sensitive potassium channels of skeletal muscle membrane. Nature 316: 736-738, 1985.

499. Spruce AE, Standen NB and Stanfield PR. Studies of the unitary properties of adenosine-5'-triphosphate-regulated potassium channels of frog skeletal muscle. $J$ Physiol 382: 213-236, 1987.

500. Standen NB, Quayle JM, Davies NW, Brayden JE, Huang Y and Nelson MT. Hyperpolarizing vasodilators activate ATP-sensitive $\mathrm{K}+$ channels in arterial smooth muscle. Science 245: 177-180, 1989. 
501. Stanfield PR, Davies NW, Shelton PA, Khan IA, Brammar WJ, Standen NB and Conley EC. The intrinsic gating of inward rectifier $\mathrm{K}+$ channels expressed from the murine IRK1 gene depends on voltage, $\mathrm{K}+$ and Mg2+. J Physiol Lond 475: 1-7, 1994.

502. Stanley CA. Perspective on the Genetics and Diagnosis of Congenital Hyperinsulinism Disorders. J Clin Endocrinol Metab 101: 815-826, 2016.

503. Stengl M, Volders PG, Thomsen MB, Spatjens RL, Sipido KR and Vos MA. Accumulation of slowly activating delayed rectifier potassium current (IKs) in canine ventricular myocytes. $J$ Physiol 551: 777-786, 2003.

504. Stoller D, Kakkar R, Smelley M, Chalupsky K, Earley JU, Shi NQ, Makielski JC and McNally EM. Mice lacking sulfonylurea receptor 2 (SUR2) ATP-sensitive potassium channels are resistant to acute cardiovascular stress. J Mol Cell Cardiol 43: 445-454, 2007.

505. Stoller D, Pytel P, Katz S, Earley JU, Collins K, Metcalfe J, Lang RM and McNally EM. Impaired exercise tolerance and skeletal muscle myopathy in sulfonylurea receptor-2 mutant mice. Am J Physiol Regul Integr Comp Physiol 297: R1144-R1153, 2009.

506. Subbotina E, Sierra A, Zhu Z, Gao Z, Koganti SR, Reyes S, Stepniak E, Walsh SA, Acevedo MR, Perez-Terzic CM, Hodgson-Zingman DM and Zingman LV. Musclin is an activity-stimulated myokine that enhances physical endurance. Proc Natl Acad Sci U S A 112: 16042-16047, 2015. 
507. Sun HS and Feng ZP. Neuroprotective role of ATP-sensitive potassium channels in cerebral ischemia. Acta Pharmacol Sin 34: 24-32, 2013.

508. Sun HS, Feng ZP, Barber PA, Buchan AM and French RJ. Kir6.2-containing ATPsensitive potassium channels protect cortical neurons from ischemic/anoxic injury in vitro and in vivo. Neuroscience 144: 1509-1515, 2007.

509. Sun HS, Feng ZP, Miki T, Seino S and French RJ. Enhanced neuronal damage after ischemic insults in mice lacking Kir6.2-containing ATP-sensitive $\mathrm{K}+$ channels. $J$ Neurophysiol 95: 2590-2601, 2006.

510. Suzuki M, Kotake K, Fujikura K, Inagaki N, Suzuki T, Gonoi T, Seino S and Takata K. Kir6.1: A possible subunit of ATP-sensitive K+ channels in mitochondria. Biochem Biophys Res Commun 241: 693-697, 1997.

511. Suzuki M, Li RA, Miki T, Uemura H, Sakamoto N, Ohmoto-Sekine Y, Tamagawa M, Ogura T, Seino S, Marban E and Nakaya H. Functional roles of cardiac and vascular ATP-sensitive potassium channels clarified by Kir6.2-knockout mice. Circ Res 88: 570-577, 2001.

\section{Suzuki M, Saito T, Sato T, Tamagawa M, Miki T, Seino S and Nakaya $H$.} Cardioprotective effect of diazoxide is mediated by activation of sarcolemmal but not mitochondrial ATP-sensitive potassium channels in mice. Circulation 107: 682-685, 2003.

513. Suzuki M, Sasaki N, Miki T, Sakamoto N, Ohmoto-Sekine Y, Tamagawa M, 
Seino S, Marban E and Nakaya H. Role of sarcolemmal K(ATP) channels in cardioprotection against ischemia/reperfusion injury in mice. J Clin Invest 109: 509$516,2002$.

514. Taira N. Nicorandil as a hybrid between nitrates and potassium channel activators. Am J Cardiol 63: 18J-24J, 1989.

515. Tajada S, Cidad P, Moreno-Dominguez A, Perez-Garcia MT and Lopez-Lopez JR. High blood pressure associates with the remodelling of inward rectifier $\mathrm{K}^{+}$ channels in mice mesenteric vascular smooth muscle cells. J Physiol 590: 6075-6091, 2012.

516. Takano $\mathbf{M}$ and Ashcroft FM. The Ba2+ block of the ATP-sensitive K+ current of mouse pancreatic beta-cells. Pflugers Arch 431: 625-631, 1996.

517. Tammaro P, Proks P and Ashcroft FM. Functional effects of naturally occurring KCNJ11 mutations causing neonatal diabetes on cloned cardiac KATP channels. $J$ Physiol 571: 3-14, 2006.

518. Tanaka Y, Horinouchi T and Koike K. New insights into beta-adrenoceptors in smooth muscle: distribution of receptor subtypes and molecular mechanisms triggering muscle relaxation. Clin Exp Pharmacol Physiol 32: 503-514, 2005.

519. Taneja TK, Mankouri J, Karnik R, Kannan S, Smith AJ, Munsey T, Christesen HB, Beech DJ and Sivaprasadarao A. Sar1-GTPase-dependent ER exit of KATP channels revealed by a mutation causing congenital hyperinsulinism. Hum Mol Genet 
18: 2400-2413, 2009.

520. Tanner GR, Lutas A, Martinez-Francois JR and Yellen G. Single K ATP channel opening in response to action potential firing in mouse dentate granule neurons. $J$ Neurosci 31: 8689-8696, 2011.

521. ter BJ, Guskov A and Slotboom DJ. Structural diversity of ABC transporters. J Gen Physiol 143: 419-435, 2014.

522. Teramoto N. Physiological roles of ATP-sensitive K+ channels in smooth muscle. $J$ Physiol 572: 617-624, 2006.

523. Teramoto $\mathbf{N}$ and Brading AF. Activation by levcromakalim and metabolic inhibition of glibenclamide-sensitive K channels in smooth muscle cells of pig proxima urethra. Br J Pharmacol 118: 635-642, 1996.

524. Teramoto N, McMurray G and Brading AF. Effects of levcromakalim and nucleoside diphosphates on glibenclamide- sensitive $\mathrm{K}+$ channels in pig urethral myocytes. Br J Pharmacol 120: 1229-1240, 1997.

525. Teramoto N, Zhu HL, Shibata A, Aishima M, Walsh EJ, Nagao M and Cole WC. ATP-sensitive $\mathrm{K}+$ channels in pig urethral smooth muscle cells are heteromultimers of Kir6.1 and Kir6.2. Am J Physiol Renal Physiol 296: F107-F117, 2009.

526. Terzic A, Jahangir A and Kurachi Y. Cardiac ATP-sensitive K+ channels: regulation by intracellular nucleotides and $\mathrm{K}+$ channel-opening drugs. Am J Physiol 269: C525- 
45, 1995.

527. Tester DJ, Tan BH, Medeiros-Domingo A, Song C, Makielski JC and Ackerman MJ. Loss-of-function mutations in the KCNJ8-encoded Kir6.1 K(ATP) channel and sudden infant death syndrome. Circ Cardiovasc Genet 4: 510-515, 2011.

528. Thabet M, Miki T, Seino S and Renaud JM. Treadmill running causes significant fiber damage in skeletal muscle of KATP channel-deficient mice. Physiol Genomics 22: 204-212, 2005 .

529. The Iona Study Group. Effect of nicorandil on coronary events in patients with stable angina: the Impact Of Nicorandil in Angina (IONA) randomised trial. Lancet 359: 1269-1275, 2002.

530. Thomas $\mathbf{P}, \mathbf{Y e} \mathbf{Y}$ and Lightner $\mathbf{E}$. Mutation of the pancreatic islet inward rectifier Kir6.2 also leads to familial persistent hyperinsulinemic hypoglycemia of infancy. Hum Mol Genet 5: 1809-1812, 1996.

\section{Thomas PM, Cote GJ, Wohllk N, Haddad B, Mathew PM, Rabl W, Aguilar} Bryan L, Gagel RF and Bryan J. Mutations in the sulfonylurea receptor gene in familial persistent hyperinsulinemic hypoglycemia of infancy. Science 268: 426-429, 1995.

532. Thomzig A, Wenzel M, Karschin C, Eaton MJ, Skatchkov SN, Karschin A and Veh RW. Kir6.1 is the principal pore-forming subunit of astrocyte but not neuronal plasma membrane K-ATP channels. Mol Cell Neurosci 18: 671-690, 2001. 
533. Thornton PS, MacMullen C, Ganguly A, Ruchelli E, Steinkrauss L, Crane A, Aguilar-Bryan L and Stanley CA. Clinical and molecular characterization of a dominant form of congenital hyperinsulinism caused by a mutation in the highaffinity sulfonylurea receptor. Diabetes 52: 2403-2410, 2003.

534. Tinker A and Harmer SC. K+ channels in the heart: new insights and therapeutic implications. Expert Rev Clin Pharmacol 3: 305-319, 2010.

535. Tinker A, Jan YN and Jan LY. Regions responsible for the assembly of inwardly rectifying potassium channels. Cell 87: 857-868, 1996.

536. Tomuschat C, O'Donnell AM, Coyle D, Dreher N, Kelly D and Puri P. Altered expression of ATP-sensitive K(+) channels in Hirschsprung's disease. J Pediatr Surg 51: 948-952, 2016.

537. Tong X, Porter LM, Liu G, Dhar-Chowdhury P, Srivastava S, Pountney DJ, Yoshida H, Artman M, Fishman GI, Yu C, Iyer R, Morley GE, Gutstein DE and Coetzee WA. Consequences of cardiac myocyte-specific ablation of KATP channels in transgenic mice expressing dominant negative Kir6 subunits. Am J Physiol Heart Circ Physiol 291: H543-H551, 2006.

538. Tornovsky S, Crane A, Cosgrove KE, Hussain K, Lavie J, Heyman M, Nesher Y, Kuchinski N, Ben Shushan E, Shatz O, Nahari E, Potikha T, Zangen D, Tenenbaum-Rakover Y, De Vries L, Argente J, Gracia R, Landau H, Eliakim A, Lindley K, Dunne MJ, Aguilar-Bryan L and Glaser B. Hyperinsulinism of infancy: novel ABCC8 and KCNJ11 mutations and evidence for additional locus 
heterogeneity. J Clin Endocrinol Metab 89: 6224-6234, 2004.

539. Toyoda Y, Hagiya Y, Adachi T, Hoshijima K, Kuo MT and Ishikawa T. MRP class of human ATP binding cassette (ABC) transporters: historical background and new research directions. Xenobiotica 38: 833-862, 2008.

540. Trapp S, Haider S, Jones P, Sansom MS and Ashcroft FM. Identification of residues contributing to the ATP binding site of Kir6.2. EMBO J 22: 2903-2912, 2003.

541. Trapp S, Proks P, Tucker SJ and Ashcroft FM. Molecular analysis of ATP-sensitive K channel gating and implications for channel inhibition by ATP. J Gen Physiol 112: 333-349, 1998.

542. Tricarico D, Mele A, Lundquist AL, Desai RR, George AL, Jr. and Conte CD. Hybrid assemblies of ATP-sensitive K+ channels determine their muscle-typedependent biophysical and pharmacological properties. Proc Natl Acad Sci U S A 103: 1118-1123, 2006.

543. Tricarico D, Selvaggi M, Passantino G, De PP, Dario C, Centoducati P, Tateo A, Curci A, Maqoud F, Mele A, Camerino GM, Liantonio A, Imbrici P and Zizzo N. ATP Sensitive Potassium Channels in the Skeletal Muscle Function: Involvement of the KCNJ11(Kir6.2) Gene in the Determination of Mechanical Warner Bratzer Shear Force. Front Physiol 7: 167, 2016.

544. Trube $\mathbf{G}$ and Hescheler $\mathbf{J}$. Inward-rectifying channels in isolated patches of the heart cell membrane: ATP-dependence and comparison with cell-attached patches. Pflugers 
Arch 401: 178-184, 1984.

545. Tsiani E, Ramlal T, Leiter LA, Klip A and Fantus IG. Stimulation of glucose uptake and increased plasma membrane content of glucose transporters in L6 skeletal muscle cells by the sulfonylureas gliclazide and glyburide. Endocrinology 136: 2505$2512,1995$.

546. Tucker SJ, Bond CT, Herson P, Pessia M and Adelman JP. Inhibitory interactions between two inward rectifier $\mathrm{K}+$ channel subunits mediated by the transmembrane domains. J Biol Chem 271: 5866-5870, 1996.

547. Tucker SJ, Gribble FM, Proks P, Trapp S, Ryder TJ, Haug T, Reimann F and Ashcroft FM. Molecular determinants of KATP channel inhibition by ATP. EMBO J 17: 3290-3296, 1998.

548. Tucker SJ, Gribble FM, Zhao C, Trapp S and Ashcroft FM. Truncation of Kir6.2 produces ATP-sensitive $\mathrm{K}+$ channels in the absence of the sulphonylurea receptor. Nature 387: 179-183, 1997.

549. Uchida T, Yashima M, Gotoh M, Qu Z, Garfinkel A, Weiss JN, Fishbein MC, Mandel WJ, Chen PS and Karagueuzian HS. Mechanism of acceleration of functional reentry in the ventricle: effects of ATP-sensitive potassium channel opener. Circulation 99: 704-712, 1999.

550. Ueda K, Inagaki $\mathbf{N}$ and Seino S. MgADP antagonism to Mg2+-independent ATP binding of the sulfonylurea receptor SUR1. J Biol Chem 272: 22983-22986, 1997. 
551. Uhde I, Toman A, Gross I, Schwanstecher C and Schwanstecher M. Identification of the potassium channel opener site on sulfonylurea receptors. J Biol Chem 274: 28079-28082, 1999.

552. van Bon BW, Gilissen C, Grange DK, Hennekam RC, Kayserili H, Engels H, Reutter H, Ostergaard JR, Morava E, Tsiakas K, Isidor B, Le MM, Eser M, Wieskamp N, de VP, Steehouwer M, Veltman JA, Robertson SP, Brunner HG, de Vries BB and Hoischen A. Cantu syndrome is caused by mutations in ABCC9. Am J Hum Genet 90: 1094-1101, 2012.

553. Van Wagoner DR. Mechanosensitive gating of atrial ATP-sensitive potassium channels. Circ Res 72: 973-983, 1993.

554. Vanoye CG, MacGregor GG, Dong K, Tang L, Buschmann AS, Hall AE, Lu M, Giebisch G and Hebert SC. The carboxyl termini of K(ATP) channels bind nucleotides. J Biol Chem 272: 23260-23270, 2002.

555. Vedovato N, Ashcroft FM and Puljung MC. The Nucleotide-Binding Sites of SUR1: A Mechanistic Model. Biophys J 109: 2452-2460, 2015.

556. Vedovato N, Cliff E, Proks P, Poovazhagi V, Flanagan SE, Ellard S, Hattersley AT and Ashcroft FM. Neonatal diabetes caused by a homozygous KCNJ11 mutation demonstrates that tiny changes in ATP sensitivity markedly affect diabetes risk. Diabetologia 59: 1430-1436, 2016.

557. Venkatesh N, Lamp ST and Weiss JN. Sulfonylureas, ATP-sensitive K+ channels, 
and cellular $\mathrm{K}+$ loss during hypoxia, ischemia, and metabolic inhibition in mammalian ventricle. Circ Res 69: 623-637, 1991.

558. Verkarre V, Fournet JC, de Lonlay P, Gross-Morand MS, Devillers M, Rahier J, Brunelle F, Robert JJ, Nihoul-Fekete C, Saudubray JM and Junien C. Paternal mutation of the sulfonylurea receptor (SUR1) gene and maternal loss of $11 \mathrm{p} 15$ imprinted genes lead to persistent hyperinsulinism in focal adenomatous hyperplasia. J Clin Invest 102: 1286-1291, 1998.

559. Villareal DT, Koster JC, Robertson H, Akrouh A, Miyake K, Bell GI, Patterson BW, Nichols CG and Polonsky KS. Kir6.2 variant E23K increases ATP-sensitive K+ channel activity and is associated with impaired insulin release and enhanced insulin sensitivity in adults with normal glucose tolerance. Diabetes 58: 1869-1878, 2009.

560. Voelker DR. Lipid assembly into cell membranes. In: Biochemistry of Lipids, Lipoproteins and Membranes, edited by Vance DE and Vance JE. Amsterdam: Elsevier, 1996, p. 391-423.

561. Wainwright CE, Elborn JS, Ramsey BW, Marigowda G, Huang X, Cipolli M, Colombo C, Davies JC, De BK, Flume PA, Konstan MW, McColley SA, McCoy K, McKone EF, Munck A, Ratjen F, Rowe SM, Waltz D and Boyle MP. Lumacaftor-Ivacaftor in Patients with Cystic Fibrosis Homozygous for Phe508del CFTR. N Engl J Med 373: 220-231, 2015.

562. Wang H, Long C, Duan Z, Shi C, Jia G and Zhang Y. A new ATP-sensitive potassium channel opener protects endothelial function in cultured aortic endothelial 
cells. Cardiovasc Res 73: 497-503, 2007.

563. Wang X, Wu J, Li L, Chen F, Wang R and Jiang C. Hypercapnic acidosis activates KATP channels in vascular smooth muscles. Circ Res 92: 1225-1232, 2003.

564. Wang Y, Hirai K and Ashraf M. Activation of mitochondrial ATP-sensitive $\mathrm{K}(+)$ channel for cardiac protection against ischemic injury is dependent on protein kinase C activity. Circ Res 85: 731-741, 1999.

565. Ward JW, McBurney A, Farrow PR and Sharp P. Pharmacokinetics and hypotensive effect in healthy volunteers of pinacidil, a new potent vasodilator. Eur $J$ Clin Pharmacol 26: 603-608, 1984.

566. Weiss JN and Lamp ST. Glycolysis prefrentially inhibits ATP-sensitive K+ channels in isolated guinea pig cardiac myocytes. Science 238: 67-69, 1987.

567. Weiss JN and Lamp ST. Cardiac ATP-sensitive K+ channels: Evidence for preferential regulation by glycolysis. J Gen Physiol 94: 911-935, 1989.

568. Wellman GC, Barrett-Jolley R, Koppel H, Everitt D and Quayle JM. Inhibition of vascular K(ATP) channels by U-37883A: a comparison with cardiac and skeletal muscle. Br J Pharmacol 128: 909-916, 1999.

569. Wellman GC, Quayle JM and Standen NB. ATP-sensitive K+ channel activation by calcitonin gene-related peptide and protein kinase A in pig coronary arterial smooth muscle. J Physiol 507 ( Pt 1): 117-129, 1998. 
570. Whorton MR and MacKinnon R. Crystal structure of the mammalian GIRK2 K+ channel and gating regulation by G proteins, PIP2, and sodium. Cell 147: 199-208, 2011.

571. Wijffels MC, Kirchhof CJ, Dorland R and Allessie MA. Atrial fibrillation begets atrial fibrillation. A study in awake chronically instrumented goats. Circulation 92: 1954-1968, 1995.

572. Willars GB, Nahorski SR and Challiss RA. Differential regulation of muscarinic acetylcholine receptor-sensitive polyphosphoinositide pools and consequences for signaling in human neuroblastoma cells. J Biol Chem 273: 5037-5046, 1998.

573. Wilson AJ, Jabr RI and Clapp LH. Calcium modulation of vascular smooth muscle ATP-sensitive $\mathrm{K}(+)$ channels: role of protein phosphatase-2B. Circ Res 87: 1019$1025,2000$.

574. Winkler M, Kuhner P, Russ U, Ortiz D, Bryan J and Quast U. Role of the aminoterminal transmembrane domain of sulfonylurea receptor SUR2B for coupling to K(IR)6.2, ligand binding, and oligomerization. Naunyn Schmiedebergs Arch Pharmacol 385: 287-298, 2012.

575. Wojtovich AP, DiStefano P, Sherman T, Brookes PS and Nehrke K. Mitochondrial ATP-sensitive potassium channel activity and hypoxic preconditioning are independent of an inwardly rectifying potassium channel subunit in Caenorhabditis elegans. FEBS Lett 586: 428-434, 2012. 
576. WOLFF F. DIAZOXIDE HYPERGLYCAEMIA AND ITS CONTINUED RELIEF BY TOLBUTAMIDE. Lancet 1: 309-310, 1964.

577. Wolk R, Cobbe SM, Kane KA and Hicks MN. Relevance of inter- and intraventricular electrical dispersion to arrhythmogenesis in normal and ischaemic rabbit myocardium: a study with cromakalim, 5-hydroxydecanoate and glibenclamide. J Cardiovasc Pharmacol 33: 323-334, 1999.

578. Wolleben CD, Sanguinetti MC and Siegl PK. Influence of ATP-sensitive potassium channel modulators on ischemia-induced fibrillation in isolated rat hearts. J Mol Cell Cardiol 21: 783-788, 1989.

579. Woodward R, Stevens EB and Murrell Lagnado RD. Molecular determinants for assembly of G-protein-activated inwardly rectifying K+ channels. J Biol Chem 272: 10823-10830, 1997.

580. Wu G, Huang CX, Tang YH, Jiang H, Wan J, Chen H, Xie Q and Huang ZR. Changes of IK, ATP current density and allosteric modulation during chronic atrial fibrillation. Chin Med J (Engl) 118: 1161-1166, 2005.

581. Wu J, Cui N, Piao H, Wang Y, Xu H, Mao J and Jiang C. Allosteric modulation of the mouse Kir6.2 channel by intracellular H+ and ATP. J Physiol 543: 495-504, 2002.

582. Wu SN, Li HF and Chiang HT. Characterization of ATP-sensitive potassium channels functionally expressed in pituitary GH3 cells. J Membr Biol 178: 205-214, 2000. 
583. Xu H, Cui N, Yang Z, Wu J, Giwa LR, Abdulkadir L, Sharma P and Jiang C.

Direct activation of cloned K(atp) channels by intracellular acidosis. J Biol Chem 276: 12898-12902, 2001.

584. Xu H, Wu J, Cui N, Abdulkadir L, Wang R, Mao J, Giwa LR, Chanchevalap S and Jiang C. Distinct histidine residues control the acid-induced activation and inhibition of the cloned K(ATP) channel. J Biol Chem 276: 38690-38696, 2001.

585. Xu S, Kim JH, Hwang KH, Das R, Quan X, Nguyen TT, Kim SJ, Cha SK and Park KS. Autocrine insulin increases plasma membrane K(ATP) channel via PI3KVAMP2 pathway in MIN6 cells. Biochem Biophys Res Commun 468: 752-757, 2015.

586. Yamada K, Ji JJ, Yuan H, Miki T, Sato S, Horimoto N, Shimizu T, Seino S and Inagaki N. Protective role of ATP-sensitive potassium channels in hypoxia-induced generalized seizure. Science 292: 1543-1546, 2001.

587. Yamada M, Isomoto S, Matsumoto S, Kondo C, Shindo T, Horio Y and Kurachi Y. Sulphonylurea receptor 2B and Kir6.1 form a sulphonylurea-sensitive but ATPinsensitive K+ channel. J Physiol 499 ( Pt 3): 715-720, 1997.

588. Yamada M and Kurachi Y. Spermine gates inward-rectifying muscarinic but not ATP- sensitive $\mathrm{K}+$ channels in rabbit atrial myocytes. Intracellular substancemediated mechanism of inward rectification. J Biol Chem 270: 9289-9294, 1995.

589. Yamada S, Kane GC, Behfar A, Liu XK, Dyer RB, Faustino RS, Miki T, Seino S and Terzic A. Protection conferred by myocardial ATP-sensitive K+ channels in 
pressure overload-induced congestive heart failure revealed in KCNJ11 Kir6.2-null mutant. J Physiol 577: 1053-1065, 2006.

590. Yamamoto S, Tanaka E and Higashi H. Mediation by intracellular calciumdependent signals of hypoxic hyperpolarization in rat hippocampal CA1 neurons in vitro. J Neurophysiol 77: 386-392, 1997.

591. Yan FF, Casey J and Shyng SL. Sulfonylureas correct trafficking defects of diseasecausing ATP-sensitive potassium channels by binding to the channel complex. J Biol Chem 281: 33403-33413, 2006.

592. Yan FF, Lin YW, MacMullen C, Ganguly A, Stanley CA and Shyng SL. Congenital hyperinsulinism associated $\mathrm{ABCC} 8$ mutations that cause defective trafficking of ATP-sensitive K+ channels: identification and rescue. Diabetes 56: 2339-2348, 2007.

593. Yang G, Wu L, Jiang B, Yang W, Qi J, Cao K, Meng Q, Mustafa AK, Mu W, Zhang S, Snyder SH and Wang R. H2S as a physiologic vasorelaxant: hypertension in mice with deletion of cystathionine gamma-lyase. Science 322: 587-590, 2008.

594. Yang H, Guo R, Wu J, Peng Y, Xie D, Zheng W, Huang X, Liu D, Liu W, Huang $\mathbf{L}$ and Song $\mathbf{Z}$. The antiepileptic effect of the glycolytic inhibitor 2-deoxy-D-glucose is mediated by upregulation of K(ATP) channel subunits Kir6.1 and Kir6.2. Neurochem Res 38: 677-685, 2013.

595. Yang HQ, Jana K, Rindler MJ and Coetzee WA. The trafficking protein, EHD2, 
positively regulates cardiac sarcolemmal KATP channel surface expression: role in cardioprotection. FASEB J fj201700027R, 2018.

596. Yang J, Jan YN and Jan LY. Control of rectification and permeation by residues in two distinct domains in an inward rectifier K+ channel. Neuron 14: 1047-1054, 1995.

597. Yang Y, Shi Y, Guo S, Zhang S, Cui N, Shi W, Zhu D and Jiang C. PKAdependent activation of the vascular smooth muscle isoform of KATP channels by vasoactive intestinal polypeptide and its effect on relaxation of the mesenteric resistance artery. Biochim Biophys Acta 1778: 88-96, 2008.

598. Yellon DM and Downey JM. Preconditioning the myocardium: from cellular physiology to clinical cardiology. Physiol Rev 83: 1113-1151, 2003.

599. Yellon DM and Hausenloy DJ. Myocardial reperfusion injury. $N$ Engl J Med 357: 1121-1135, 2007.

600. Yoshida H, Feig JE, Morrissey A, Ghiu IA, Artman M and Coetzee WA. K ATP channels of primary human coronary artery endothelial cells consist of a heteromultimeric complex of Kir6.1, Kir6.2, and SUR2B subunits. J Mol Cell Cardiol 37: 857-869, 2004.

601. Yu L, Jin X, Cui N, Wu Y, Shi Z, Zhu D and Jiang C. Rosiglitazone selectively inhibits K(ATP) channels by acting on the K(IR) 6 subunit. Br J Pharmacol 167: 26$36,2012$. 
602. Yu L, Jin X, Yang Y, Cui N and Jiang C. Rosiglitazone inhibits vascular KATP channels and coronary vasodilation produced by isoprenaline. Br J Pharmacol 164: 2064-2072, 2011.

603. Zawar C, Plant TD, Schirra C, Konnerth A and Neumcke B. Cell-type specific expression of ATP-sensitive potassium channels in the rat hippocampus. J Physiol 514 ( Pt 2): 327-341, 1999.

604. Zerangue N, Malan MJ, Fried SR, Dazin PF, Jan YN, Jan LY and Schwappach B. Analysis of endoplasmic reticulum trafficking signals by combinatorial screening in mammalian cells. Proc Natl Acad Sci U S A 98: 2431-2436, 2001.

605. Zerangue N, Schwappach B, Jan YN and Jan LY. A new ER trafficking signal regulates the subunit stoichiometry of plasma membrane $\mathrm{K}_{\text {AтP }}$ channels. Neuron 22: 537-548, 1999.

606. Zhang C, Miki T, Shibasaki T, Yokokura M, Saraya A and Seino S. Identification and characterization of a novel member of the ATP-sensitive $\mathrm{K}+$ channel subunit family, Kir6.3, in zebrafish. Physiol Genomics 24: 290-297, 2006.

607. Zhang F, Xuan Y, Cui J, Liu X, Shao Z and Yu B. Nicorandil modulated macrophages activation and polarization via NF-kappab signaling pathway. $\mathrm{Mol}$ Immunol 88: 69-78, 2017.

608. Zhang H, Craciun LC, Mirshahi T, Rohacs T, Lopes CM, Jin T and Logothetis DE. PIP(2) activates KCNQ channels, and its hydrolysis underlies receptor-mediated 
inhibition of M currents. Neuron 37: 963-975, 2003.

609. Zhang Q, Ramracheya R, Lahmann C, Tarasov A, Bengtsson M, Braha O, Braun M, Brereton M, Collins S, Galvanovskis J, Gonzalez A, Groschner LN, Rorsman NJ, Salehi A, Travers ME, Walker JN, Gloyn AL, Gribble F, Johnson PR, Reimann F, Ashcroft FM and Rorsman P. Role of KATP channels in glucoseregulated glucagon secretion and impaired counterregulation in type 2 diabetes. Cell Metab 18: 871-882, 2013.

610. Zhang Y, Tazzeo T, Chu V and Janssen LJ. Membrane potassium currents in human radial artery and their regulation by nitric oxide donor. Cardiovasc Res 71: 383-392, 2006.

611. Zhou M, Tanaka O, Sekiguchi M, Sakabe K, Anzai M, Izumida I, Inoue T, Kawahara K and Abe $\mathbf{H}$. Localization of the ATP-sensitive potassium channel subunit (Kir6. 1/uK(ATP)-1) in rat brain. Brain Res Mol Brain Res 74: 15-25, 1999.

612. Zhou M, Tanaka O, Suzuki M, Sekiguchi M, Takata K, Kawahara K and Abe H. Localization of pore-forming subunit of the ATP-sensitive K(+)-channel, Kir6.2, in rat brain neurons and glial cells. Brain Res Mol Brain Res 101: 23-32, 2002.

613. Zhou Q, Chen PC, Devaraneni PK, Martin GM, Olson EM and Shyng SL. Carbamazepine inhibits ATP-sensitive potassium channel activity by disrupting channel response to MgADP. Channels (Austin) 8: 376-382, 2014.

614. Zhu Z, Sierra A, Burnett CM, Chen B, Subbotina E, Koganti SR, Gao Z, Wu Y, 


\section{Anderson ME, Song LS, Goldhamer DJ, Coetzee WA, Hodgson-Zingman DM}

and Zingman LV. Sarcolemmal ATP-sensitive potassium channels modulate skeletal muscle function under low-intensity workloads. J Gen Physiol 143: 119-134, 2014.

\section{Zingman LV, Alekseev AE, Bienengraeber M, Hodgson D, Karger AB, Dzeja PP} and Terzic A. Signaling in channel/enzyme multimers: ATPase transitions in SUR module gate ATP-sensitive K+ conductance. Neuron 31: 233-245, 2001.

616. Zingman LV, Hodgson DM, Bast PH, Kane GC, Perez-Terzic C, Gumina RJ, Pucar D, Bienengraeber M, Dzeja PP, Miki T, Seino S, Alekseev AE and Terzic A. Kir6.2 is required for adaptation to stress. Proc Natl Acad Sci U S A 99: 13278-13283, 2002.

617. Zingman LV, Zhu Z, Sierra A, Stepniak E, Burnett CM, Maksymov G, Anderson ME, Coetzee WA and Hodgson-Zingman DM. Exercise-induced expression of cardiac ATP-sensitive potassium channels promotes action potential shortening and energy conservation. J Mol Cell Cardiol 51: 72-81, 2011.

618. Zoga V, Kawano T, Liang MY, Bienengraeber M, Weihrauch D, McCallum B, Gemes G, Hogan Q and Sarantopoulos C. KATP channel subunits in rat dorsal root ganglia: alterations by painful axotomy. Mol Pain 6: 6, 2010 .

619. Zunkler BJ, Henning B, Ott T, Hildebrandt AG and Fleck E. Effects of tolbutamide on ATP-sensitive $\mathrm{K}+$ channels from human right atrial cardiac myocytes. Pharmacol Toxicol 80: 69-75, 1997. 


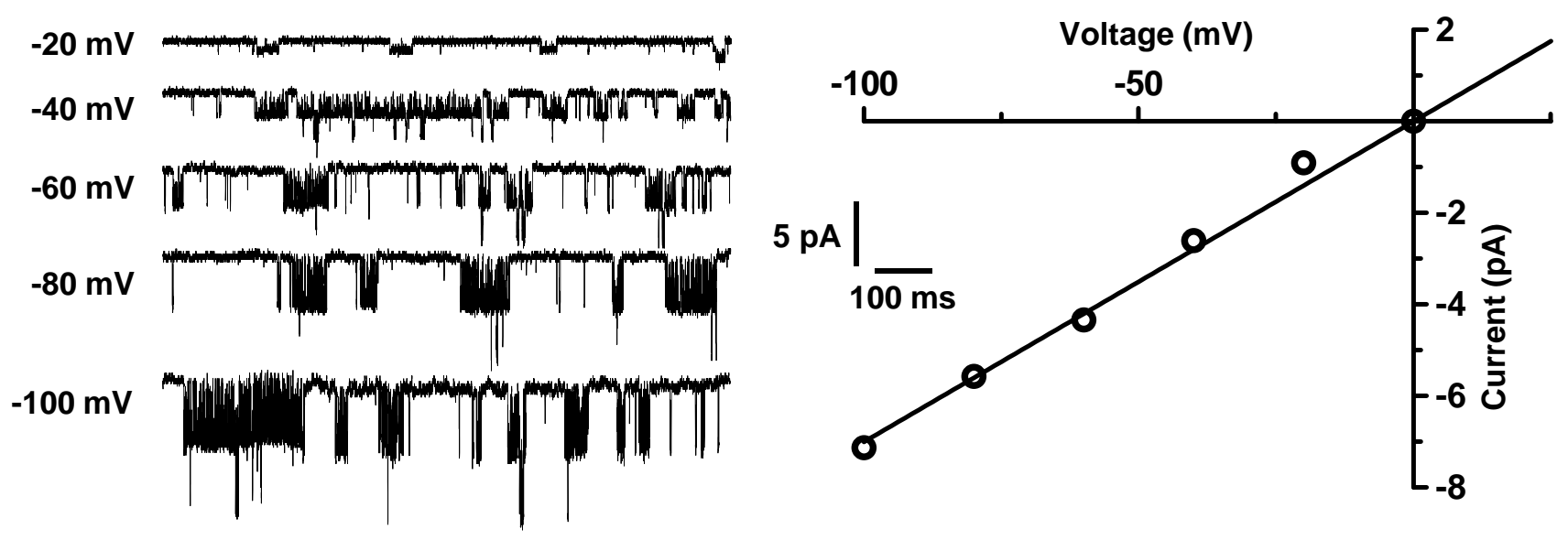

Figure 1 


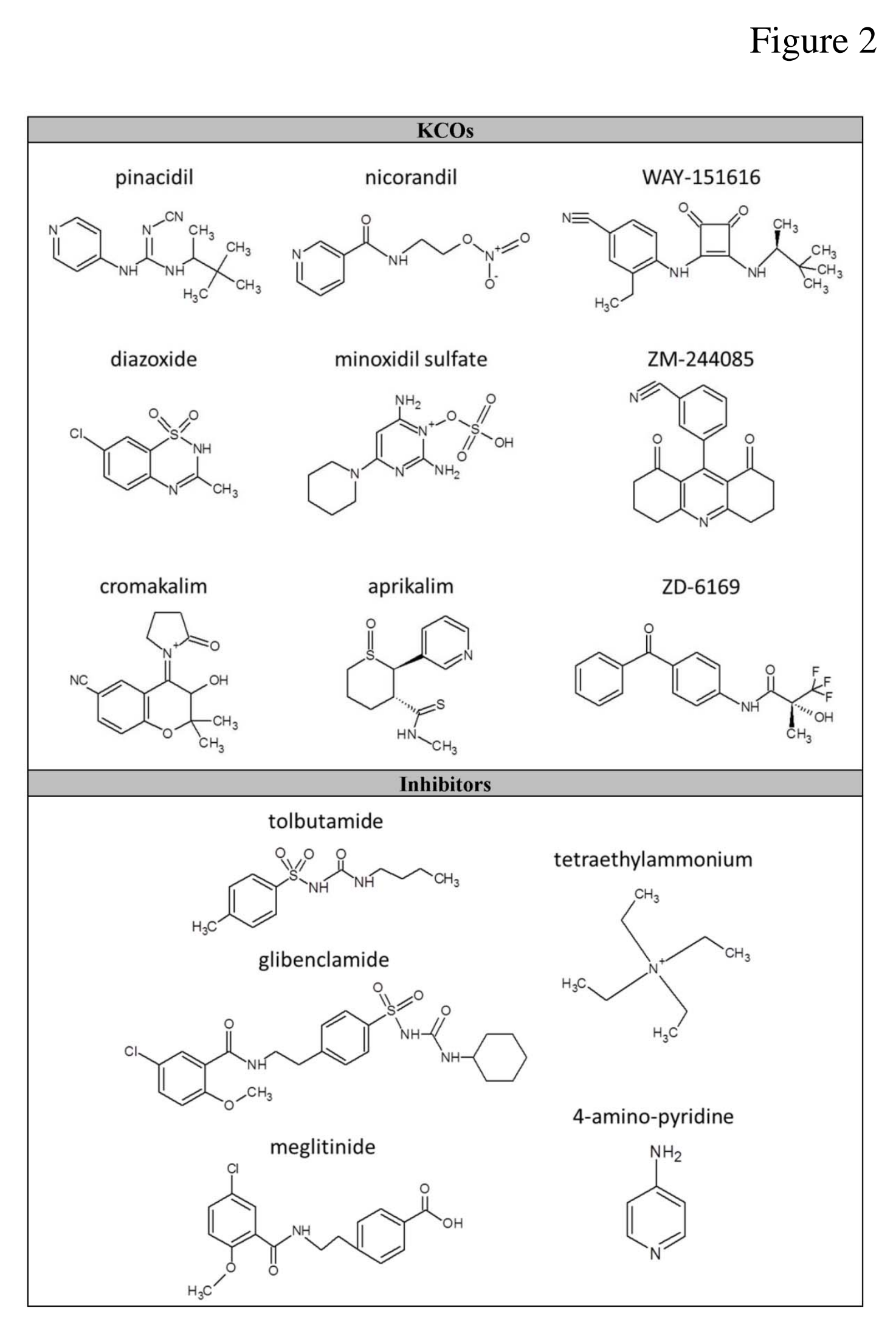






Figure 3 
A

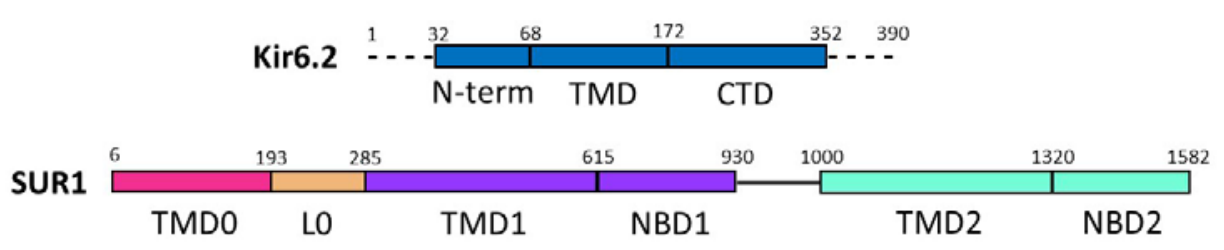

B

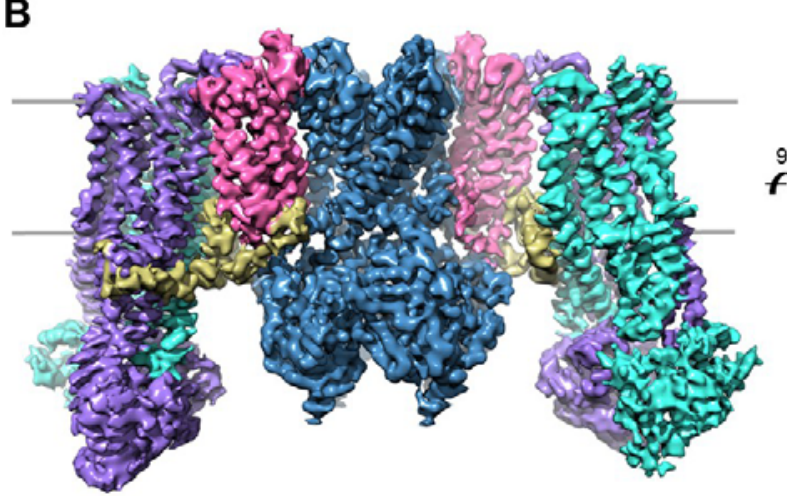

D

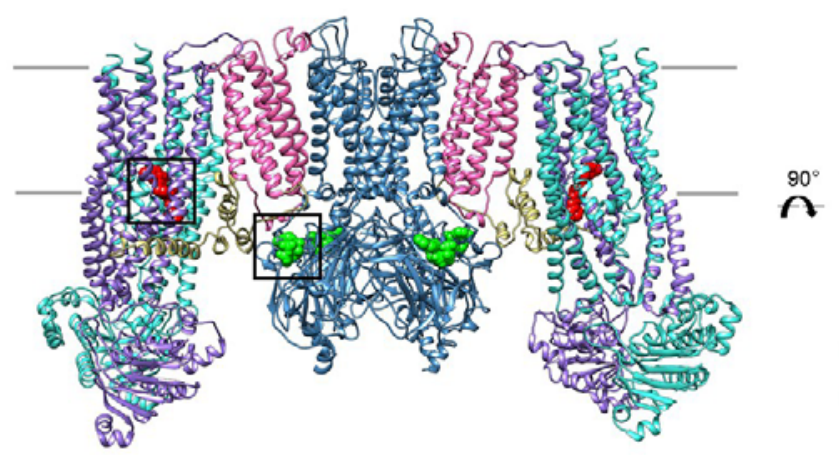

C

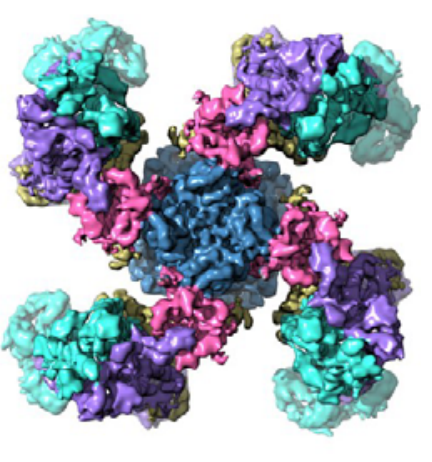

E



Figure 4 
A

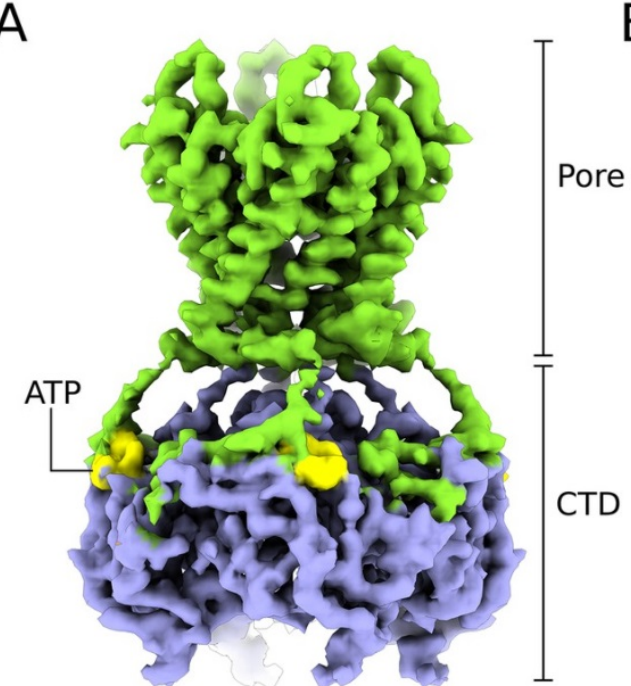

B

ore

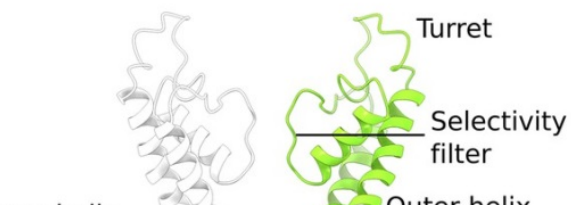

Inner helix os



$\mathrm{G}$ loop gate helix

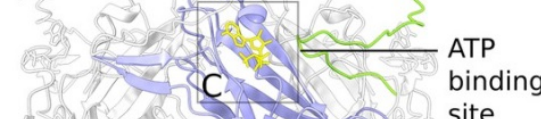

rot site

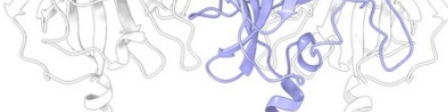

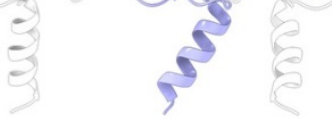

C

Kir6.2 ATP binding site

D

ATP EM density

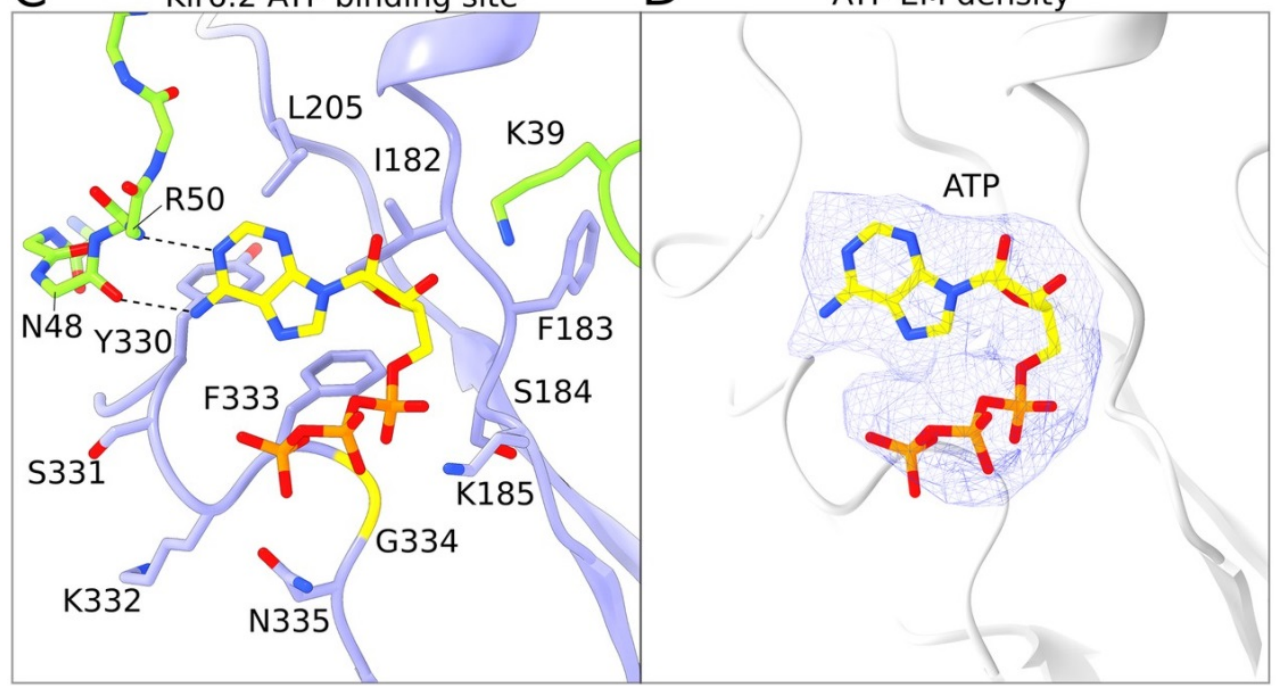

Figure 5 




Figure 6 


\section{Dilation}

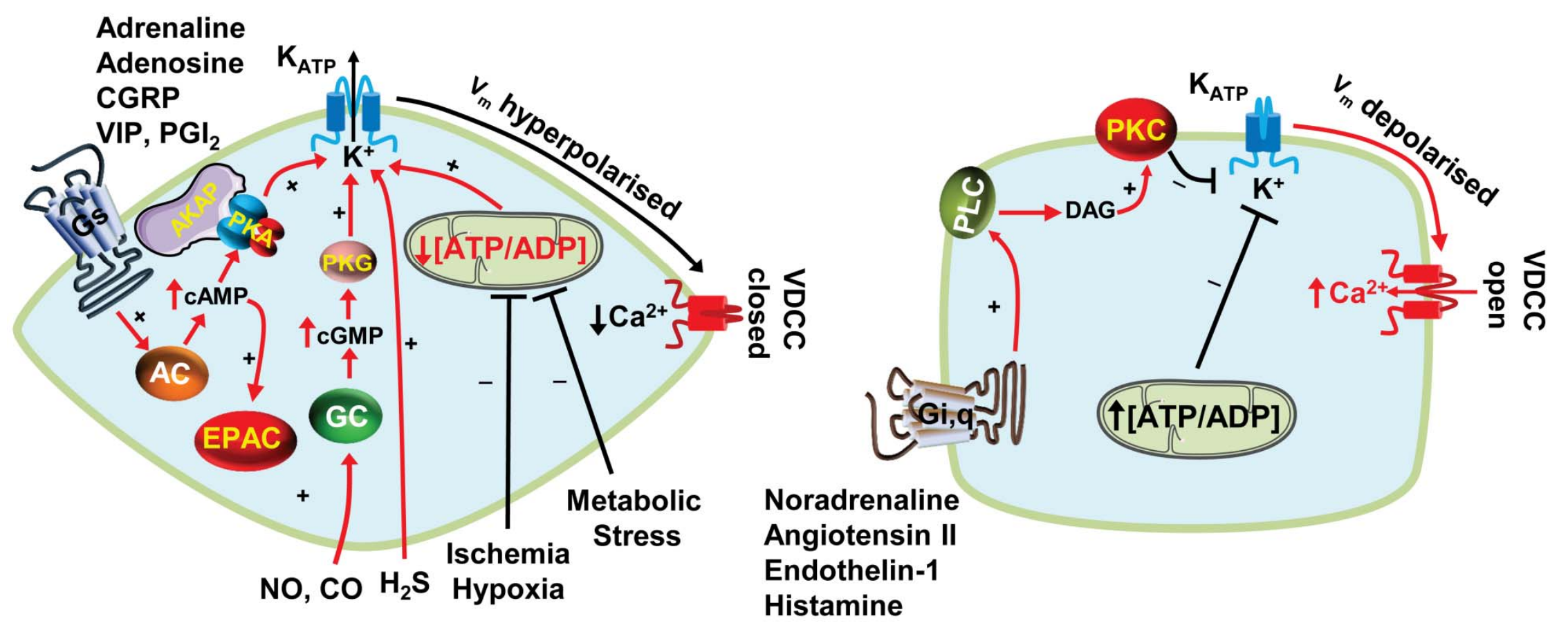

Figure 7 


\section{Low Glucose}

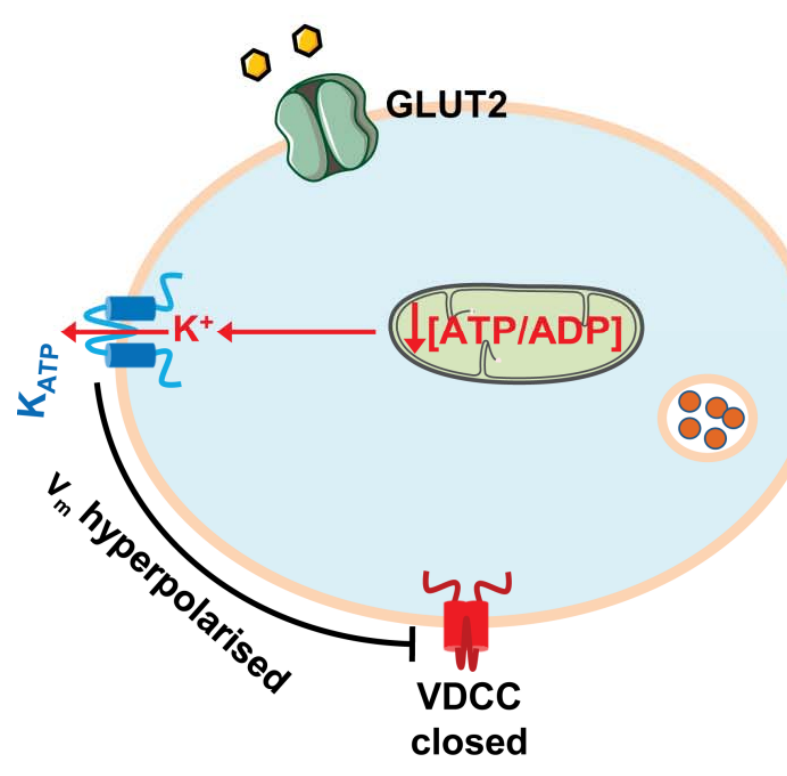

\section{High Glucose}



Figure 8 


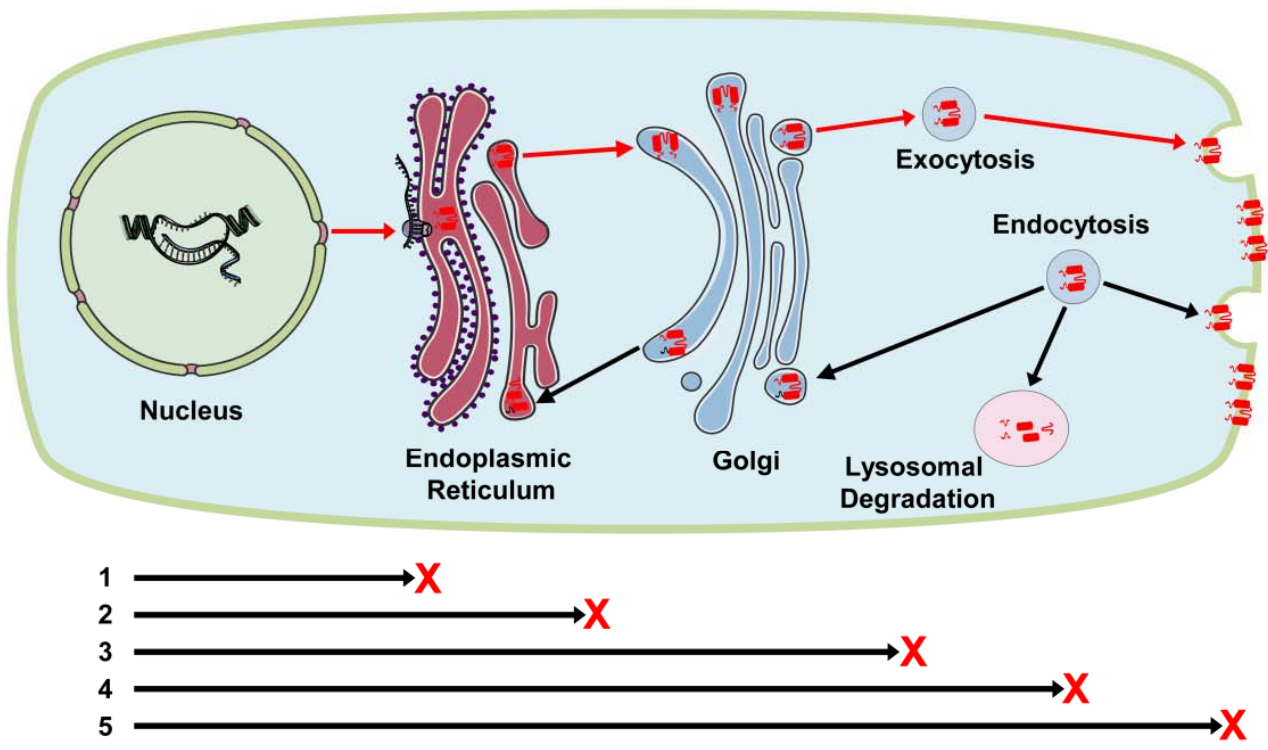

Figure 9 

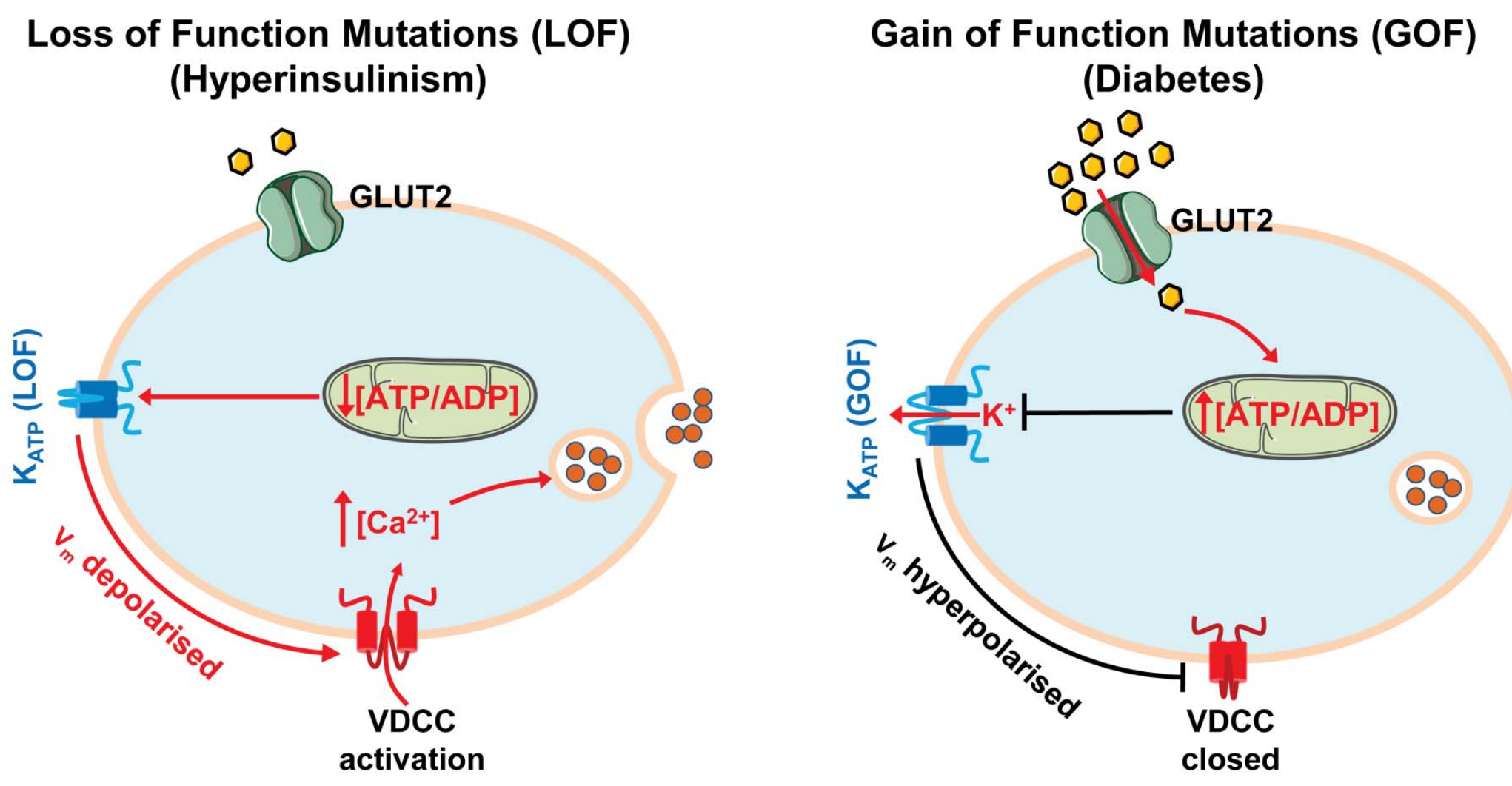

Figure 10 


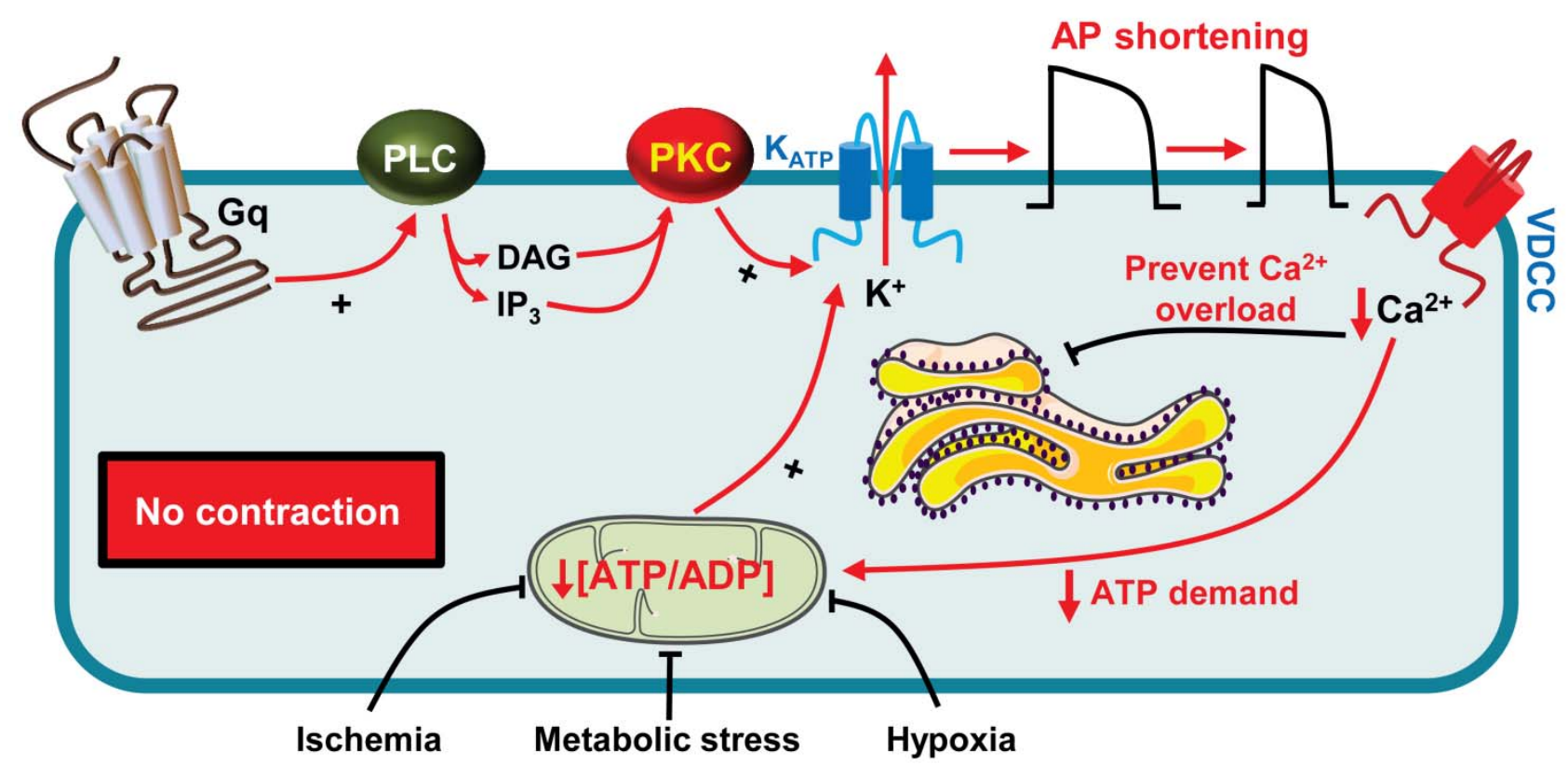

Figure 11 